\title{
ENVIRONMENTAL RESISTANCE OF FLAX/BIO-BASED EPOXY AND FLAX/POLYURETHANE COMPOSITES MANUFACTURED BY RESIN TRANSFER MOULDING
}

\author{
Nils Cuinat-Guerraz \\ Department of Mechanical Engineering \\ McGill University
}

A thesis submitted to McGill University in partial fulfilling of the requirements of the degree of Master's in Engineering

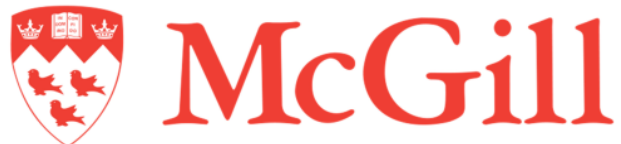

August 2015

(C) Nils Cuinat-Guerraz, 2015 


\section{AbSTRACT}

In recent years, many car manufacturers such as Audi, BMW and Ford have developed natural fibre composite components. The driver behind developing interior parts with natural fibres as reinforcement is to save weight without compromising mechanical properties, with the additional benefit of moving towards a more sustainable part production. Current biocomposites are based on the application of short, non-woven natural fibres. However, bonding hydrophilic natural fibres to a hydrophobic polymeric matrix can sometimes lead to a relatively poor interface, mostly because of the different polarities of the two components. In addition, natural fibre composites are highly sensitive to water absorption. The aim of this study was to compare the physical properties two biocomposites: (1) a flax/bio-based epoxy and (2) a flax/polyurethane. In fact, polyurethane is synthesized by polyaddition of an poly-isocyanate and a polyol, an alcohol containing several hydroxyl groups. Flax fibres are mainly composed of cellulose, a natural polymer that presents multiple hydroxyl groups. A crosslinking reaction between the polyurethane matrix and the cellulose in the fibres could increase the interface strength. Both materials were manufactured using a resin transfer moulding (RTM) process in order to maximize the fibre volume fraction and were reinforced with the same flax woven fabric. Composite samples were then aged at $90 \% \mathrm{RH}$ and $30^{\circ} \mathrm{C}$. The results showed that both composites followed a Fickian diffusion behaviour and that flax/polyurethane composites were less sensitive to moisture ageing than flax/bio-epoxy composites. The chemical bonds between the hydroxyl groups of the fibres and the isocyanate lead to a stronger interface which improved the mechanical properties as compared to the flax/bio-epoxy composites. When exposed to moisture, the flax/polyurethane composites show more stable mechanical performances, especially the short beam strength, the compressive strength and the compressive modulus. Scanning electron micrographs were taken to look at the interface between the flax elementary fibres and the polymer matrix and clearly showed a better fibre/matrix adhesion in the case of the flax/polyurethane composites. Finally, dynamic mechanical analysis (DMA) was performed to study the evolution of the glass transition temperature $\left(T_{g}\right)$ in function of the water uptake for composite samples immersed in distilled water at $30^{\circ} \mathrm{C}$. 


\section{ABREGE}

Depuis plusieurs années, de nombreux constructeurs automobiles dont Audi, BMW et Ford ont développé des pièces en composite renforcés par des fibres naturelles. Le développement de composants pour les intérieurs de voiture renforcé par des fibres naturelles permet d'économiser $\mathrm{du}$ poids sans pour autant compromettre les propriétés mécaniques, avec l'avantage supplémentaire de produire des pièces dans un matériau plus durable. Les biocomposites actuels contiennent surtout des fibres naturelles courtes, non-tissés. Toutefois, l'adhésion de fibres naturelles hydrophiles à une matrice polymère hydrophobe conduit bien souvent à une mauvaise interface dû à la différence de polarité entre les deux composants. D'autre part, les composites contenants des fibres naturelles sont très sensibles à l'absorption d'eau. Le but de cette étude était de comparer les propriétés physiques de deux biocomposites: (1) un composite lin/bio-époxy (2) un composite lin/polyuréthane. En effet, le polyuréthane est synthétisé par polyaddition d'un isocyanate et d'un polyol, un alcool contenant plusieurs groupes hydroxyles. D'autre part, les fibres de lin sont principalement composées de cellulose, un polymère naturel qui présente de multiples groupes hydroxyles. La réticulation entre la matrice de polyuréthanne et la cellulose des fibres peut potentiellement augmenter la résistance de l'interface. Ces deux matériaux ont été fabriqués en utilisant un procédé de moulage par transfert de résine (RTM) dans le but de maximiser la fraction volumique de fibres et ont été renforcées avec le même renfort tissé en fibre de lin. Les échantillons en composites ont ensuite été conditionné à 90\% d'humidité relative et à une température de $30^{\circ} \mathrm{C}$. Les résultats montrent que les deux composites absorbent l'humidité en suivant la loi de diffusion de Fick et que les composites lin/polyuréthane absorbent mois d'eau que les composites lin/bio-époxy. Les liaisons chimiques entre les groupes hydroxyles des fibres et les groupes isocyanate de la résine conduisent à une interface plus solide et à des propriétés mécaniques supérieures à celles des composites lin/bio-époxy. Lorsqu'ils sont exposés à l'humidité, les composites de lin/polyuréthane possèdent des performances mécaniques

plus stables, en particulier en ce qui concerne la résistance au cisaillement interlaminaire et la résistance à la compression. Les images prises par un microscope électronique à balayage (SEM) montrent clairement une meilleure adhérence fibre/matrice dans le cas des composites 
lin/polyuréthane. Enfin, des analyses mécaniques dynamiques (DMA) ont été réalisées pour étudier l'évolution de la température de transition vitreuse $\left(T_{g}\right)$ avec l'absorption d'eau pour des échantillons immergés dans de l'eau distillée à $30^{\circ} \mathrm{C}$. 


\section{ACKNOWLEDGEMENTS}

I extend my deepest thanks to Prof. Pascal Hubert and Prof. Marie-Josée Dumont, my research supervisors, for the opportunities, support and guidance they provided. None of this would have been possible without them.

This project was made possible by the Network for Innovative Plastic Materials and Manufacturing Processes (NIPMMP), the Centre de Recherche sur les Systèmes Polymères et Composites à Haute Performance (CREPEC), Texonic, Henkel, Arkema, McGill University and Centrale Nantes. I thank all involved for the financial, material and intellectual support. I am also grateful to Pascal Bourseguin for his help and input regarding the machining of the RTM mould; Scott Manktelow for letting me use equipment at the Macdonald Campus machine shop and Yvan Gariépy for helping me with the testing of the composites. At McGill, I had an amazing graduate experience with the members of the Structure and Composites Material Laboratory, not only colleagues but also friends. Last but not least, I would like to mention my loving family and their support throughout the entire project.

Finally, I thank the evaluation committee members for accepting to review this thesis, and for their time and input. 


\section{TABLE OF CONTENTS}

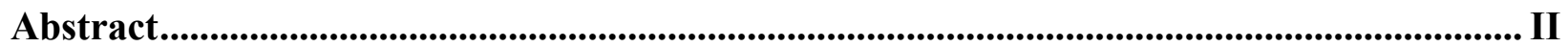

Abrégé ....................................................................................................................................................III

Acknowledgements ............................................................................................................................. V

Table of Contents ................................................................................................................................. VI

List of Figures................................................................................................................................................ VIII

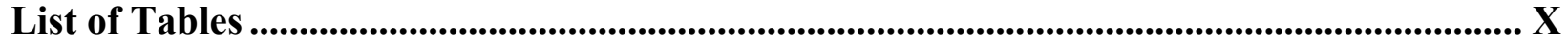

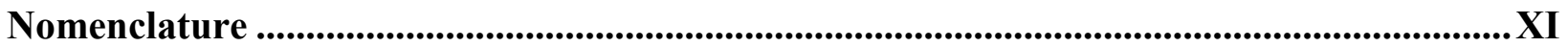

1 Chapter 1: Introduction .......................................................................................... 1

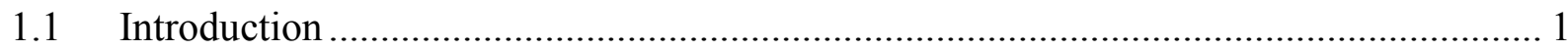

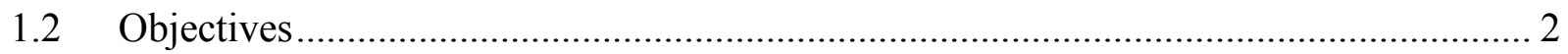

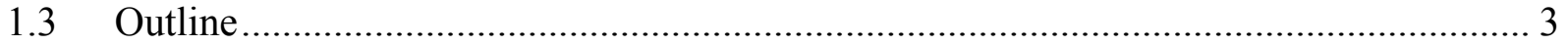

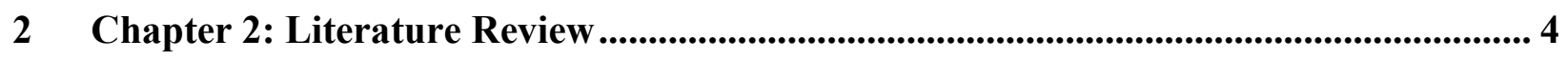

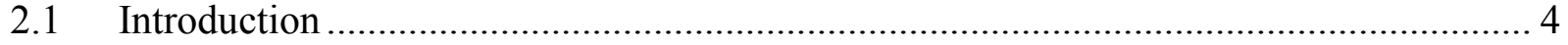

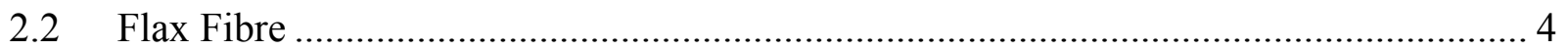

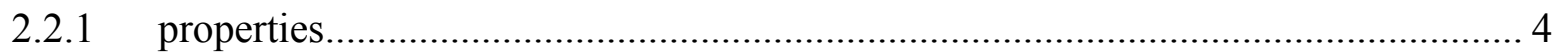

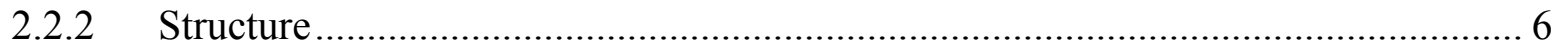

2.3 Challenges of Natural Fibre Composites ……………................................................. 8

2.3.1 Variability of Flax Fibre Properties and Quality ……….................................... 8

2.3.2 Adhesion between the Matrix and the Reinforcement............................................ 8

2.3.3 Fibre Content and Architecture......................................................................... 11

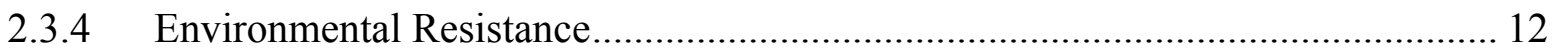

2.4 Water Uptake of Flax Reinforced Composites ……............................................... 13

2.4.1 Diffusion and Absorption of Water ................................................................. 13

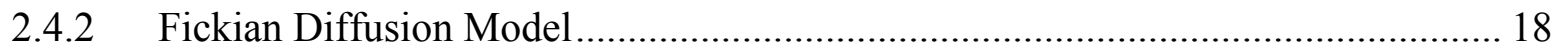

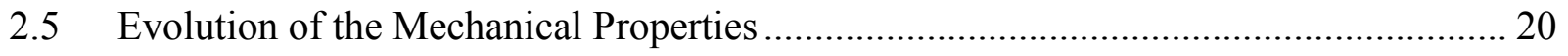

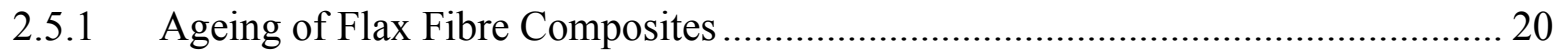

2.5.2 Recovery of the Mechanical Properties after Drying ……................................... 26

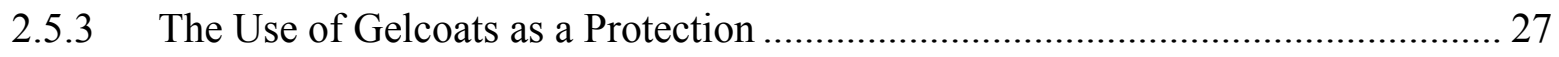

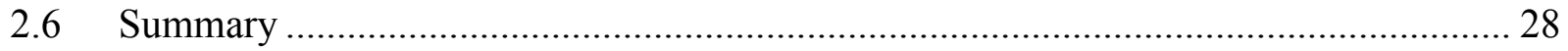


3 Chapter 3: Composite Manufacturing using Resin Transfer Moulding ........................ 29

3.1 Resin Transfer Moulding Process .......................................................................... 29

3.2 Aluminum Mould Design................................................................................ 34

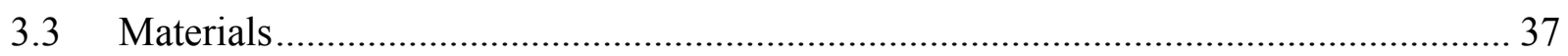

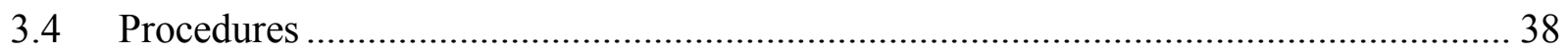

3.4.1 Mould Filing Time ......................................................................................... 38

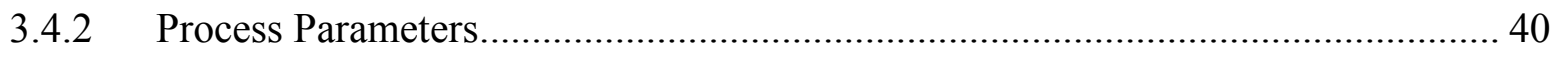

Injection Procedure ............................................................................... 41

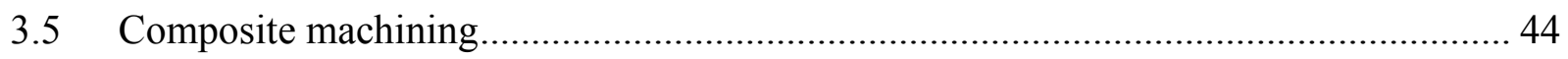

4 Chapter 4: Water Absorption and Gravimetric Analysis ................................................. 46

4.1 Samples Conditioning ....................................................................................... 46

4.1.1 Moisture Conditioning before mechanical testing ............................................ 46

4.1.2 Water Immersion before Dynamic Mechanical Analysis ................................... 47

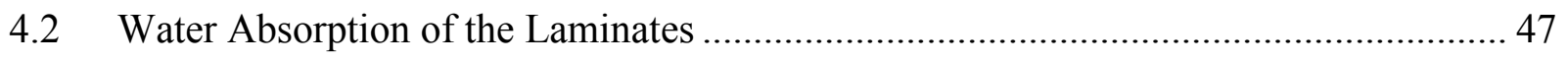

5 Chapter 5: Mechanical Testing Results and Discussion ................................................... 50

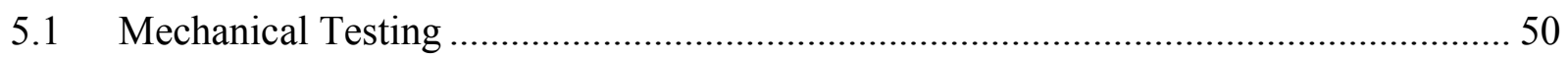

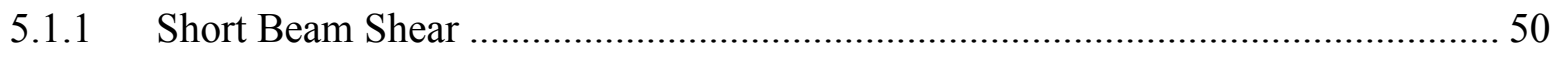

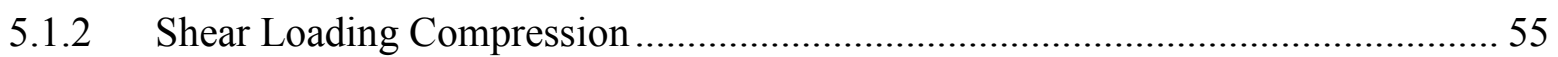

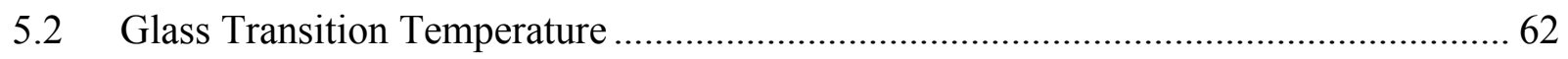

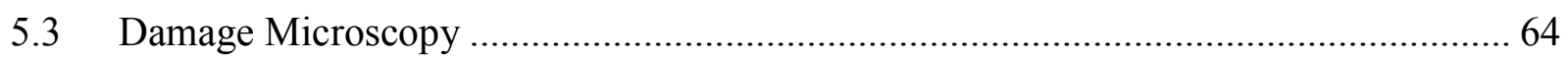

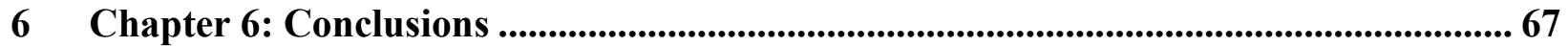

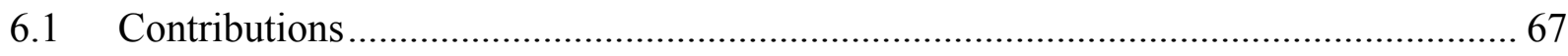

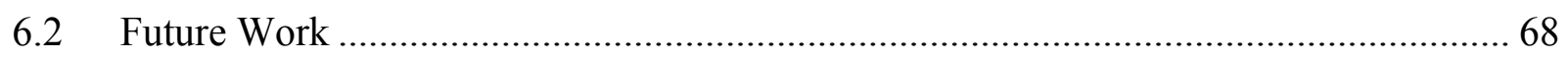

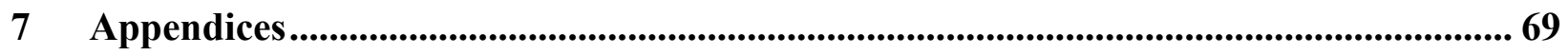

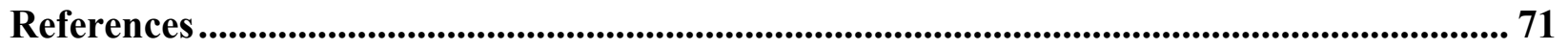




\section{LIST OF FIGURES}

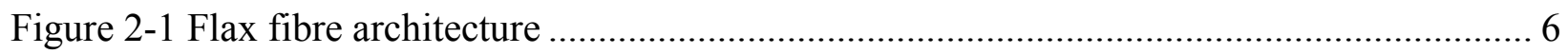

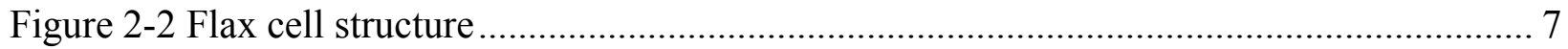

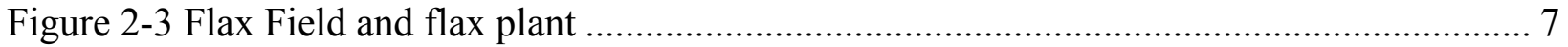

Figure 2-4 Different fibre/matrix adhesion mechanisms ........................................................... 9

Figure 2-5 SEM images of untreated fibres (a) and EDTA treated fibres (d) .............................. 10

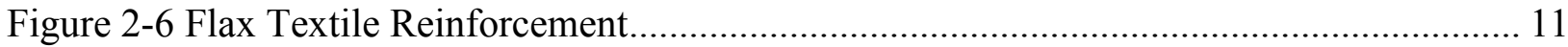

Figure 2-7 Schematic representation of water uptake phenomenon into flax fibres composites . 13

Figure 2-8 SEM images of water induced degradation in flax/PLA injected composites ............ 15

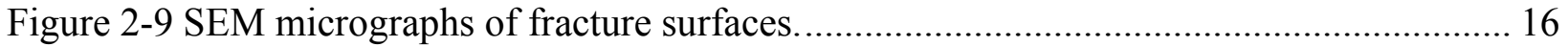

Figure 2-10 Evolution of the water uptake of flax/epoxy composite .......................................... 19

Figure 2-11 Evolution of the water uptake of glass fibre composites immerged in water ........... 20

Figure 2-12 Effect of moisture content on the modulus of green flax/polypropylene, duralin flax/PP, and duralin flax/maleic anhydride modified polypropylene ........................................... 22

Figure 2-13 Effect of moisture content on the tensile strength of green flax/polypropylene, duralin flax/PP, and duralin flax/maleic anhydride modified polypropylene .............................. 23

Figure 2-14 Tensile behaviour of injected flax/PLLA composites, before and after drying ........ 26

Figure 3-1 The carbon fibre reinforced chassis of the BMW i8 is manufactured using RTM ..... 29

Figure 3-2 Resin transfer moulding setup used to manufacture the composite panels................. 30

Figure 3-3 Carbon fibre reinforced roof of the BMW M3 ……................................................ 30

Figure 3-4 The roof of the BMW M3 is being removed from the RTM press ............................. 31

Figure 3-5 Carbon fibre reinforced roof of the BMW M3 after demoulding ............................... 32

Figure 3-6 Typical resin viscosity evolution during cure ............................................................. 33

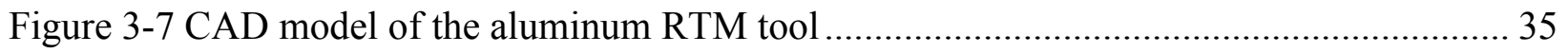

Figure 3-8 Simplified drawing of the bottom part of the RTM tool - top and side view .............. 36

Figure 3-9 Detailed view of the mould injection cavities (a) thin section (b) deep section .......... 37

Figure 3-10 Bottom part of the RTM mould with its O-ring and tubing ..................................... 41

Figure 3-11 RTM mould - bottom part, spacer and preform ……………………….................. 42 
Figure 3-12 RTM tool under the press.

Figure 3-13 Drawing indicating the locations and dimensions of the test coupons machined in the composite panels

Figure 4-1 Water uptake of flax fibre reinforced composites after $90 \% \mathrm{RH}$ ageing at $30^{\circ} \mathrm{C} \ldots \ldots . .48$

Figure 4-2 Water uptake of flax fibre reinforced composites after immersion in distilled water 48

Figure 5-1 Typical fracture modes of flax composites tested in short beam shear.................... 51

Figure 5-2 Short beam shear tests after $90 \% \mathrm{RH}$ ageing at $30^{\circ} \mathrm{C}$ - flax/bio-epoxy ................... 52

Figure 5-3 Short beam shear tests after $90 \% \mathrm{RH}$ ageing at $30^{\circ} \mathrm{C}$ - flax/polyurethane ............... 53

Figure 5-4 Evolution of the short beam strength of the composites with the water uptake ........ 54

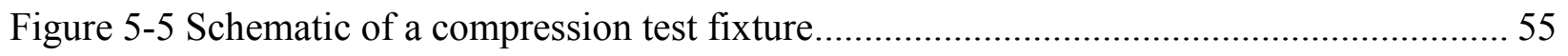

Figure 5-6 Typical fracture modes of flax composites tested in shear loading compression ....... 56

Figure 5-7 Shear loading compression tests after $90 \% \mathrm{RH}$ ageing at $30^{\circ} \mathrm{C}$ - flax/bio-epoxy ...... 57

Figure 5-8 Shear loading compression tests after $90 \% \mathrm{RH}$ ageing at $30^{\circ} \mathrm{C}$ - flax/polyurethane.. 58

Figure 5-9 Normalized compressive strength of the composites .......................................... 59

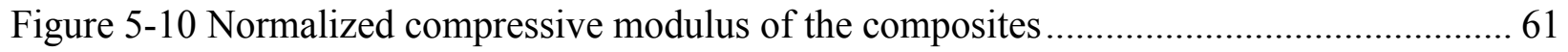

Figure 5-11 Storage modulus of the flax/polyurethane composites measured by DMA for

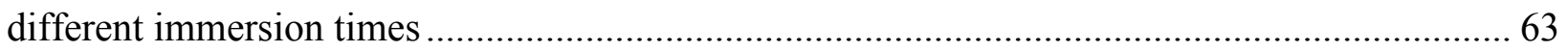

Figure 5-12 Storage modulus of the flax/bio-epoxy composites measured by DMA for different

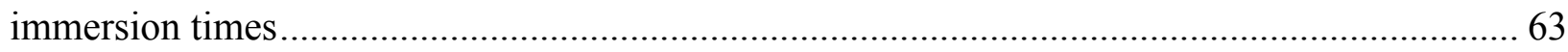

Figure 5-13 Evolution of the glass transition temperature with water uptake .......................... 64

Figure 5-14 SEM images - Side view of shear loading compression test coupons ................... 65

Figure 5-15 SEM images - Fibre/matrix interface in an undamaged area before and after

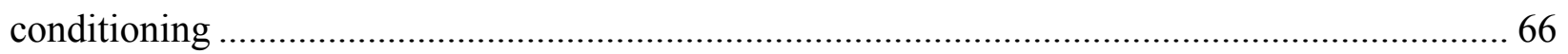

Figure 7-1 Ultimate compressive strength of flax/bio-epoxy and flax/polyurethane composites 69

Figure 7-2 Compressive modulus of flax/bio-epoxy and flax/polyurethane composites ............ 69

Figure 7-3 Viscosity of the LOCTITE MAX 3 Polyurethane resin........................................ 70 


\section{LIST OF TABLES}

Table 2-1 Main Physical Properties of cellulose-based fibres.............................................. 5

Table 2-2 Maximum Water Uptake at Saturation for Glass and Natural Fibre Composites ........ 17

Table 2-3 Evolution of the mechanical properties of flax fibres reinforced composites............. 25

Table 3-1 Main physical and mechanical properties of the resins ......................................... 38

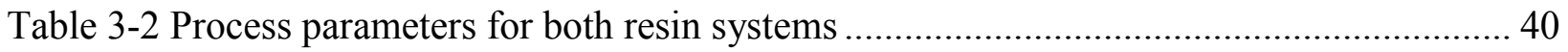




\section{NoMenClATURE}

\section{ABbreviations}

$\begin{array}{ll}\text { RTM } & \text { Resin Transfer Moulding } \\ \text { RH } & \text { Relative Humidity } \\ \text { PU } & \text { Polyurethane } \\ \text { VOC } & \text { Volatile Organic Compound } \\ \text { HP RTM } & \text { High Pressure Resin Transfer Moulding } \\ \text { DMA } & \text { Dynamic Mechanical Analysis } \\ \text { SEM } & \text { Scanning Electron Microscopy }\end{array}$




\section{CONSTANTS AND VARIABLES}

\begin{tabular}{|c|c|}
\hline$W_{0}$ & weight of the dry specimen \\
\hline$W_{t}$ & weight of wet specimen \\
\hline$M_{t}$ & relative uptake weight \\
\hline$M_{m}$ & maximum moisture uptake \\
\hline$t$ & time \\
\hline$D$ & diffusivity \\
\hline$h$ & thickness of the specimen \\
\hline$k$ & permeability \\
\hline$\mu$ & dynamic viscosity \\
\hline$V_{f}$ & fibre volume fraction \\
\hline$u$ & superficial velocity \\
\hline$\nabla p$ & pressure gradient at the flow front \\
\hline$x$ & position of the flow front \\
\hline$t_{\text {filling }}$ & time required to fill the entire mould \\
\hline$\Delta P$ & pressure difference between the inlet and the flow front \\
\hline$P$ & inlet pressure \\
\hline$L$ & width of the mould \\
\hline$E^{\prime}$ & storage modulus \\
\hline$w t \%$ & fibre weight fraction \\
\hline$m_{f}$ & mass of the dry fibre reinforcement \\
\hline$m_{\text {part }}$ & mass of the composite panel \\
\hline$\rho_{f}$ & density of the fibres \\
\hline$\rho_{r}$ & density of the resin \\
\hline
\end{tabular}




\section{CHAPTER 1: INTRODUCTION}

\subsection{INTRODUCTION}

Bio-composites are materials which are reinforced with natural fibres or fillers, regardless of the type of matrix that is used [1]. In the past few years, flax fibres have been the subject of a significant amount of research regarding their potential for the development of bio-composites due to their specific properties (Table 2-1), their price, their recyclability and their health advantages, such as the emission of volatile organic compounds (VOC) when machined [2, 3]. It makes them easily implementable in an already exiting factory as opposed to synthetic fibre composites which require several dedicated equipment to ensure health and safety. Other properties, such as low wear on tools and good acoustic properties are also mentioned as benefits of natural fibres [2-6]. Approximately 315,000 tonnes of natural fibres were used as composite reinforcement in 2010, which accounted for $13 \%$ of the total reinforcement materials (glass, carbon and natural fibres) [7]. It is forecasted that about 830,000 tonnes of natural fibres will be incorporated in composite materials by 2020 [8]. Compared to glass fibres, flax fibres have similar specific properties and are available at a lower price $[9,10]$. Regarding the recyclability, one advantage of flax fibre composites over glass fibre composites is that they can be "thermally recycled", which means that they can be burned to produce energy without leaving large amount of residues [2]. The automotive industry is probably the one that uses the largest quantity of natural fibres. Most of the technologies are based on the application of the natural fibres as a non-woven material [2].

If natural fibres seem to be a particularly promising reinforcement, they also have disadvantages that need to be overcome before considering them for structural components: (1) the quality of natural fibres is not homogenous due to the variability of the conditions in which they are grown; (2) natural fibres start degrading at a temperature of about $200^{\circ} \mathrm{C}$, a temperature at which most thermoplastics are processed; (3) natural fibres are hydrophilic and are therefore difficult to bond 
with an hydrophobic polymeric matrix; and (4) natural fibres absorb more moisture than synthetic fibres.

Several studies have shown that the mechanical properties of natural fibres composites are strongly affected by moisture absorption [3, 4, 11-24], but for now there is no clear understanding of the exact combination of water absorption mechanisms. Strong bonds between the fibres and the matrix will maximize the mechanical performance of the composite as well as preventing the infiltration of water at the interface [20,25]. Flax fibre cells are made of several walls, one primary and 3 secondary walls, that are composed of cellulose microfibrils $(\approx 70 \%)$ held together by hemicellulose $(\approx 15 \%)[3,26]$. Both of these constituents have a high number of hydroxyl $(\mathrm{O}-\mathrm{H})$ groups in their chemical structure which leads to a high polarity. Because bonding hydrophilic natural fibres to a hydrophobic polymeric matrix can lead to a relatively poor interface, it could be beneficial to use the flax hydroxyl groups in the polymerisation reaction to create covalent bonds between the fibres and the matrix. Polyurethane resins are a good candidate since N-H groups of the isocyanate pre-polymer react with $\mathrm{O}-\mathrm{H}$ groups of the polyol monomer.

\subsection{OBJECTIVES}

This study aimed at comparing two flax fibre reinforced composites using a bio-based epoxy resin and a polyurethane resin as matrices. As one of the goals of using natural fibres is to manufacture a material made of sustainable resources, the bio-based epoxy resin is a relevant choice to maximize the natural content of the composite. This thesis focuses on two main issues: the interface adhesion between the flax fibres and the polymeric matrix and the moisture absorption of the composite after processing. Even though a very large quantity of work has been

published on various natural fibres based bio-composites [4, 12-14, 17-20, 22-25, 27], it is not always easy or sometimes even possible to compare the materials used in different studies. In fact, the fibres type and architecture, the resin, the manufacturing process, the part dimensions, the ageing conditions and the tests performed often make a clear comparison impossible, even if common behaviours or phenomenon can be observed. An effort has been made in the present work to give an accurate comparison between two matrices which interact differently with the 
fibres. This could help to better understand the fibre/matrix interface and the water absorption mechanisms in bio-composites.

\subsection{OUTLINE}

The main body of this thesis progresses as follows. The present chapter introduces and motivates the present work. Chapter 2 reviews relevant literature and identity areas that can be further studied or improved. Chapters $3-5$ present the main findings of the thesis, while chapter 6 summarizes its key results. In addition to the main body, several appendices are also included to provide further details and supporting data. 


\section{CHAPTER 2: LiterATURE REVIEW}

\subsection{INTRODUCTION}

This literature review focuses on two main issues: the interface between the flax fibres and the polymeric matrix and the moisture absorption of the composite after processing. After introducing the structure of natural fibres, the water uptake of the composite and the evolution of the mechanical properties will be discussed.

\subsection{FLAX FIBRE}

Compared to other natural fibres, flax fibres offer a good compromise between the elongation at break, the tensile strength and the specific modulus (Table 2-1) [3, 9, 10, 28-36]. Jute, hemp, kenaf and sisal fibres are also used in composites because of their properties and availability [2, $5]$.

\subsubsection{PROPERTIES}

Table 2-1 shows that bast fibres and especially flax fibres are the best candidates for composite materials with natural reinforcements. They offer the best compromise between elongation at break, tensile strength, specific modulus, price and availability [3, 9, 10, 28-36]. Ramie fibres are the stiffest and the strongest fibres and would be the best choice if they were more available. In fact, their extraction process is very expensive because of their high gum content $[37,38]$.

Thuault et al. have studied the effects of the hygrothermal environment on the mechanical properties of flax fibres [39]. They reported that the mechanical properties of flax fibres increase with RH until it reaches $68 \%$. After that point, water can seep into the fibre and disorganize the microfibrils network, resulting in a decrease in fibre strength. On the other hand, when flax fibres are exposed to temperature higher than $40^{\circ} \mathrm{C}$, the ductility of their amorphous phase is reduced due to water release, resulting in a decrease of their Young's modulus. 
Table 2-1 Main Physical Properties of cellulose-based fibres compared with conventional synthetic fibres (adapted from [3])

\begin{tabular}{|c|c|c|c|c|c|c|c|c|}
\hline Fibre & $\begin{array}{l}\text { Density } \\
\left(\mathrm{g} / \mathrm{cm}^{3}\right)\end{array}$ & $\begin{array}{c}\text { Diameter } \\
(\mu \mathrm{m}) \\
\end{array}$ & $\begin{array}{c}\text { Elongation at } \\
\text { break } \\
(\%) \\
\end{array}$ & $\begin{array}{c}\text { Tensile } \\
\text { strength } \\
(\mathrm{MPa}) \\
\end{array}$ & $\begin{array}{c}\text { Young's } \\
\text { Modulus } \\
(\mathrm{GPa}) \\
\end{array}$ & $\begin{array}{c}\text { Specific } \\
\text { modulus } \\
\left(\mathrm{GPa} . \mathrm{cm}^{3} / \mathrm{g}\right)\end{array}$ & $\begin{array}{l}\text { Price } \\
(€ / \mathrm{Kg}) \\
\end{array}$ & References \\
\hline Flax & $1.40-1.50$ & $40-620$ & $2.7-3.2$ & 343-1035 & $27-80$ & $19-53$ & $0.57-2.33[2]$ & {$[9,10]$} \\
\hline Jute & $1.30-1.50$ & $30-140$ & $1.4-3.1$ & $187-773$ & $3-55$ & $3-37$ & $0.12-0.35$ & {$[9,10]$} \\
\hline Abaca & 1.5 & $17-21$ & $10-12$ & 980 & 72 & 48 & $0.81-0.92$ & [32] \\
\hline Sisal & $1.30-1.50$ & $100-300$ & $2.0-2.9$ & $507-855$ & $9.0-28.0$ & $7-19$ & $0.70-1.02$ & {$[9,31,34]$} \\
\hline Kenaf & $1.22-1.40$ & $40-90$ & 3.7-6.9 & $295-930$ & $22-53$ & $18-38$ & $0.53-0.61$ & [32] \\
\hline Ramie & 1.5 & $40-60$ & $3.6-3.8$ & $400-938$ & $44-128$ & $29-85$ & $1.44-2.40$ & {$[9,10,36]$} \\
\hline Hemp & $1.40-1.50$ & $16-50$ & $1.3-4.7$ & $580-1110$ & $3-90$ & $2-60$ & $0.57-1.73$ & [10] \\
\hline Cotton & $1.50-1.60$ & $16-21$ & $2.0-10.0$ & $287-597$ & $5.5-12.6$ & $4-8$ & $1.61-4.59$ & {$[9,28]$} \\
\hline Coir & $1.25-1.50$ & $100-450$ & $15.0-47.0$ & $106-270$ & $3.0-6.0$ & $2-4$ & $0.24-0.48$ & {$[10,28,30]$} \\
\hline Banana & $1.30-1.35$ & $50-280$ & 3-10 & $529-914$ & $7.7-32.0$ & $6-24$ & $0.7-0.9$ & {$[28]$} \\
\hline Henequen & 1.49 & $20-500$ & $3.0-5.0$ & $430-580$ & $10.1-16.3$ & $7-11$ & $0.38-0.67$ & [28] \\
\hline Bagasse & $0.55-1.25$ & $200-400$ & 0.9 & $20-290$ & $2.7-17.0$ & $5-14$ & 0.15 & {$[36]$} \\
\hline Pineapple & $1.52-1.56$ & $200-8800$ & 0.8 & $170-1627$ & $6.21-82$ & $4-53$ & $0.36-0.72$ & {$[29,30,34,35]$} \\
\hline E-glass & $2.50-2.55$ & $10-20$ & 2.5 & $2000-3500$ & 73 & 29 & 1.25 & [33] \\
\hline Aramide & $1.40-1.45$ & 12 & 3.3-3.7 & $3000-3150$ & $63.0-67.0$ & $45-48$ & 7.2 & [33] \\
\hline Carbon & $1.40-1.75$ & 5.5-6.9 & 1.4-1.8 & 4000 & $230.0-240.0$ & 164-171 & 12 & [33] \\
\hline
\end{tabular}




\subsubsection{STRUCTURE}

The flax (Linum Usitatissimum) stem is mainly composed of a wood core and a skin (Figure 2-1). The bast fibres are located in the skin and are extracted and separated until technical fibres are obtained. Technical fibres consist in 10 to 40 elementary fibres $(\varnothing 0.1-0.8 \mathrm{~mm})$ that are $20-$ $50 \mathrm{~mm}$ long [2].

Figure 2-2 shows that the flax fibre cells have a wall structure somehow comparable to a natural composite material. The cell walls are made of cellulose microfibrils held together by hemicellulose $[3,26]$. The different orientations of the cellulose microfibrils and the hollow core of the cell (lumen) contribute to the high specific properties of flax fibres.

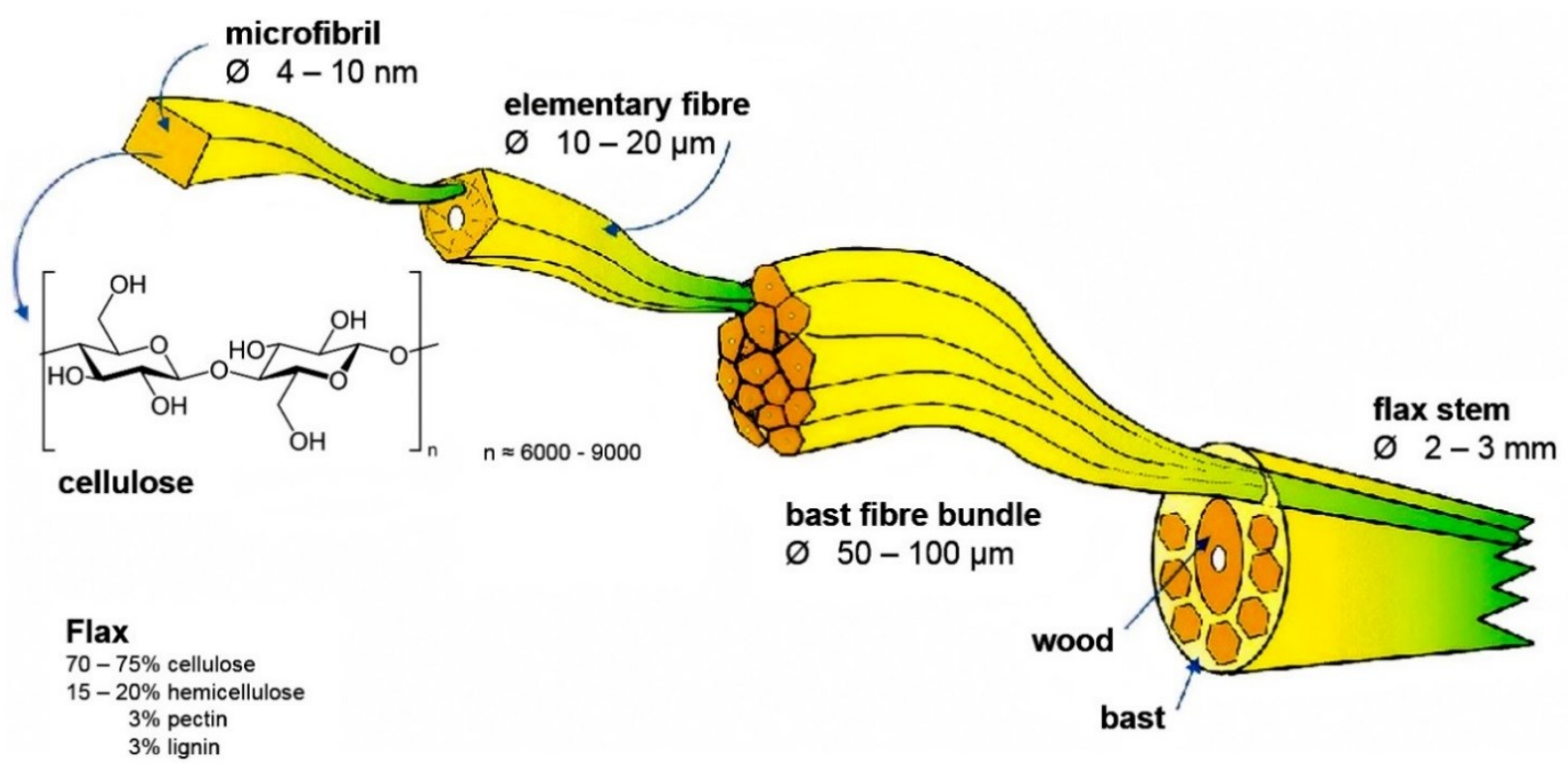

Figure 2-1 Flax fibre architecture [40] 


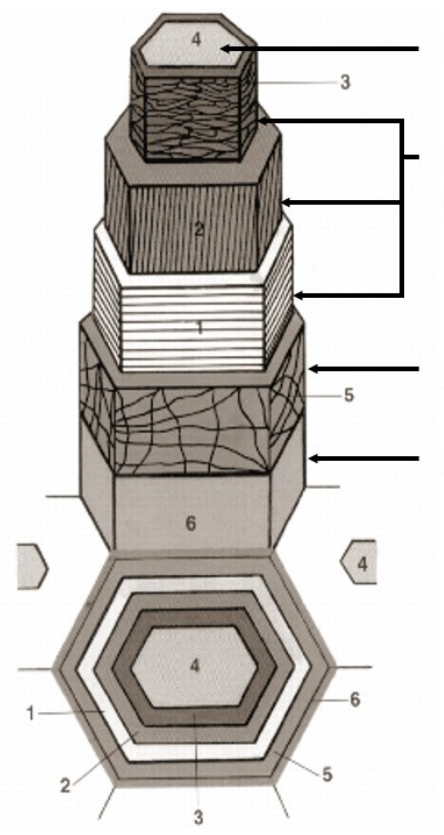

(4) Lumen

(1-3) Secondary Wall

3 different layers with a different orientation of cellulose microfibrils

(5) Primary wall

(6) Middle lamella

Figure 2-2 Flax cell structure [41]
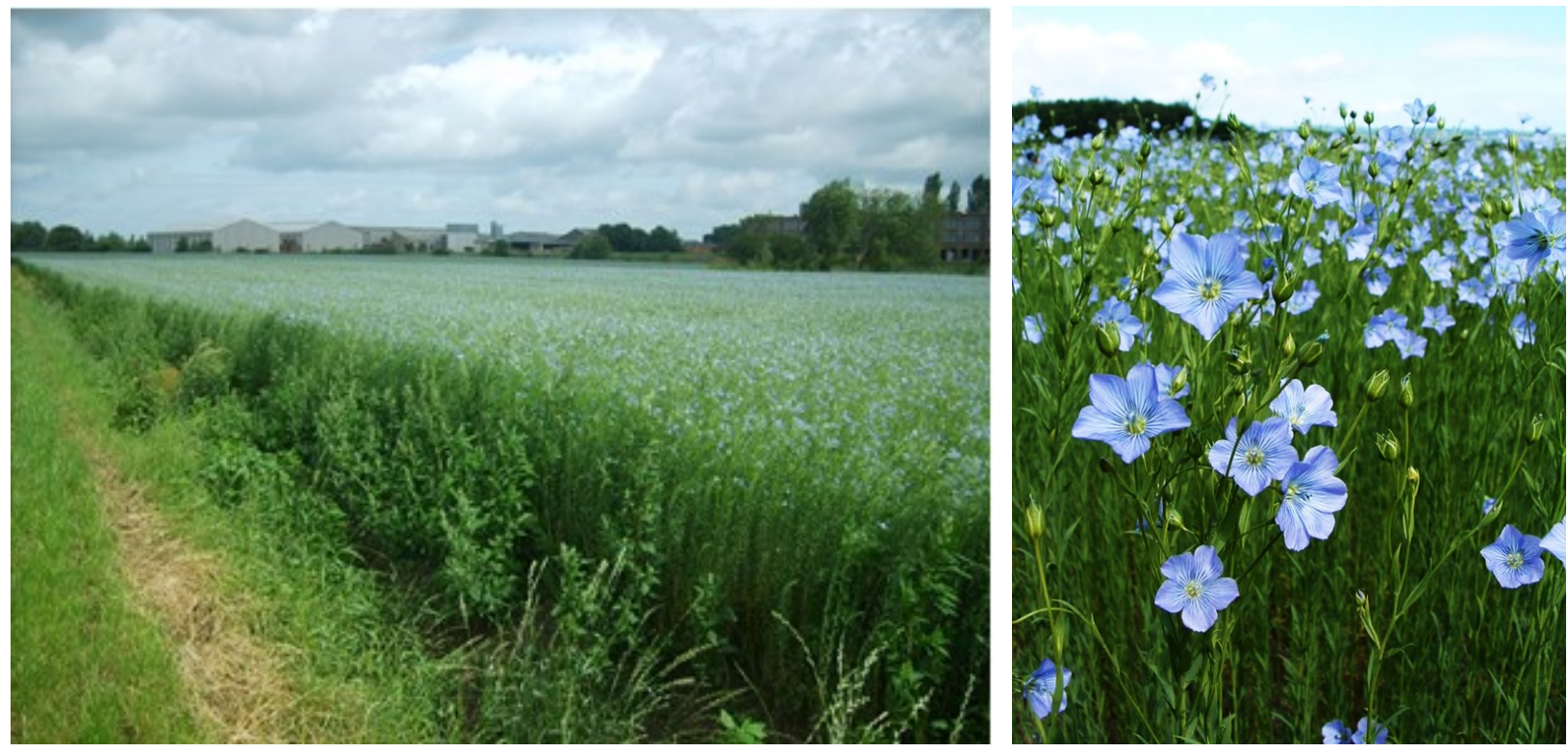

Figure 2-3 Flax Field and flax plant [42] 
As a flax plant is $\sim 1 \mathrm{~m}$ tall (Figure 2-3), there is no equivalent to the synthetic continuous fibres. Therefore, technical fibres must be yarned before being transformed in a woven or a unidirectional (UD) material. An optimum must be found between a low twisted yarn $(\sim 30$ turns $/ \mathrm{m})$ with a very low strength and a highly twisted yarn $(\sim 50$ turns $/ \mathrm{m})$ that is difficult to process [43]. In contrast to yarns used in the textile industry, the composite yarn needs to have a lower level of twist; high enough to enable the use of textile processes such as weaving and to limit fibre misalignment in the composite. At the same time, low levels of twist will lead to improved impregnation by the polymer resin [43].

\subsection{Challenges of NATURAL Fibre Composites}

\subsubsection{Variability Of Flax Fibre Properties and Quality}

One of the major issues with natural fibres is the variability of their properties and quality. Different factors can influence the resulting properties of natural fibres such as the location and the time of harvest, the maturity, the climate, the manufacturing process, the fibre extraction processes, as well as their sensitivity to temperature, moisture and UV radiation [2-6, 44-47].

\subsubsection{ADHESION BETWEEN THE MATRIX AND THE REINFORCEMENT}

Fibre/matrix adhesion is a very common topic that has been widely studied (see W.C. Wake [48] and D. Hull [49] for more detailed reviews). It can be attributed to a combination of five main mechanisms: (1) adsorption and wetting, (2) inter-diffusion, (3) electrostatic attraction, (4) chemical bonding and (5) mechanical adhesion (Figure 2-4) [49]. This paragraph will focus specifically on natural fibre interfaces. 
(a)

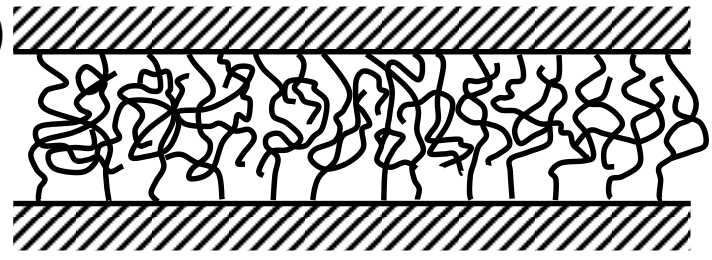

(b)

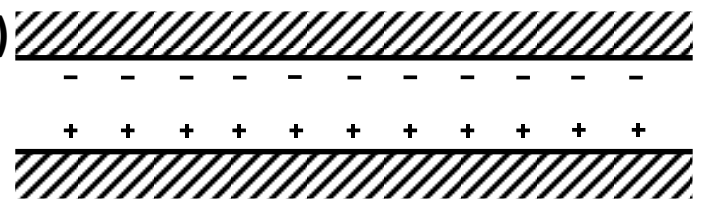

(c)

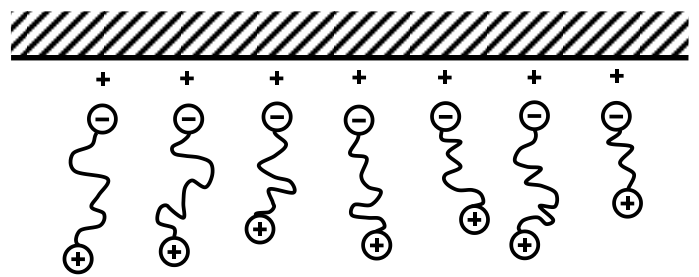

(d)

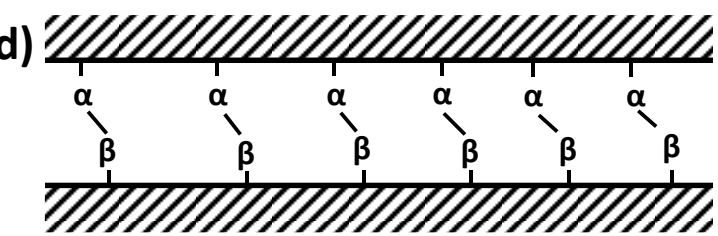

(e)

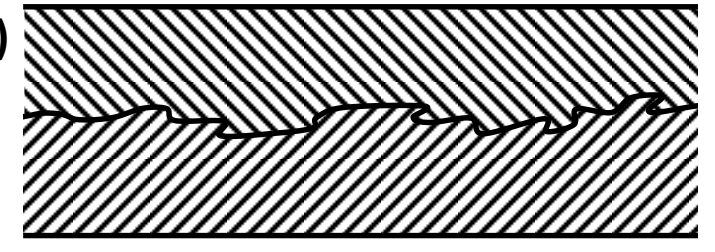

Figure 2-4 Different fibre/matrix adhesion mechanisms. (a) Bond formed by molecular entanglement following inter-diffusion. (b) Bond formed by electrostatic attraction. (c) Cationic groups at the end of the molecule attracted to anionic surface resulting in polymer orientation at the surface (d) Chemical bond formed between groups A on the surface and groups B on the other surface. (e) Mechanical bond formed when a liquid polymer wets a rough solid surface. [49]

Another very important challenge raised by the use of natural fibres is the quality of the interface between the reinforcements and the matrix $[5,18,50]$. In fact, a hydrophobic matrix adheres poorly with hydrophilic natural fibres. To improve the strength at the interface, different chemical pre-treatments have been applied to natural fibres; however the results were mitigated $[6,11,45,51-54]$. Mercerization, acrylation, acetylation and the grafting of coupling agent such as silane, maleic anhydride, peroxide or permanganate are the most studied pre-treatments. These chemical treatments increase the overall cost of the composite and the processing time. Also, the environmental advantages of natural fibres are impacted by the use of various chemical. 

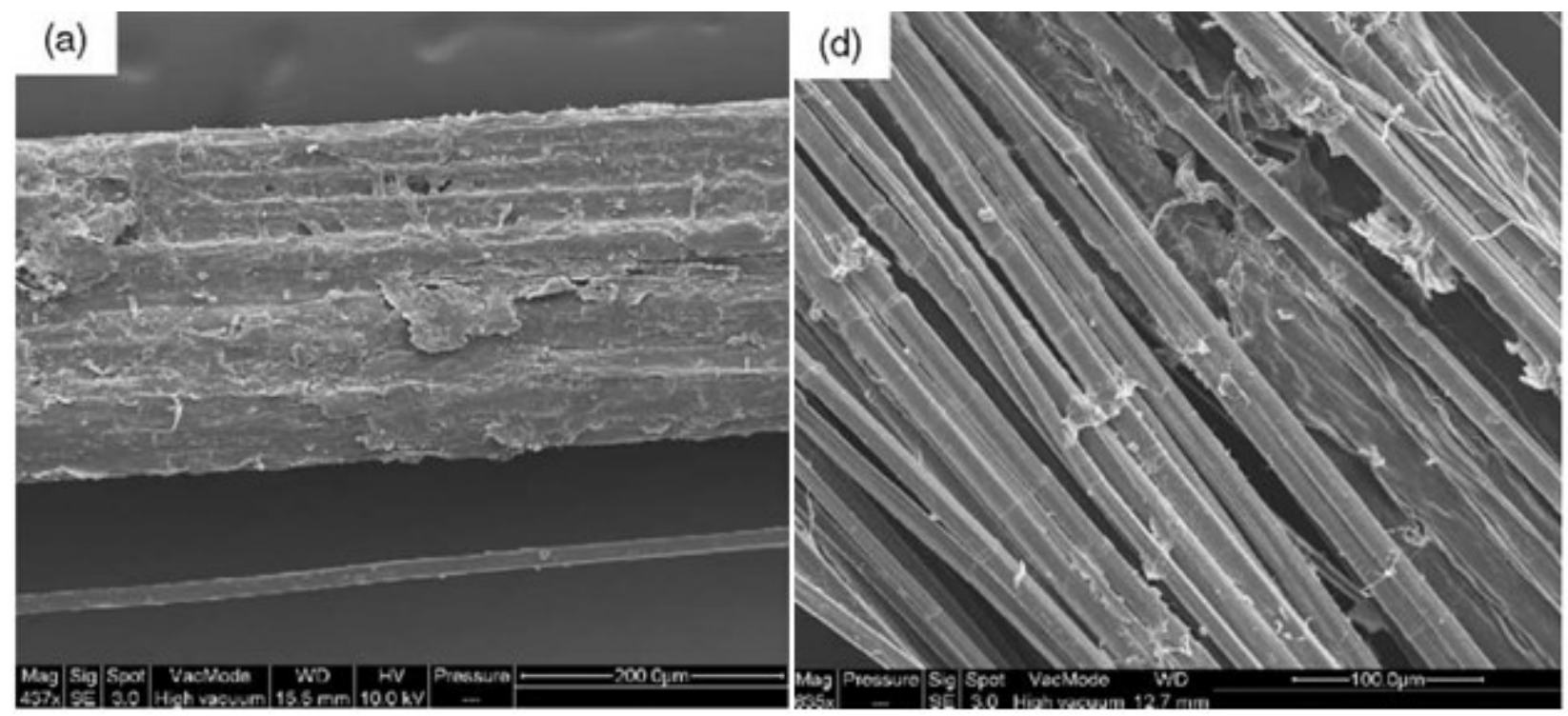

Figure 2-5 SEM images of untreated fibres (a) and EDTA treated fibres (d) [55]

(a) Intact fibre bundles are visible in the untreated fibres, which also display what appears to be a large amount of debris adhering to the surface of the fibre bundles.

(d) The greatest separation appears to have been brought about by the EDTA treatment, elementary fibre are visible.

Figure 2-5 shows fibres treated with EDTA. The goal is to separate the elementary fibres in order to improve their impregnation [55]. The result is an increase of the composite tensile strength, up to a maximum of 50\% [55]. The other properties, such as the Young's Modulus, are not particularly affected. Fibre pull-out and micro-bond tests can be performed to study the adhesion between the fibres and the matrix [56]. However, these tests are delicate, difficult to perform and don't take into account the effects of the reinforcement architecture, manufacturing process and potential defects that will occurs in a real composite part. They remain valuable tools to compare different matrices. 


\subsubsection{Fibre CONTENT AND ArChitecture}

In composite materials, the reinforcements contribute the most to the resulting mechanical properties while the matrix is used to hold the fibres together. Therefore, achieving a high fibre volume fraction is the key goal pursued. Moreover, the resin being more expensive than the fibres is another incentive for increased fibre content within the composite.

For now, most flax composite are being reinforced by the use of mats. Their fibre volume fraction rarely exceeds $40 \%[4,13,18,27]$. It can reach $50 \%$ when using pultrusion or injection moulding processes $[4,27,57]$. When the composites are reinforced with flax unidirectional fibres (UD) or textiles, the fibre volume fraction usually drops to 30-35\%. At maximum, the fibre volume fraction can reach $40 \%[11,12,14,17,58]$. The challenge is to increase the fibre volume fraction and use tailored textiles to improve the mechanical properties of flax fibre composites and reduce the impact of fibre defects [50].
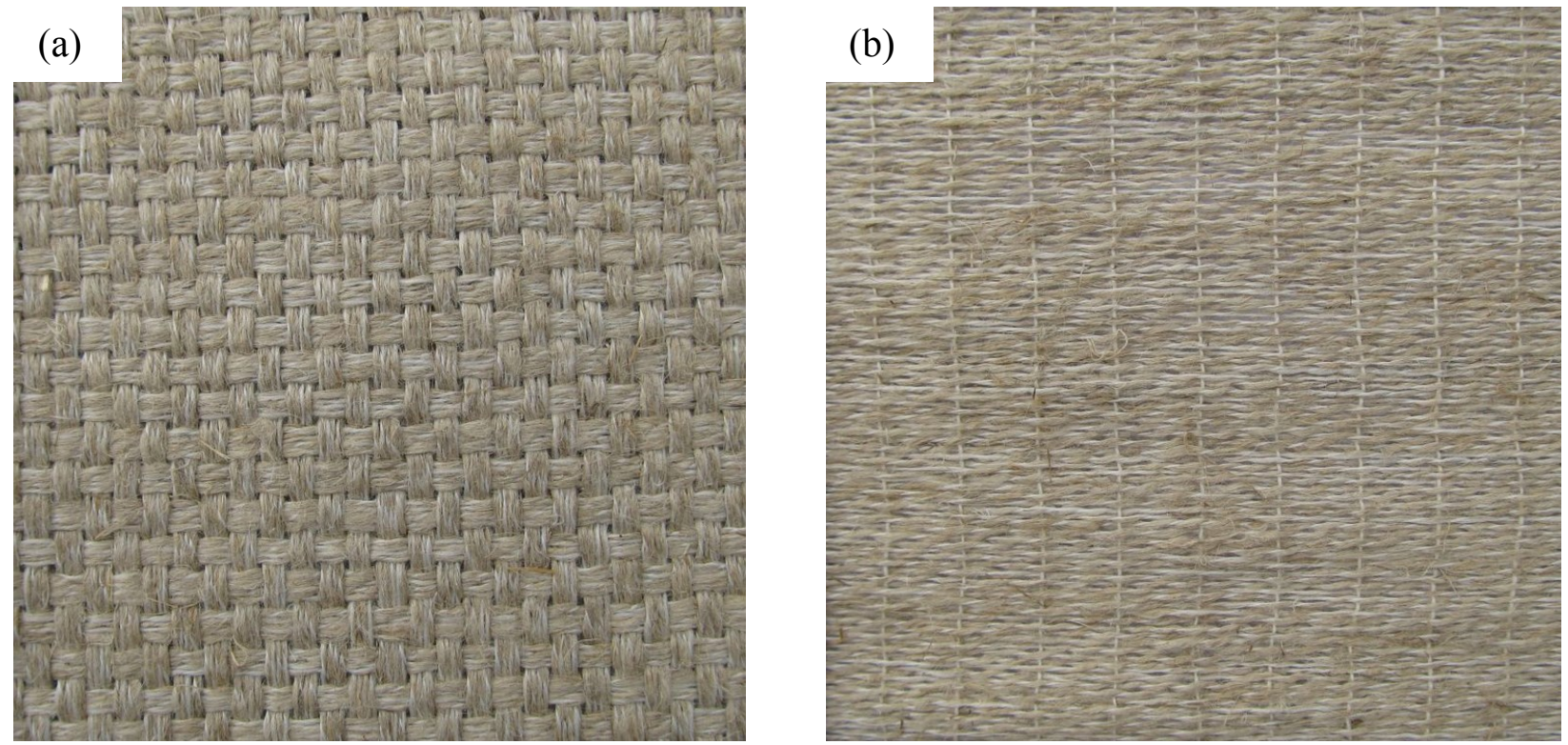

Figure 2-6 Flax Textile Reinforcement (a) Biotex Flax 4x4 Hopsack 500gsm (b) Biotex Flax UD 275gs 
In addition, if flax fibres have specific properties comparable to those of E-glass, it is not the case when used in a laminate. When comparing a flax/epoxy laminate with a glass/epoxy laminate (same resin, same dimensions) with an identical volume fraction (40\%), the specific tensile strength of the glass/epoxy laminate is more than two times higher than the flax/epoxy laminate [58]. This shows that the fibre/matrix interface is weaker in the flax composites.

It should also be noted that flax fabrics tend to be thicker that their glass fibre equivalent. This lead to a lower number of plies in flax composites and makes it more difficult to increase the volume fraction.

\subsubsection{ENVIRONMENTAL RESISTANCE}

The hydrophilic nature of natural fibres renders flax composites highly sensitive to moisture and therefore, their poor resistance to water absorption is a major problem. In fact, flax composites absorb up to $\sim 13 \%$ of water $[4,11-14,16-18,27]$ where E-Glass composite only absorb $\sim 1 \%$ $[12,14,59]$. Even with fibre and matrix treatments (in some studies, maleic anhydride is grafted to a polypropylene matrix) the material is still affected by the absorbed water $[5,18,50]$.

The water absorption leads to a decrease in the mechanical properties, an increase of the fibres diameter (swelling), fibre/matrix debonding and other water induced degradations.

In order to develop stronger and more durable natural fibre reinforced composites that can be used in other environment than car interiors, it is essential to understand the effects of water on the mechanical properties and on the adhesion between the fibre and the matrix. The following sections will focus on that mater by describing previous research which focused on the environmental resistance of flax fibre reinforced composites. 


\subsection{WATER UPTAKE OF FLAX REINFORCED COMPOSITES}

\subsubsection{DIFFUSION AND ABSORPTION OF WATER}

The diffusion and the absorption of water in a material is one of the main causes of ageing and degradation [60]. It involves a wide range of chemical and physical phenomena.

A composite part is, by definition, not homogenous. Moreover, polymer matrices are most of the time hydrophobic whereas flax fibres are hydrophilic. Therefore, it is difficult to characterize or model what is exactly happening in the material. That is why, most studies focus on the effect of water on the mechanical properties or the water induced defects [4, 12-14, 16-18, 27, 59, 61].

\subsubsection{Combination of CHEMICAL AND PHYSiCAL PHENOMENA}

There is no clear understanding of the combination of phenomena explaining water absorption in a natural fibre reinforced material. However, some of these physical and chemical phenomena can be approximated and listed (Figure 2-7).

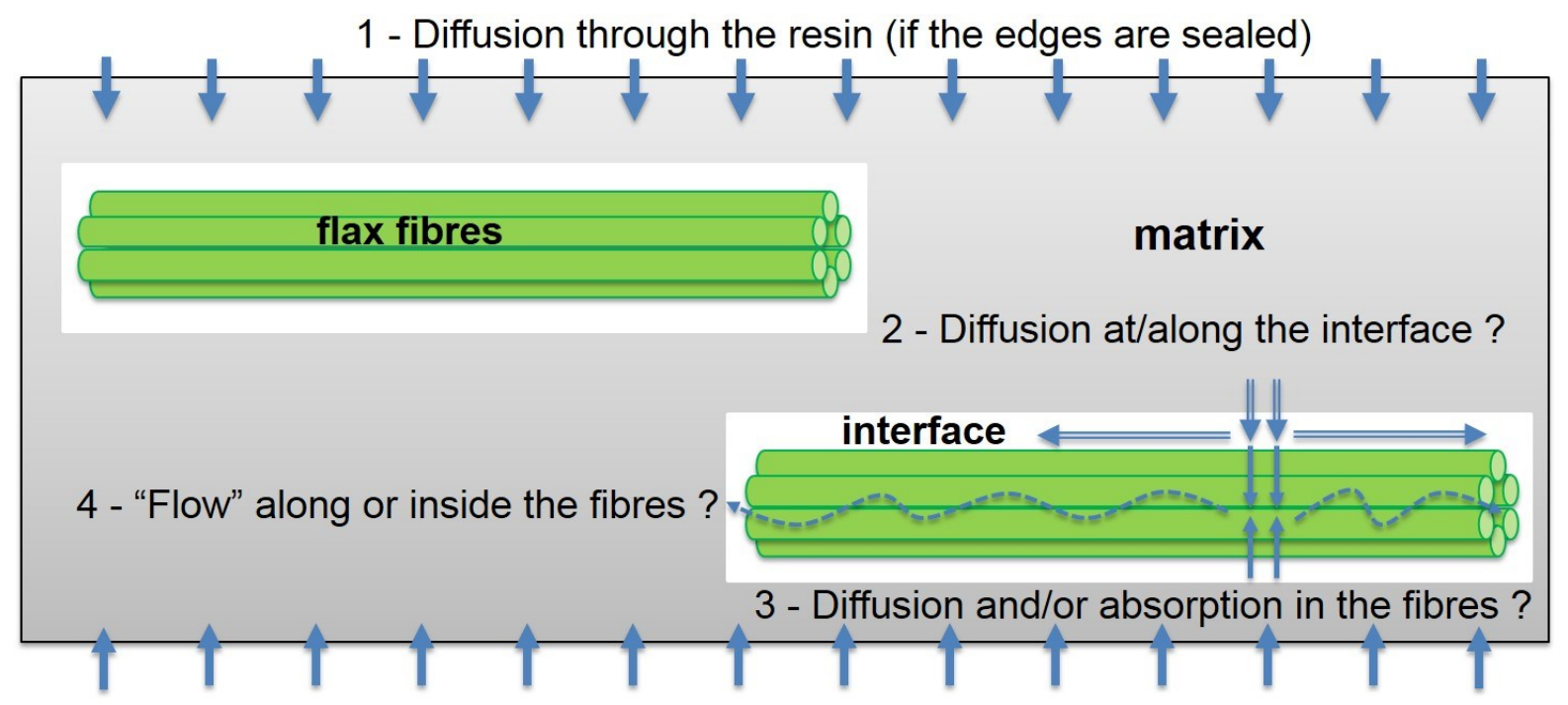

Figure 2-7 Schematic representation of water uptake phenomenon into flax fibres composites [11] 
The composite part first absorbs water via diffusion trough the resin (1) (only if the edges are sealed, otherwise water can also diffuse trough the fibres). Because the resin has a low diffusion coefficient $\left(10^{-7}-10^{-6} \mathrm{~mm}^{2} / \mathrm{s}\right)$, this is a relatively slow process. Then, water can diffuse at, and/or along the interface (2). Thereafter or maybe simultaneously, the fibres will diffuse/absorb water due to their hydrophilic nature (3). Fibres can also act as "water tank" by trapping water into micro- and macro-voids of the fibre bundle [11]. Because the core of the fibres is hollow, we can wonder if some of the absorbed water would be able to flow inside the fibres, which could act as channels for water (4). Furthermore, capillarity certainly plays a role at the interface and inside the fibres.

It should be noted that these phenomena do not happen necessarily in the order presented in Figure 2-7 and remain quite complex to define. In addition, hydrolysis is another chemical phenomenon that can also degrade the matrix and the interface, especially polyesters [59].

Note that the presence of defects, (such as micro-space, voids or cracks) accelerates water transport. Finally, the way in which a composite absorbs water depends on many parameters: hygrometric rate, temperature, fibre fraction, fibre nature, porosity fraction, reinforcement geometry, and matrix type [17]. The absorption of water involves a plasticizing and a swelling effect on the matrix. This can lead to delamination and fibre/matrix debonding [59] (Figure 2-8).

The overall water uptake behaviour of the composite can be modeled using Fick's Law (cf. 2.4.2) to provide a good indicator of the weight gain or moisture content. However, it is not representative of the complex phenomenon described above. In fact, Fick's Law is only valid for homogenous materials, and composite materials are, by definition, made of at least two heterogeneous materials. 

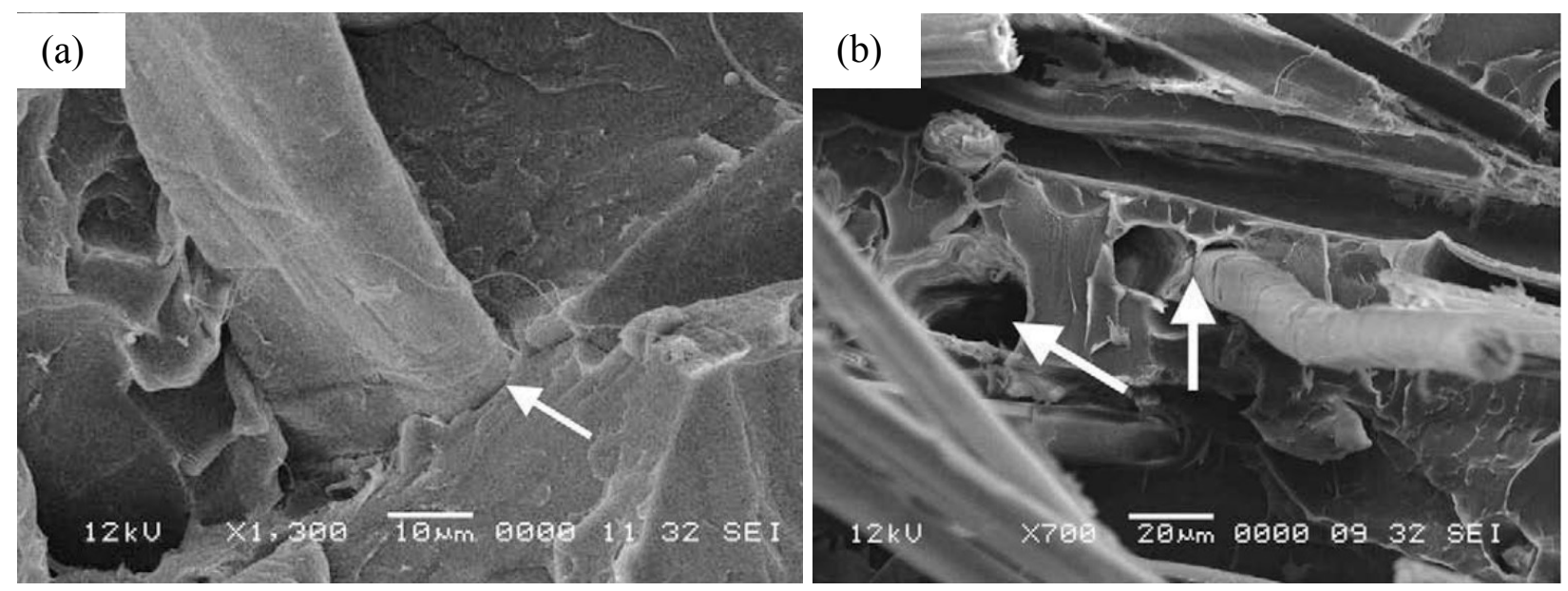

Figure 2-8 SEM images of water induced degradation in flax/PLA injected composites. [13]

(a) unaged (b) after 3 months at 40C. Arrows indicate the fibre/matrix interface.

Swelling of the fibres and the debonding between fibre and matrix is visible.

\subsubsection{COMPARISON WITH GLASS FIBRE COMPOSITES}

Because flax fibres have comparable properties to glass fibres, it can be interesting to compare their water absorption behaviour.

The first thing that can be noticed is that the composite does not simply have a combination of the resin and the fibres properties. For instance, when a polymer is used with glass fibres (glass fibres do not absorb water), the composite has different absorption properties than that of the polymer. The resin alone has a Fickian behaviour with a plateau when the saturation is reached. It is not the case when the water uptake of the composite is considered. Experiments were conducted for glass fibres and confirmed the presence of additional mechanisms as explain in 2.4.1.1 [59, 62, 63].

The diffusion and absorption coefficients of glass fibres are negligible when compared to the coefficients of the resin, while the opposite is true for flax fibres. Glass fibres can even act as an obstacle to the water diffusion in the composite [59] thus, the interfaces are mainly responsible for the water absorption behaviour of glass fibre composite. It is also the case for flax fibre 
reinforced composite. However, the hydrophilic flax fibres absorb water and help the diffusion in the composite part. Figure 2-9 shows the differences in interface quality and fibre/matrix adhesion that can be obtained in the case of treated or non-treated glass fibres. A good adhesion directly affects the surface of the fibres (Figure 2-9 (b) and (d)).

Table 2-2 shows the water uptake of different composites after ageing. Compared to glass fibre composites, the water uptake of flax fibre composite is almost 10 times greater, making it a more challenging issue. In both cases, the quality of the fibre/matrix interface is critical.
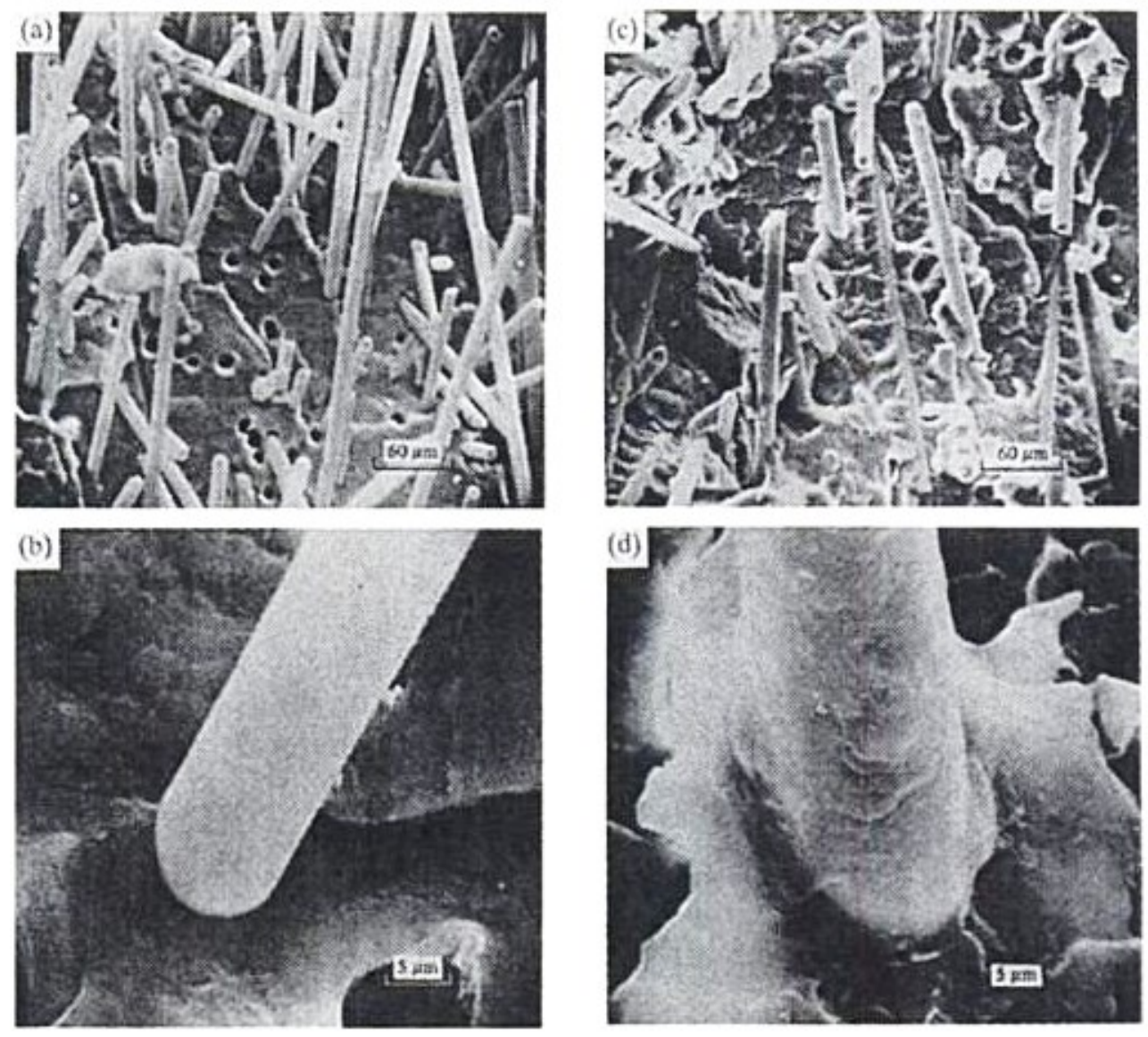

Figure 2-9 SEM micrographs of fracture surfaces from injection moulded polypropylene containing short glass fibres.

A coupling agent was present on the fibres used to make specimens (c) and (d) but absent for (a) and (b). The higher bond strength induced by the coupling agent is clear from the adherence of polymer to the fibres and the shorter pull-out lengths. [courtesy of Dow-Corning Corporation] [49] 
Table 2-2 Maximum Water Uptake at Saturation for Glass and Natural Fibre Composites

\begin{tabular}{|c|c|c|c|c|c|c|c|c|c|}
\hline Fibre & Architecture & Resin & $\begin{array}{c}\text { Fibre } \\
\text { Fraction } \\
(\mathrm{Vf} \%) \\
\end{array}$ & $\begin{array}{c}\text { Fibre } \\
\text { Treatment }\end{array}$ & $\begin{array}{c}\text { Thickness } \\
(\mathrm{mm}) \\
\end{array}$ & $\begin{array}{c}\text { Ageing } \\
\text { time } \\
\text { (h) } \\
\end{array}$ & $\begin{array}{c}\text { Water } \\
\text { Temperature } \\
\left({ }^{\circ} \mathrm{C}\right)\end{array}$ & $\begin{array}{c}\begin{array}{c}\text { Water } \\
\text { uptake }\end{array} \\
(\%) \\
\end{array}$ & References \\
\hline E-Glass & 5 plies mat +4 plies plain weave & Vinylester & 22 & - & $\approx 5.0$ & 6500 & 40 & 0.5 & [59] \\
\hline E-Glass & 8 plies UD & Epoxy & 40 & - & 2.2 & 1000 & 25 & 1.05 & {$[12]$} \\
\hline E-Glass & 2 plies UD & Epoxy & 51 & - & 1.0 & 1300 & 22 & $0.4 \pm 0.0$ & {$[14]$} \\
\hline Flax & mat & PP & 38.56 & - & - & 5000 & 25 & 11.36 & {$[4]$} \\
\hline Flax & mat & $\mathrm{PP}$ & 48.49 & - & - & 5000 & 25 & 13.96 & [4] \\
\hline Flax & mat & PP & 38 & - & 3.0 & 1500 & 25 & 18 & [18] \\
\hline Flax & mat & $\mathrm{PE}$ & 40.38 & - & 3.1 & 11515 & 22.5 & 9.7 & [27] \\
\hline Flax & mat & $\mathrm{PE}$ & 51.30 & - & 3.1 & 11515 & 22.5 & 13.2 & {$[27]$} \\
\hline Flax & mat & PLA & 26.98 & - & - & 2200 & 40 & 10.8 & [13] \\
\hline Flax & $2 \mathrm{~mm}$ (extrusion) & PLA & 16 & - & - & 1440 & sea & 3.3 & [23] \\
\hline Flax & 5 plies UD (film infusion) & PLA & 47 & & 2.1 & 1344 & 23 & 14 & {$[22]$} \\
\hline Flax & 11 plies UD (prepreg) & Epoxy & 51 & - & 2.3 & 1000 & 25 & 13.37 & [12] \\
\hline Flax & 11 plies UD (prepreg) & Epoxy & 44 & - & 2.5 & 910 & 40 & 6.94 & [17] \\
\hline Flax & 2 plies [0/90] $4 \times 4$ weave & Bio-epoxy & $\approx 40$ & - & - & 1600 & $\mathrm{RT}-98 \% \mathrm{RH}$ & 6.1 & [19] \\
\hline Flax & 2 plies [0/90] $4 \times 4$ weave & Bio-epoxy & $\approx 40$ & Alkaline & - & 1600 & $\mathrm{RT}-98 \% \mathrm{RH}$ & 4.4 & [19] \\
\hline Flax & 6 plies [0/90] $2 \times 2$ twill & PLA & $\approx 40$ & - & 2.07 & 100 & $\mathrm{RT}$ & 27.51 & {$[24]$} \\
\hline Flax & 6 plies [0/90] $2 \times 2$ twill & PP & $\approx 40$ & - & 2.66 & 100 & $\mathrm{RT}$ & 28.30 & {$[24]$} \\
\hline Flax & 8 plies [0/90] fabric & Bio-Epoxy & 41 & - & 3 & 961 & 23 & 9.61 & {$[21]$} \\
\hline Sisal & UD & Bio-PU & 30 & Alkaline & 3 & 720 & 30 & $>1$ & {$[20]$} \\
\hline Sisal & 1 ply [0/90] fabric & Bio-PU & 27 & Alkaline & 3 & 400 & $\mathrm{RT}$ & 4.3 & {$[25]$} \\
\hline Wood Chips & mat & $\mathrm{PE}$ & 58.72 & - & 3.1 & 11515 & 22.5 & 11.8 & [27] \\
\hline Hemp & mat & $\mathrm{PE}$ & 51.3 & - & 3.1 & 11515 & 22.5 & 14.4 & {$[27]$} \\
\hline
\end{tabular}




\subsubsection{FiCKIAN DIFFUSION MODEL}

The kinetic of water absorption is determined experimentally, by weighting the samples. The amount of absorbed water is evaluated by the relative uptake weight $M_{t}[12,17,18,27,59]$

$M_{t}=\frac{W_{t}-W_{0}}{W_{0}} \times 100(\%)$

where $W_{0}$ is the weight of the dry specimen and $W_{t}$ is the weight of wet specimen at time $t$.

In most studies $[12,17,18,27,59]$, Fick's second law of diffusion is used to model the global water absorption behaviour of the composite. However, even if this model gives accurate results (Figure 2-10), it is not representative of the various phenomenon happening in a two-phase material [13]. Celino et al. have studied and modelled the water absorption behaviour of natural fibres and found that immersed fibres behave differently and absorb close to ten times more water than fibres exposed to humidity [64]. Immerged fibres are better described by Langmuir theory whereas fibres exposed to vapor follow a Fickian diffusion model [64].

For a plate with a uniform initial distribution and equal initial surface concentration, Fick's law leads to the following equation

$\frac{M_{t}}{M_{m}}=1-\frac{8}{\pi^{2}} \sum_{n=0}^{\infty} \frac{1}{(2 n+1)^{2}} \exp \left(\frac{-(2 n+1)^{2} \pi^{2} D t}{h^{2}}\right)$

where $M_{t}$ is the moisture uptake at time $t, M_{m}$ is its maximum moisture uptake, at equilibrium state, $D$ is the diffusivity and $h$ is the thickness of the specimen.

When $M_{t} / M_{m}$ is lower than $\sim 0.6$, the initial part of the curve can be correlated by:

$$
\frac{M_{t}}{M_{m}}=\frac{4}{h} \sqrt{\frac{D t}{\pi}}
$$


When $M_{t} / M_{m}$ is higher than $\sim 0.6$, Shen and Springer [65] proposed an approximation:

$\frac{M_{t}}{M_{m}}=1-\exp \left[-7.3\left(\frac{D t}{h^{2}}\right)^{0.75}\right]$

It is possible to determine a diffusion coefficient $D$ from Eq. (3). Nevertheless, because a composite is made from different materials, this coefficient doesn't have the same physical significance as the usual diffusion coefficient of a single-phase material. It can therefore only be used to compare composite materials that have all been tested using the same procedure.

According to different studies, the theoretical water uptake behaviour predicted from Fick's law and the experimental results show a good correlation (Figure 2-10) [12, 17, 18, 27]. For glass fibre composites, the saturation plateau takes a very long time to reach (up to 7 months) and depends on the resin used (Figure 2-11).

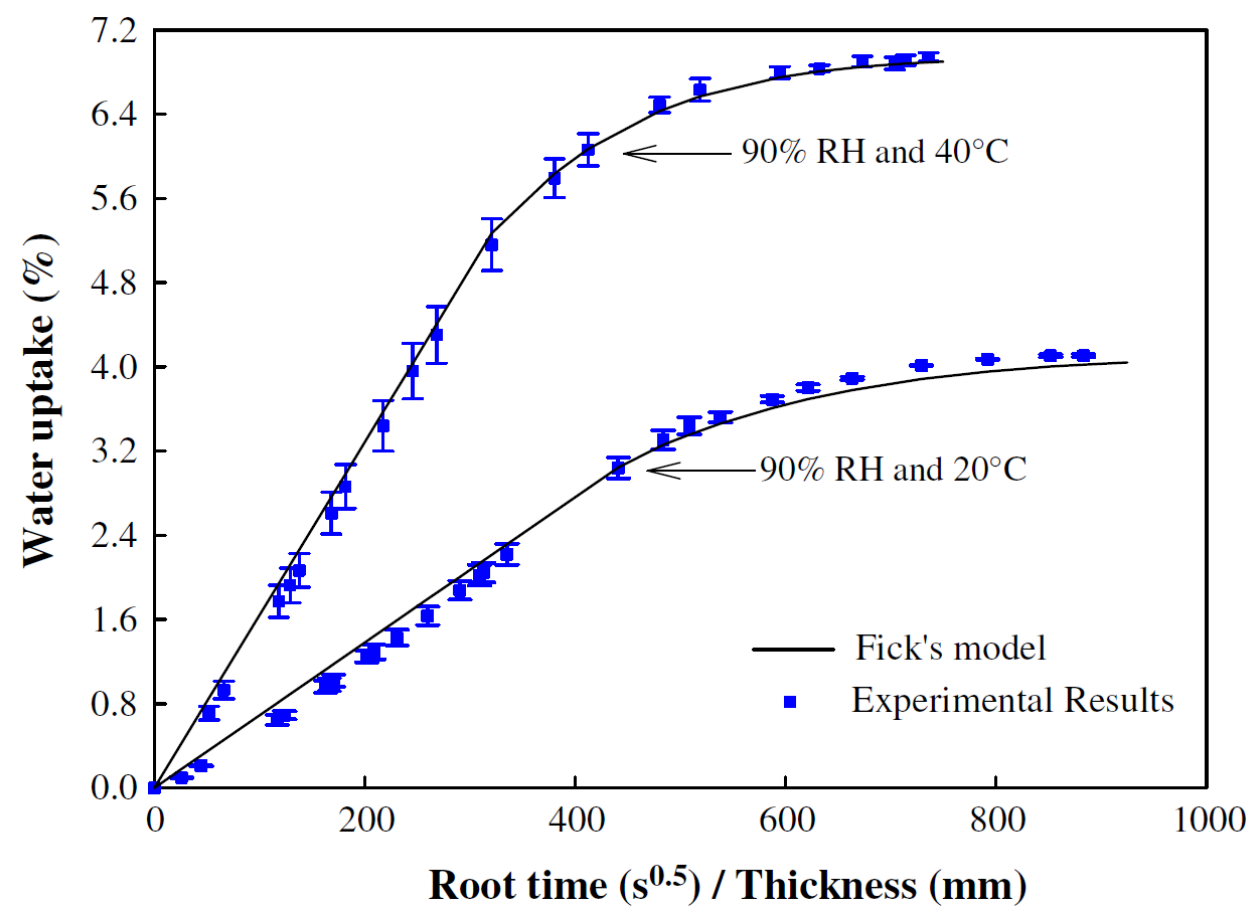

Figure 2-10 Evolution of the water uptake of flax/epoxy composite (11 plies, UD laminate, pre-preg) [17] 


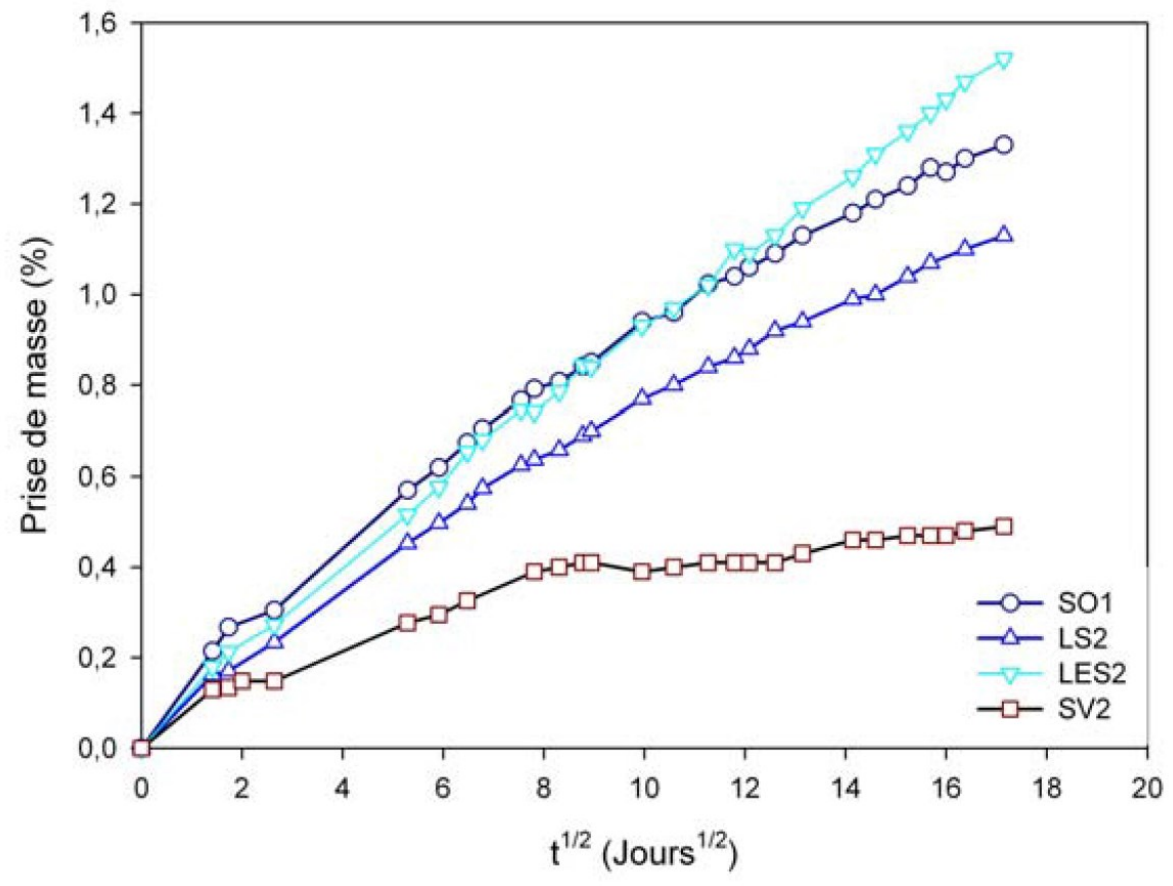

Figure 2-11 Evolution of the water uptake of glass fibre composites ( 5 plies mat, 4 plies PW, contact moulding) immerged in water at $40^{\circ} \mathrm{C}[59]$

(SO1) Standard Orthophtalic Polyester; (LS2) Low Styrene Content DCPD Polyester;

(LES2) Low Styrene Content and Low Styrene Emission DCPD Polyester; (SV2) Vinylester

\subsection{Evolution of the Mechanical Properties}

\subsubsection{Ageing OF FlaX Fibre Composites}

Natural fibres have greater moisture absorption than synthetic fibres and therefore it is essential to understand how the mechanical properties of the composite evolve with the moisture content. For example, water absorption in the fibre matrix/interface has been identified as one of the main long term effects leading to the reduction of the mechanical properties through interfacial cracking in polymer matrix of composite materials $[11,66]$. 
If the environmental durability of flax fibre reinforced composites has been quite studied in the last few years $[4,11-14,16-18,27,59,61,67]$, the comparison of the results is difficult. All results are in agreement regarding the decrease of the mechanical properties but the fibres, the matrix, the thickness, the surface, the manufacturing process and the ageing conditions are very different from one study to another. In some cases, the composites are immersed in sea water $[13,59]$, distilled water $[4,11,12,16,27]$ and even sometimes in tap water $[14,18]$. In other studies, the samples are conditioned under a certain percentage of relative humidity [17]. Moreover, in most studies, samples are aged at room temperature whereas in some other studies, samples are aged at higher temperature in order to accelerate the ageing process. Very few studies presents results with the edges of the samples sealed to prevent the absorption of the water directly into the fibres [22]. However, sealing the edges will slow down the adsorption process but it has no effect in the long term because the material will eventually reach saturation. The following paragraphs present the evolution of some mechanical properties.

\subsubsection{EVOLUTION OF THE STIFFNESS}

One of the most serious effects of moisture absorption on the composite is the degradation of the mechanical properties. Depending on the material, the drop in the stiffness can be significant (from $20 \%$ to $80 \%$ lower than that of dry samples, Table $2-3$ ).

Figure 2-12 shows an initial increase in the composite stiffness for Duralin flax fibres. Duralin fibres are obtained by using a specific process that consists of a steam step of the rippled flax at temperature above $160{ }^{\circ} \mathrm{C}$ and a drying step above $150{ }^{\circ} \mathrm{C}$ [18]. This initial increase in stiffness is present whether the fibres have been pre-treated or not $[13,68]$. This phenomenon is due to the plasticizing effect of water. At a low moisture content, the water molecules might also reinforce the adhesion between the fibres and the matrix by changing the distribution and the number of hydrogen bonds [61]. Alix et al. [68] have proposed a water absorption mechanism for flax fibres: part of the water was adsorbed on specific sites (low mobility of the fixed water molecules) and the rest absorbed according to Henry's law (higher mobility of the absorbed molecules), later forming aggregates. As the moisture content becomes higher (usually around $\sim 5 \%$ ) the plasticizing effect of water is no longer present and the stiffness drops. 


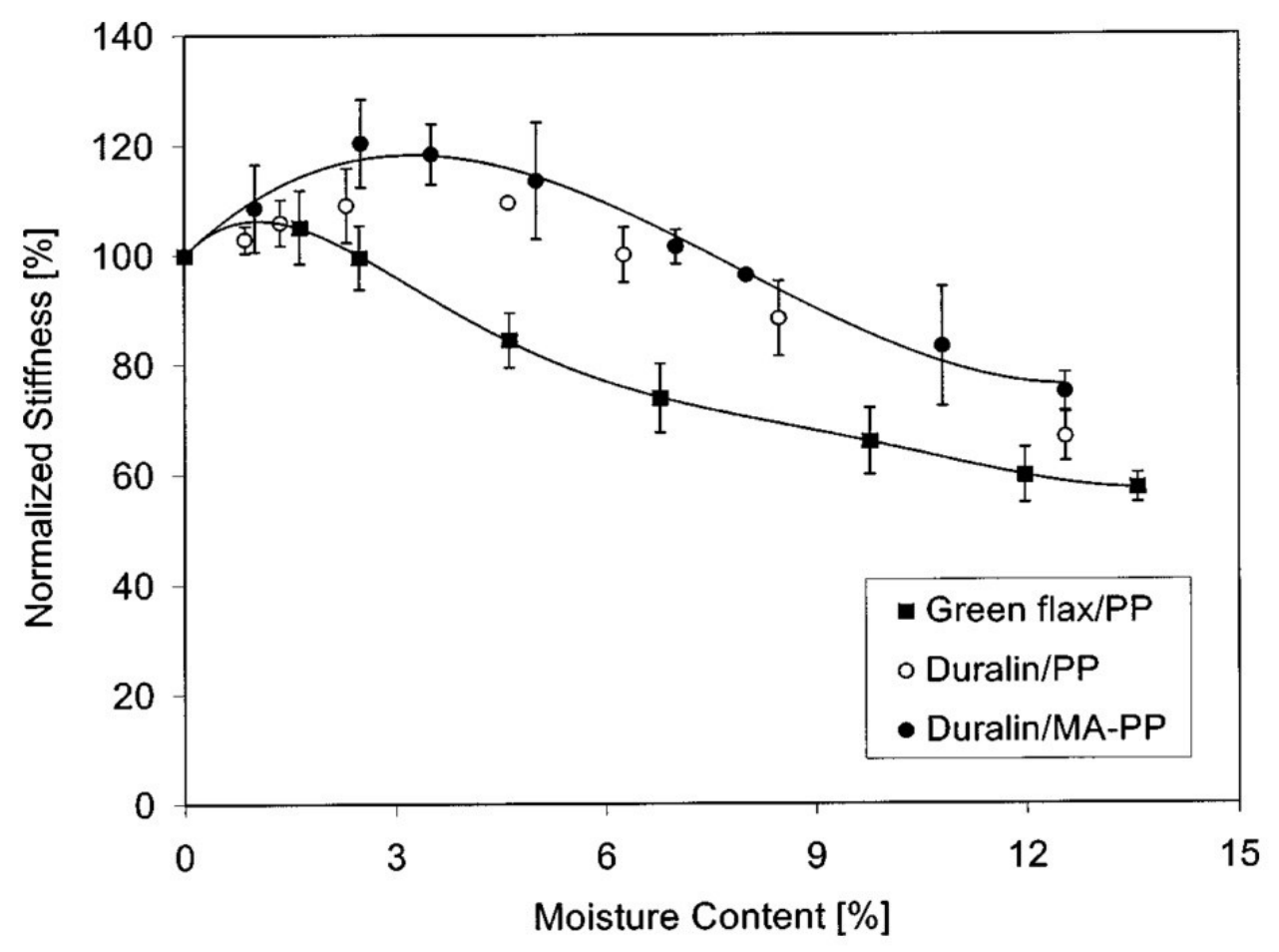

Figure 2-12 Effect of moisture content on the modulus of green flax/polypropylene, duralin flax/PP, and duralin flax/maleic anhydride modified polypropylene (non-woven mat, film stacking) [18]

\subsubsection{EVOLUTION OF THE STRENGTH}

In Figure 2-13, the normalized tensile strength is plotted as a function of the moisture content. Compared to the drop in composite stiffness, the tensile strength of flax fibre reinforced composites is not much affected by the water uptake. Depending on the composite components, the drop in the stiffness can range from $2 \%$ to $55 \%$ as compared to that of dry samples (Table 2-3). The trend is similar to the ones observed for the composite stiffness. The initial increase in composite performance is likely due to the plasticizing effect of water. Similar effects of water absorption on composites' mechanical properties were reported for other composite systems based on natural fibres $[4,13,17,18,69]$. 


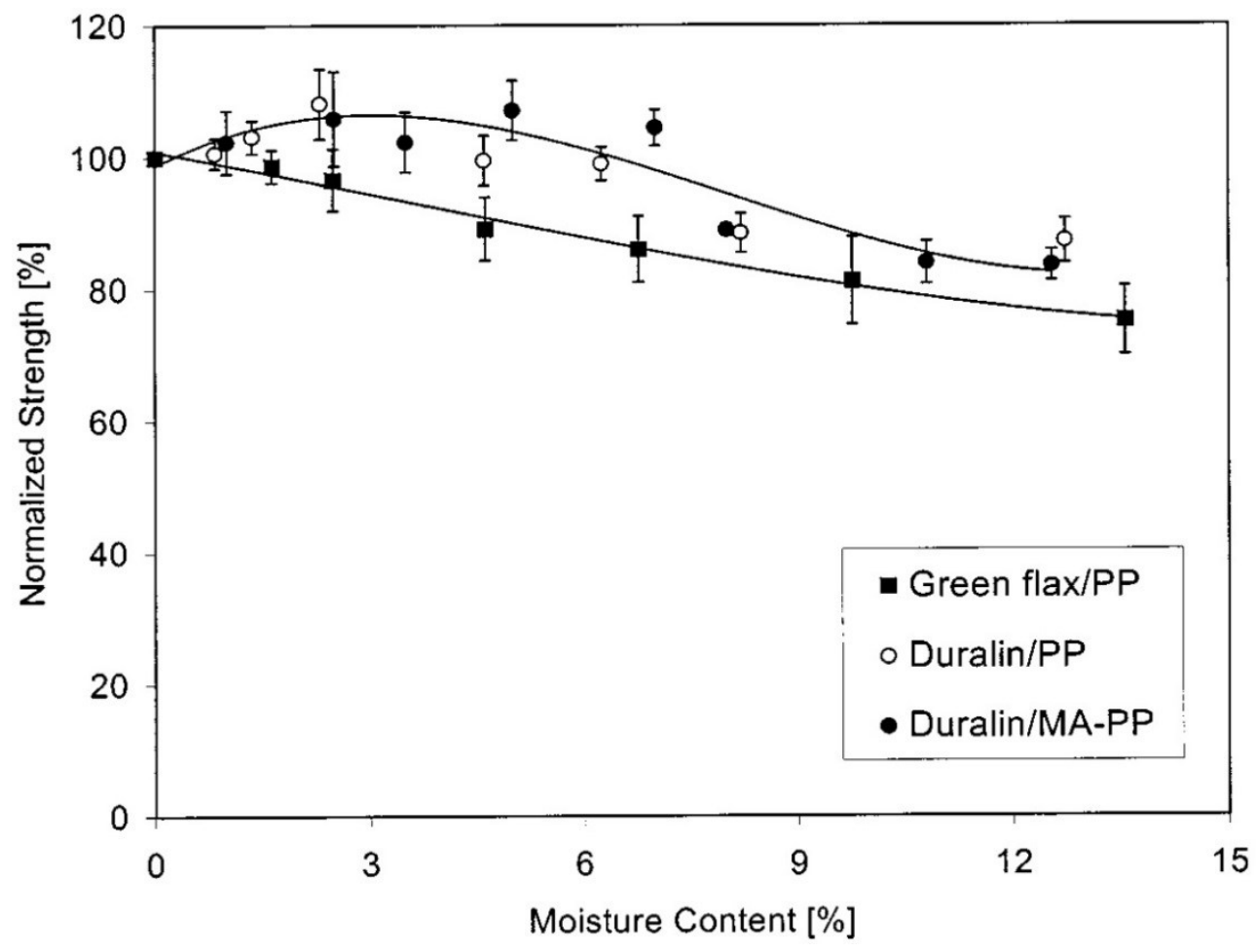

Figure 2-13 Effect of moisture content on the tensile strength of green flax/polypropylene, duralin flax/PP, and duralin flax/maleic anhydride modified polypropylene (non-woven mat, film stacking) [18]

\subsubsection{RESULTING MECHANICAL PROPERTIES}

The evolution of the mechanical properties of flax composites during aging exist in the literature. Unfortunately, in most of these studies, only tensile tests are performed. Even when mechanical tests are performed, the results are difficult to compare accurately from a study to another (Table 2-3), because there are differences between the ageing condition, the materials and the dimensions of the samples.

As shown in Table 2-3, the decrease observed in the mechanical properties is highly dependent on the amount of fibres in the composite. With higher fibre volume fraction, a larger quantity of water absorbed is expected to lead to a decrease in mechanical properties. Data form Table 2-3 show that some resin systems have a lower resistance to moisture than others. This is especially 
true for polylactic acid (PLA), a polymer that can be easily degraded by hydrolysis, making it an interesting matrix for biodegradable composite with a short life cycle.

A maximum in fibre strength and stiffness is observed at intermediate levels of relative humidity, when the water uptake is between $1 \mathrm{wt} \%$ to $3 \mathrm{wt} \%$ (Figure 2-12 and Figure 2-13). However, the composites' mechanical performance drops significantly when high moisture content is reached. Furthermore, moisture can cause fungus development on the fibre surface after several days of immersion in water, resulting in the degradation of the fibres [18].

Some studies [70, 71] even suggested that the interfacial shear strength can be increased at limited level of moisture. It was shown that, in the case of thermoplastic, the gap between natural fibres and polypropylene can be filled by the dimensional increase of fibres when they are swollen by water, leading to higher interfacial shear strengths between fibres and polymer matrix [18]. However, this might not be the case for more brittle polymers such as thermosets: the long term effects of absorbed water in the composite might still affect the mechanical properties. Masseteau et al. [61] studied the effect of the fibre moisture content prior to manufacturing the composite. They concluded that it might not be necessary to dry the fibres to obtain good composite properties. A small amount of absorbed water can slightly increase the polarity of both the matrix and the fibres. The adhesion and therefore the stress transfer are improved when there is water at the interface. Nevertheless, if small moisture content can improve the interfacial strength, the optimum is very likely to be material dependent and the durability of this kind of improvement still needs to be assessed. In addition, even a very small amount of water present in the fibres can affect the manufacturing process.

It should also be noted that some fibre treatments can delay the absorption process but cannot reduce the final amount of water that will eventually be absorbed by the composite after a long period of time. There are many fibre treatments and some of them can improve the resulting mechanical properties after ageing (Figure 2-12 and Figure 2-13), but this topic will not be discussed here. 
Table 2-3 Evolution of the mechanical properties of different flax fibres reinforced composites. All the samples are aged in water.

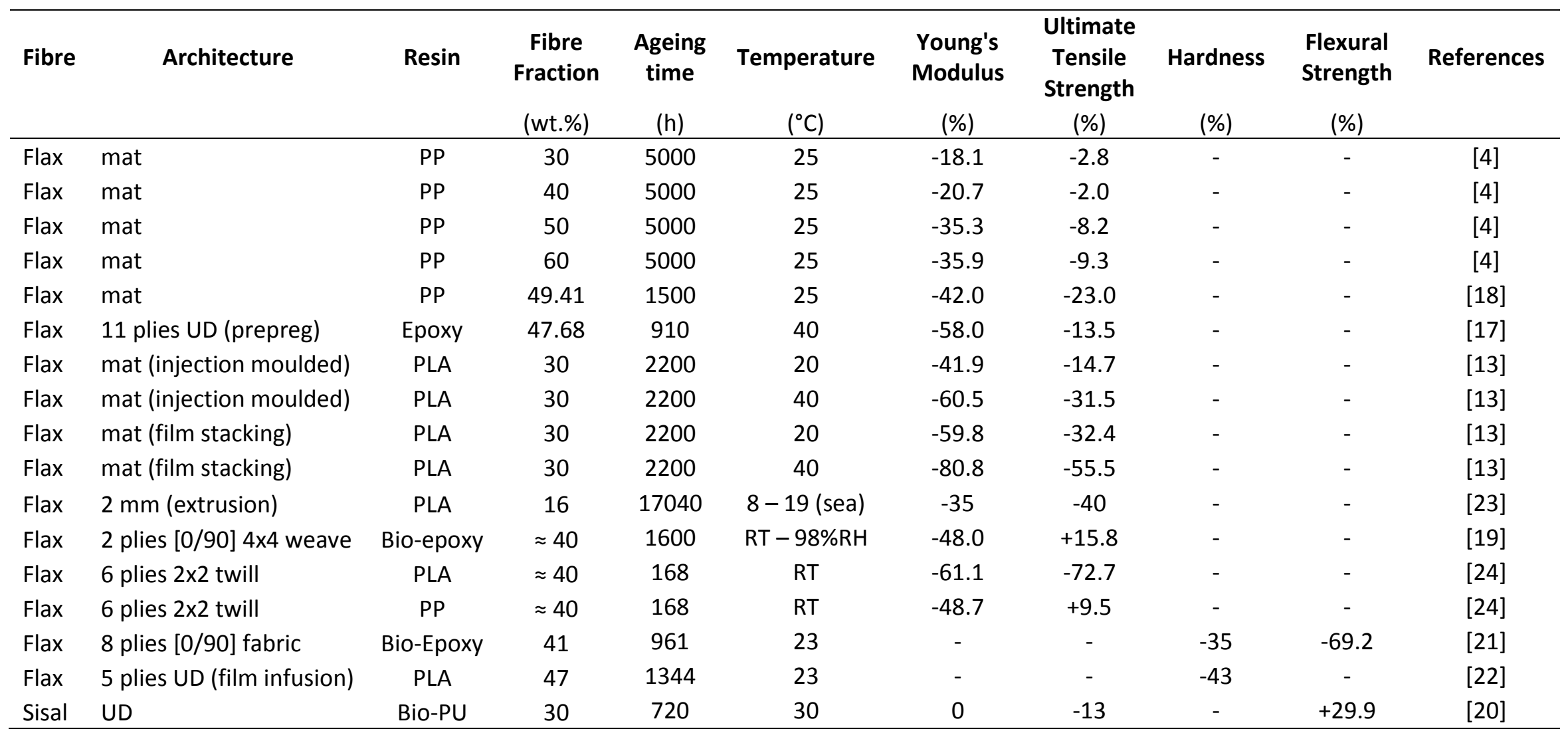




\subsubsection{Recovery OF The Mechanical Properties AFter Drying}

Le Duigou et al. [13] have studied the influence of drying flax/PLLA composites. They showed that the composites become more ductile with ageing. For the first 15 days, this behaviour is completely reversible after drying, showing that plasticization is the dominant mechanism. For a longer period of time, the recovery of the mechanical properties decreases gradually after drying (Figure 2-14). This indicates an irreversible degradation of the composite and shows how significantly moisture can affect the material.

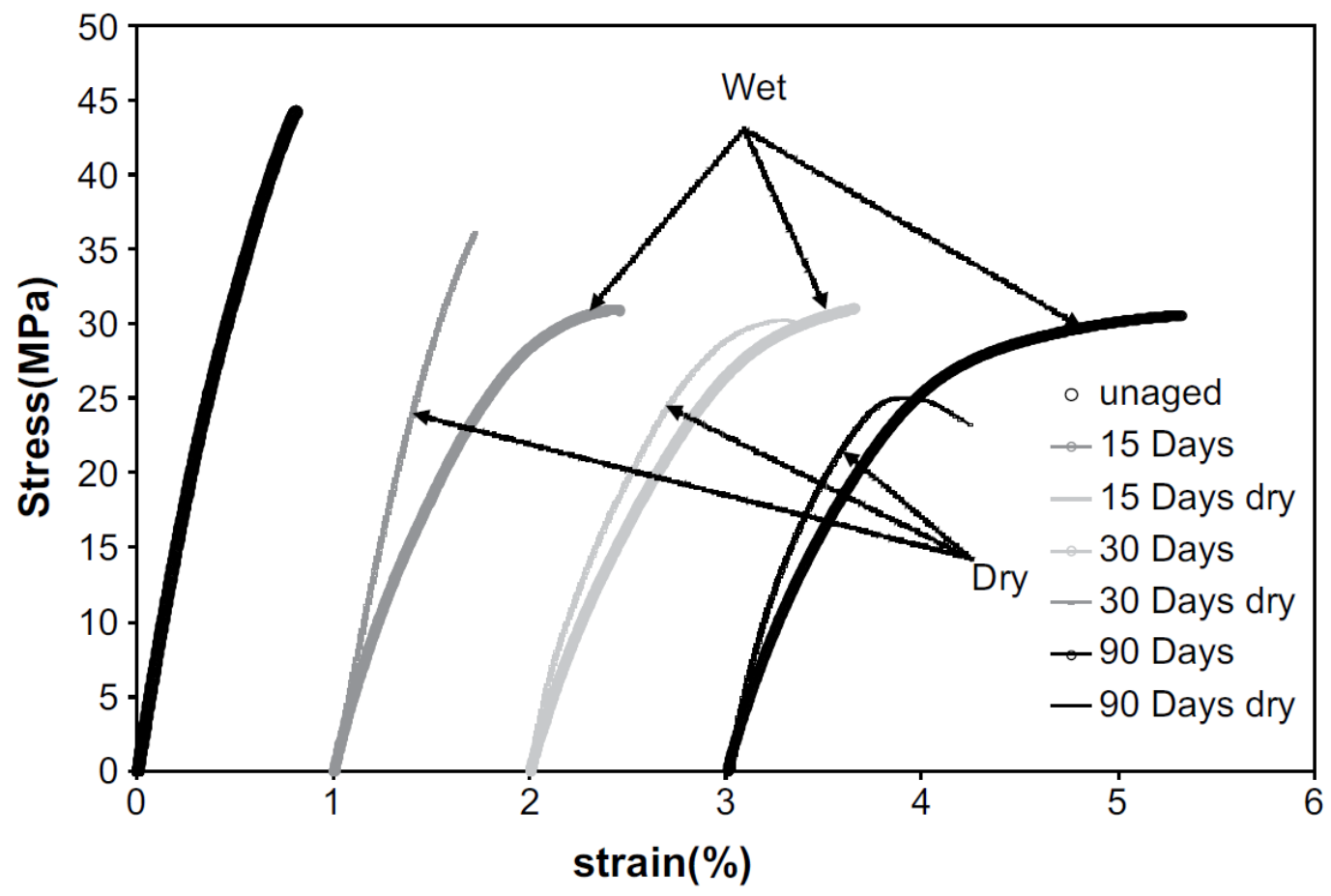

Figure 2-14 Tensile behaviour of injected flax/PLLA composites, before and after drying (flax mat, 30 wt.\%). The curves have been offset by $1 \%$ for clarity. [13] 


\subsubsection{The Use of Gelcoats as a Protection}

Gelcoats are often mentioned as an effective protection to slow and reduce the amount of water absorbed by the composite. A gelcoat is a material, most of the time an epoxy or a polyester resin, used to provide a high-quality surface finish. They are also supposed to increase the resistance to ultraviolet degradation and hydrolysis. Gelcoats are applied to moulds as a layer, with a thickness typically ranging from 0.5 to $0.8 \mathrm{~mm}$.

Gelcoats are used in the aerospace and the marine industry because they provide an excellent surface finish. However, the results are more controversial regarding their effect on moisture absorption. According to Kim et al. [72], the amount of absorbed water was lower by about $2 \%$ when the composite was protected with a gelcoat. Nevertheless, Lebel [73] clearly stated that "According to the tests carried out and the information found in the literature, the presence of gelcoat does not slow water absorption" and that "it's impossible to reduce water absorption by using a gel coat". In fact, as the gelcoat is a polymer applied on the surface of the composite, it slightly increases the matrix thickness. In the case of glass fibre reinforced composite, the maximum moisture uptake is small enough $(>1 \%)$ so that the gelcoat barely affect the time needed to reach saturation. However, because natural fibres are mainly responsible for the water absorbed by the composite, the use of gelcoat might be beneficial. Adding a layer of polymer between the reinforcement and the surface could prevent the fibres to be rapidly reached by water during the diffusion process.

Moreover, the surface quality is likely to affect the diffusion process during the service life of the composite. A smooth surface allows the water to repel easily whereas a rough surface has a bigger surface area that helps the formation of droplets and increases the amount of water absorbed by the composite. Sealing the edges of the composite is also very important to prevent water from going directly into the interface and into the fibres.

Finally, the results are probably very dependent on the gelcoat that is used and it is unrealistic to test them all. Furthermore, manufacturers do not provide the water diffusion coefficient of their products, which could be very useful to compare gelcoats. 


\subsection{SUMMARY}

Flax fibres are completely different from synthetic fibres in terms of physical and chemical properties. In order to achieve high-quality composites, their processing behaviour and especially their interaction with polymeric resin systems need to be understood. The hydrophilic nature of flax fibres leads to a high water uptake in the composite, inducing a significant loss in all mechanical properties. It is a major obstacle for the development of natural fibre composites. Furthermore, matrix properties have a direct influence on the mechanical behaviour and on the interface quality of flax fibre reinforced composites. Natural fibres also swell when absorbing moisture, which can increase the degradation rate of the interface. Most studies only determine the maximum water uptake and very few of them show the evolution of the mechanical properties during ageing. The emphasis of many of these reports is related to the drop in the mechanical performance. A better understanding of how the fibre/matrix adhesion is affected by the polymer properties could help developing resin systems with high natural fibre compatibility. In the end, the evolution of the interface during ageing, and how it can be improved by using functionalized polymers, has a direct impact on the quality and performance of this type of composites. 


\section{Chapter 3: CoMposite MANUfacturing}

\section{USING RESIN TRANSFER MOULDING}

\subsection{Resin Transfer Moulding Process}

The automotive industry is increasingly using resin transfer moulding (RTM) to produce composite body panels at high volumes and relatively low costs (Figure 3-1). The RTM process is a closed-mould technique during which an entirely dry fibre bed is infiltrated with neat resin. This process is well-suited for complex parts, which may be difficult to lay up using preimpregnated reinforcements, and for parts that require detailed features, surface finish and dimensional stability $[74,75]$. In addition, because it is a closed-mould process, the emission of volatiles is limited and the injected parts have a good surface finish on all sides. Large and hollow shapes can also be moulded using this process.

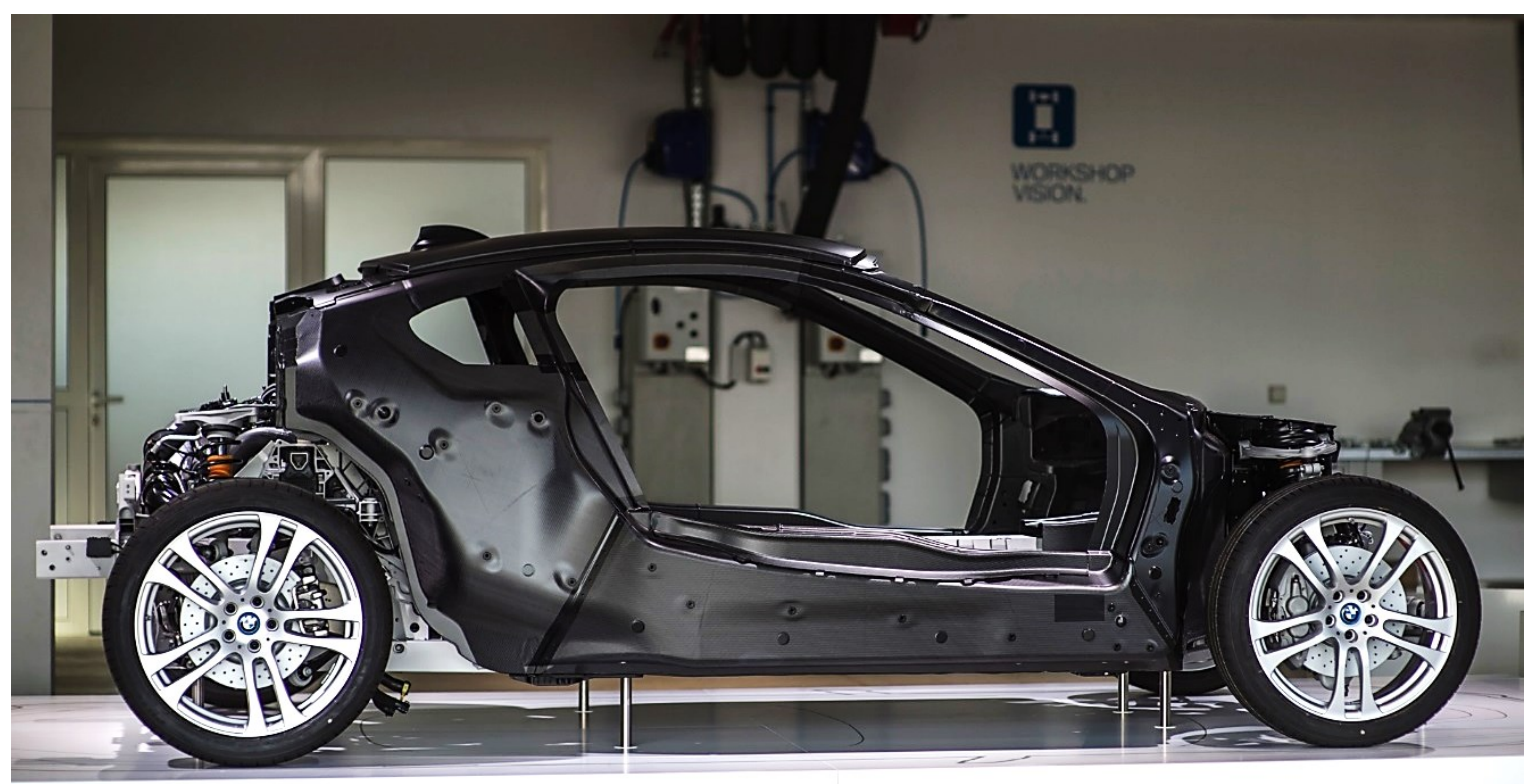

Figure 3-1 The carbon fibre reinforced chassis of the BMW i8 is manufactured using RTM [76] 
The RTM setup that was used to manufacture the composite panels is shown in Figure 3-2.

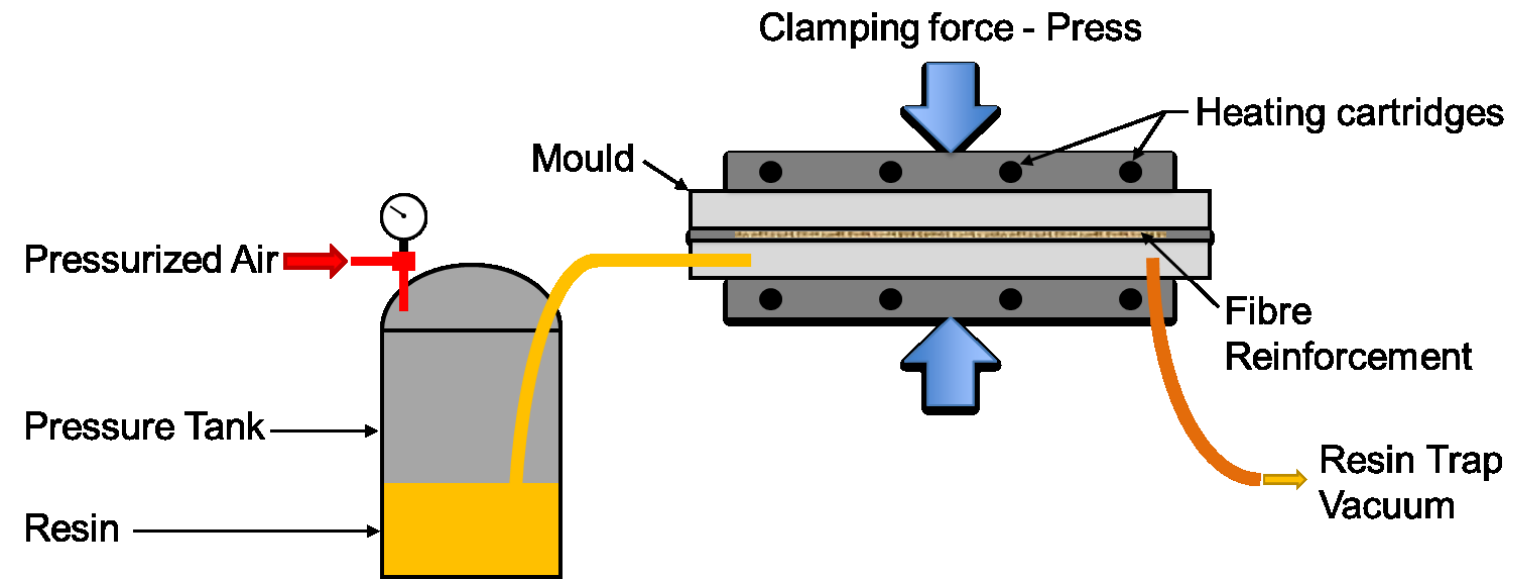

Figure 3-2 Resin transfer moulding setup used to manufacture the composite panels

The RTM process can be described by the following steps:

(1) The mould, generally made of more than one section, is first sprayed with release agent to allow an easy demoulding of the part after cure (Figure 3-3 (a)).

(2) A dry fibre "preform" is placed in the mould cavity (Figure 3-3 (b)).
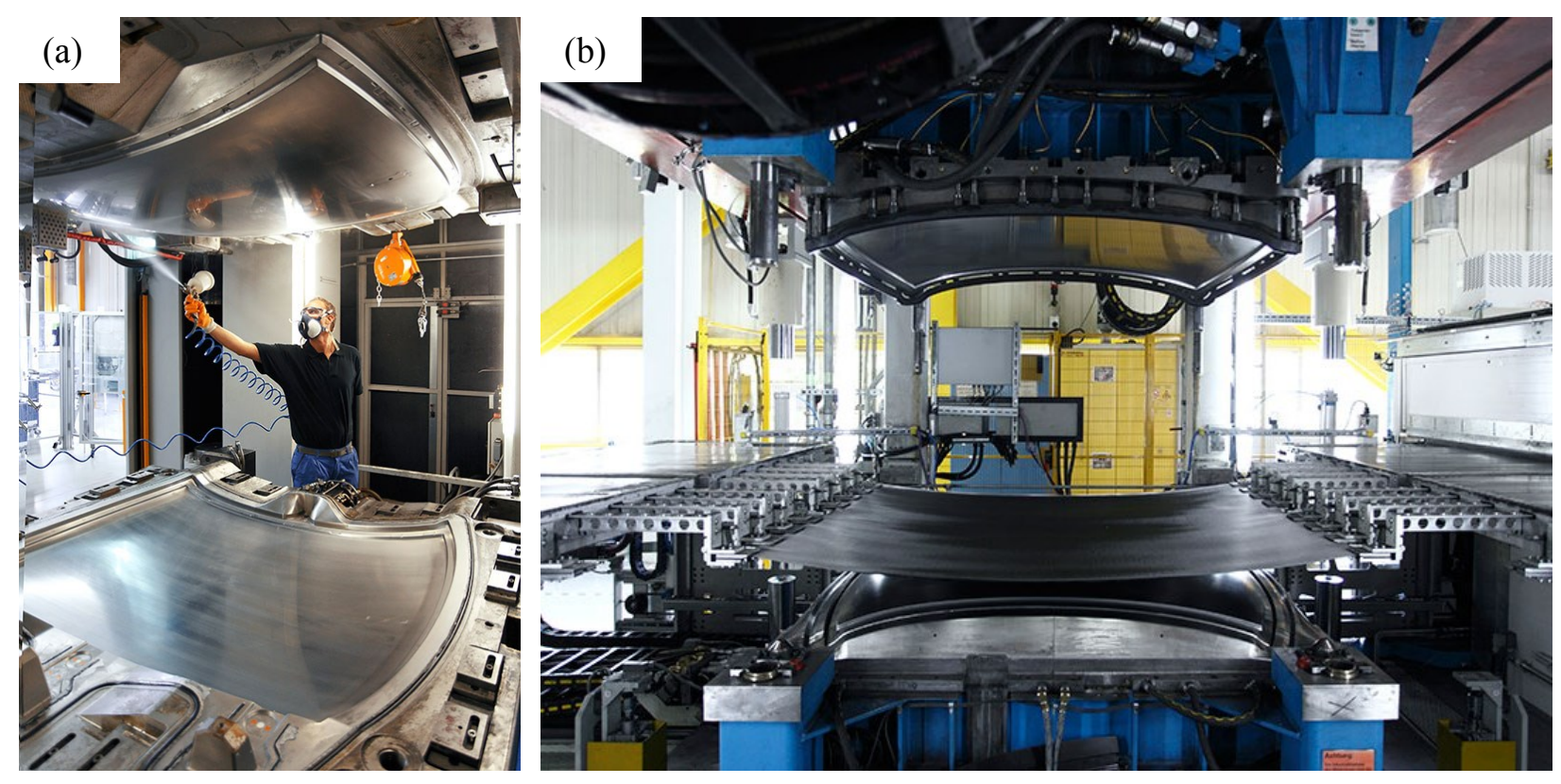

Figure 3-3 Carbon fibre reinforced roof of the BMW M3 (a) Release agent spayed on the RTM mould (b) Carbon fibre preform layed on the mould [76] 
(3) The mould is then closed and heated.

(4) The reinforcement is infiltrated with resin from a pressurized tank connected to the mould injection ports (Figure 3-2). Process parameters vary widely, but generally the involved pressures driving the resin flow range from 1 to 10 bars. When the involved pressure are higher, up to 150 bars in the mixing head and from 30 to 120 bars inside the mould, depending on part size and geometry, the process is referred to as high pressure resin transfer moulding (HP RTM).

(5) When the mould is completely filled, the excess resin flows through the outlets or vent ports. The position of the vent ports depends on the injection strategy, the location of the resin inlets and the size of the part.

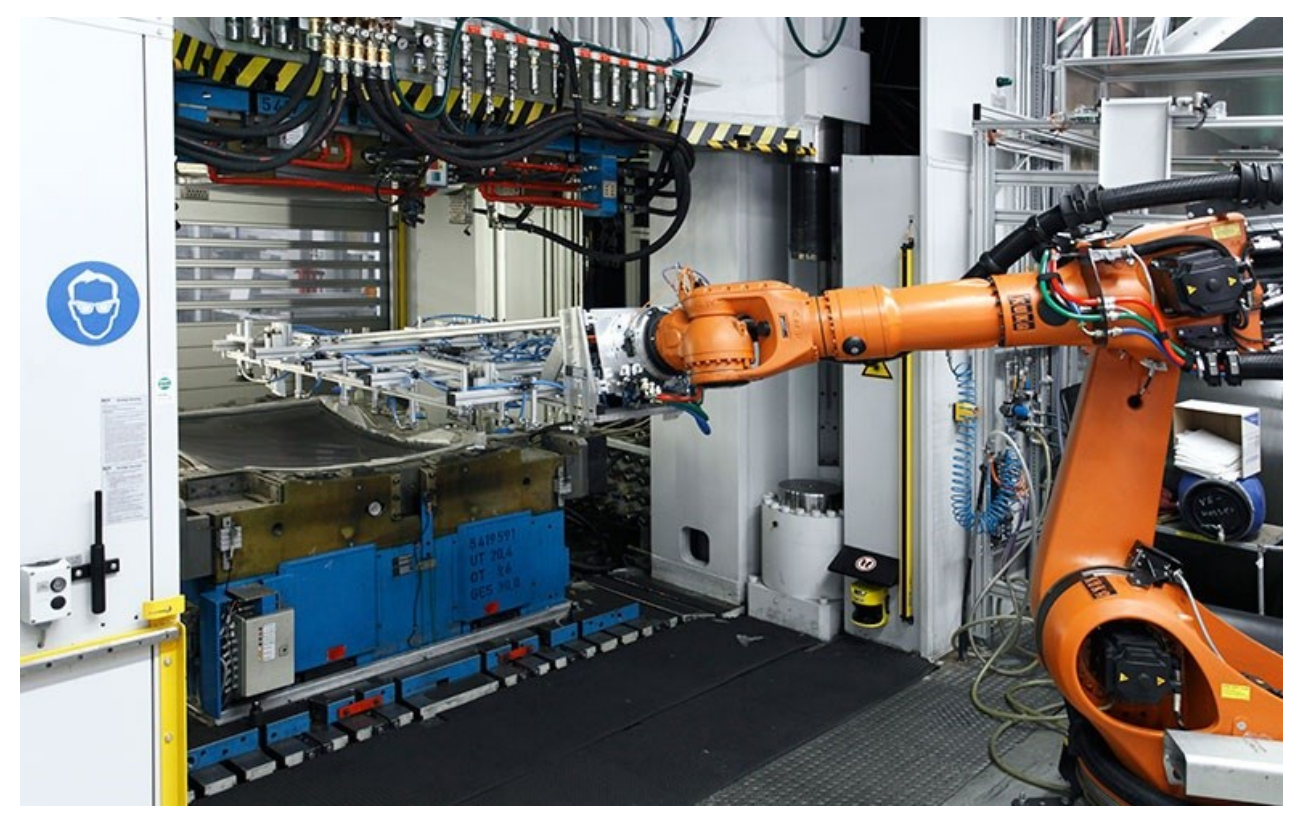

Figure 3-4 The roof of the BMW M3 is being removed from the RTM press. The preform was infused and the part is cured [76]

(6) After cure, the part is demoulded and may be post-cure to ensure complete polymerisation (Figure 3-5). 


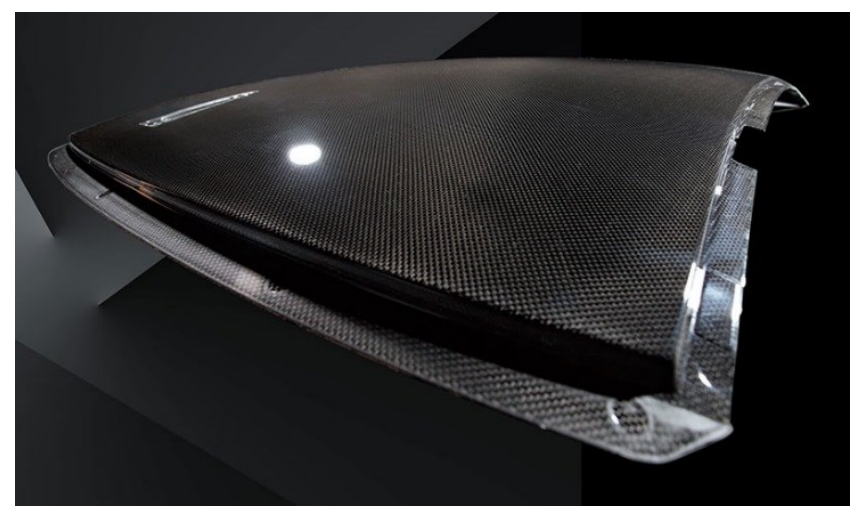

Figure 3-5 Carbon fibre reinforced roof of the BMW M3 after demoulding [76]

In addition to the injection pressure, there are two important material properties that have a direct impact on the resin flow through the reinforcement: the preform permeability $k$ and the resin viscosity $\mu$. Permeability of a porous medium (the preform) represents the resistance to the flow and depends on the tows size and fabric architecture [77-79]. It is generally direction-dependent: most fibre reinforcements have different transverse and through-thickness permeability [80]. In addition, it is a function of the pore network morphology, and thus of the fibre volume fraction, compaction and arrangement in the preform [75]. The permeability in a specific direction may be obtained from steady-state or transient experiments using Darcy's Law (3.4.1) [81, 82]. However, several challenges remain, including the dual-scale nature of many preforms, which may lead to unsaturated flow; the difficulty of reconciling results obtained with model fluids (such as silicone oil) to resin flow and, most importantly, the many sources of variability and uncertainty inherent to the preform materials $[75,83]$.

When using a RTM process, the viscosity is a key parameter for choosing a suitable resin. It becomes even more important when using natural fibres and high fibre volume fraction $\left(V_{f}\right)$, i.e. above $40 \%$. A low viscosity resin system has numerous advantages for the RTM process: it is easier to mix and degas, faster to inject, wets the fibres more rapidly and leads to a better impregnation of the preform. The resin viscosity determines the working time for liquid moulding processes and has therefore a direct impact on the process cycle time. In its liquid stage, the resin viscosity depends on the temperature and the degree of cure. An increase in 
temperature leads to higher molecular mobility and therefore to lower viscosity, but also accelerates cure [75]. On the other hand, the viscosity also increases with the degree of cure as the resin polymerize and the molecular weight increase. The effect of these two phenomena on the resin viscosity is shows in Figure 3-6. The gel point, the point where the viscosity becomes infinite, determines the resin working time. If the time required to fill the mould cavity is above the working time, the resin cannot be used and another injection strategy need to be considered in order to reduce the injection time.

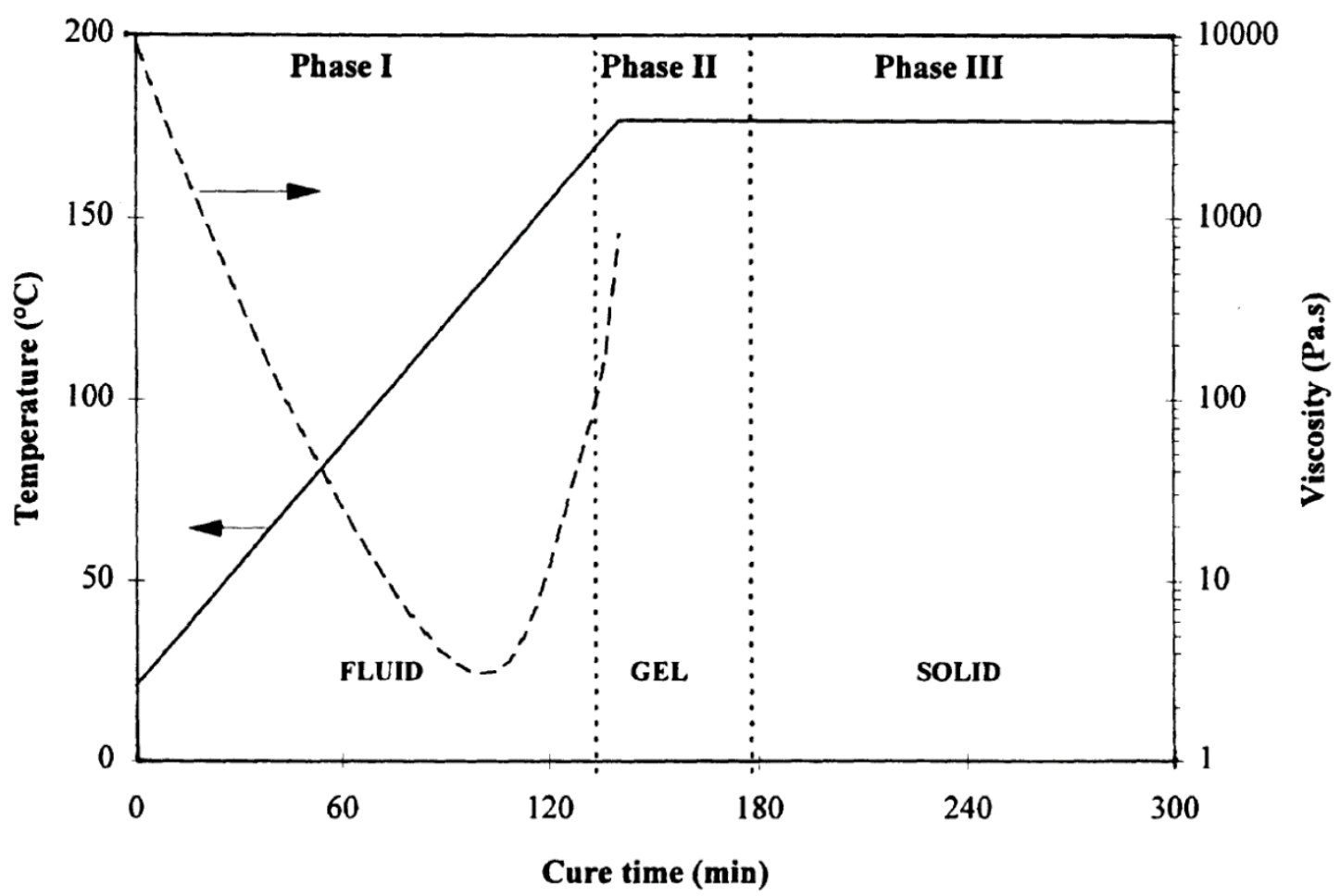

Figure 3-6 Typical resin viscosity evolution during cure. The resin is fluid during Phase I before it reaches gel point in Phase II [84] 


\subsection{ALUMinum Mould DeSigN}

Properly designed and manufactured tooling has a crucial importance in composite processing. Mold design and component design are inextricably linked to each other and need to be considered simultaneously with production engineering. In most variants of RTM, the tooling is solely responsible for the geometry and tolerances of the part. The location of the inlet and the outlet determine how the resin will enter and leave the part. For very large part, it affects the filling process and thus the quality of the components [85].

K. Potter [85] listed the most important requirements for a rigid RTM mould:

- The tool has to form a cavity of accurate dimensions

- It must be possible to introduce the resin into the cavity in such a way that the reinforcement filling the cavity can be uniformly wetted out with resin. The excess of resin must be able to exit the cavity.

- Some elements of mould sealing are usually required to control the resin flow

- Fibre bed compaction and injection pressures must be reacted without excessive deflections or any damage to the mould structure

- Depending on the resin system, heating and cooling may be required to control exotherm temperatures and to cure the composite part

- The lay-up of reinforcement into the tool must be facilitated, and the demoulding of cured parts must be possible without damage to the tool or component

Many materials can be used to manufacture RTM mould, ranging from plastics to cast iron. For low to moderate production volumes, i.e. 100 to 1000 parts, glass fibre reinforced composite tools are commonly used [85]. Aluminum mould are very attractive for both prototyping and production [85]. Aluminum is relatively cheap and easy to machine but extra care has to be taken to avoid scratching the surface. Steel or invar tools are used for relatively small and very complex parts where tolerances are absolutely critical, or if production volumes are very high [85]. Other materials can be used to manufacture RTM mould such as nickel electroforms, ceramics and graphite. 
For this research project, the RTM mould was made from cast aluminum blocks. Aluminum has a low density which makes it easy to handle. Moreover, it is a relatively soft metal so it can be machined at minimal cost with very good tolerances. It has a thermal conductivity of around 200 $\mathrm{W} \cdot \mathrm{m}^{-1} \cdot \mathrm{K}^{-1}$ which makes it easy to ensure a uniform temperature distribution across the tool, especially considering that the temperature involved in RTM rarely exceed $180^{\circ} \mathrm{C}$. The number of composite panel required for the present thesis does not exceed 50 parts; therefore aluminum is a perfectly suited material for the purposes of this research. The main drawback is that aluminum can be easily scratched during part removal, even with the use of plastic scrapper. Minor scratches are easy to repair and to polish out, but will eventually degrade the cavity dimensions. As most mechanical tests require rectangular test coupons, the RTM mould was designed to produce flat rectangular panels (Figure 3-7).

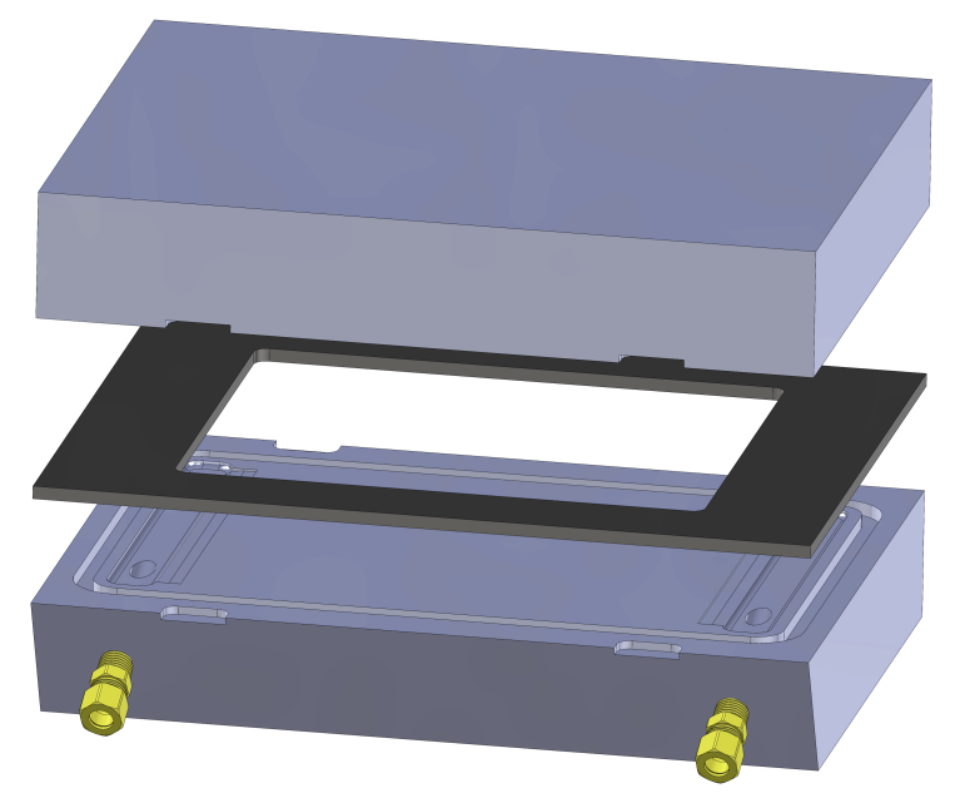

Figure 3-7 CAD model of the aluminum RTM tool

The resin transfer moulding aluminium tool is composed of three parts (Figure 3-7). The bottom part of the mould is connected to inlet and the outlet tubing via brass compression tube fittings (Figure 3-8). A spacer of the desired thickness (in this case $5.00 \mathrm{~mm}$ ) is placed between the bottom and the top part of the mould. The mould was designed with a spacer for more versatility. 
Changing the part thickness comes back to changing the size of the spacer, which is a much cheaper option than changing the entire mould. An optimum seal is achieved by using two silicone O-rings and vacuum grease. The O-rings groove dimensions were calculated for a face seal using a silicone O-ring AS568A -451 . The cavity dimensions are $208 \mathrm{~mm} \times 163 \mathrm{~mm} \times 5$ mm (Figure 3-8).
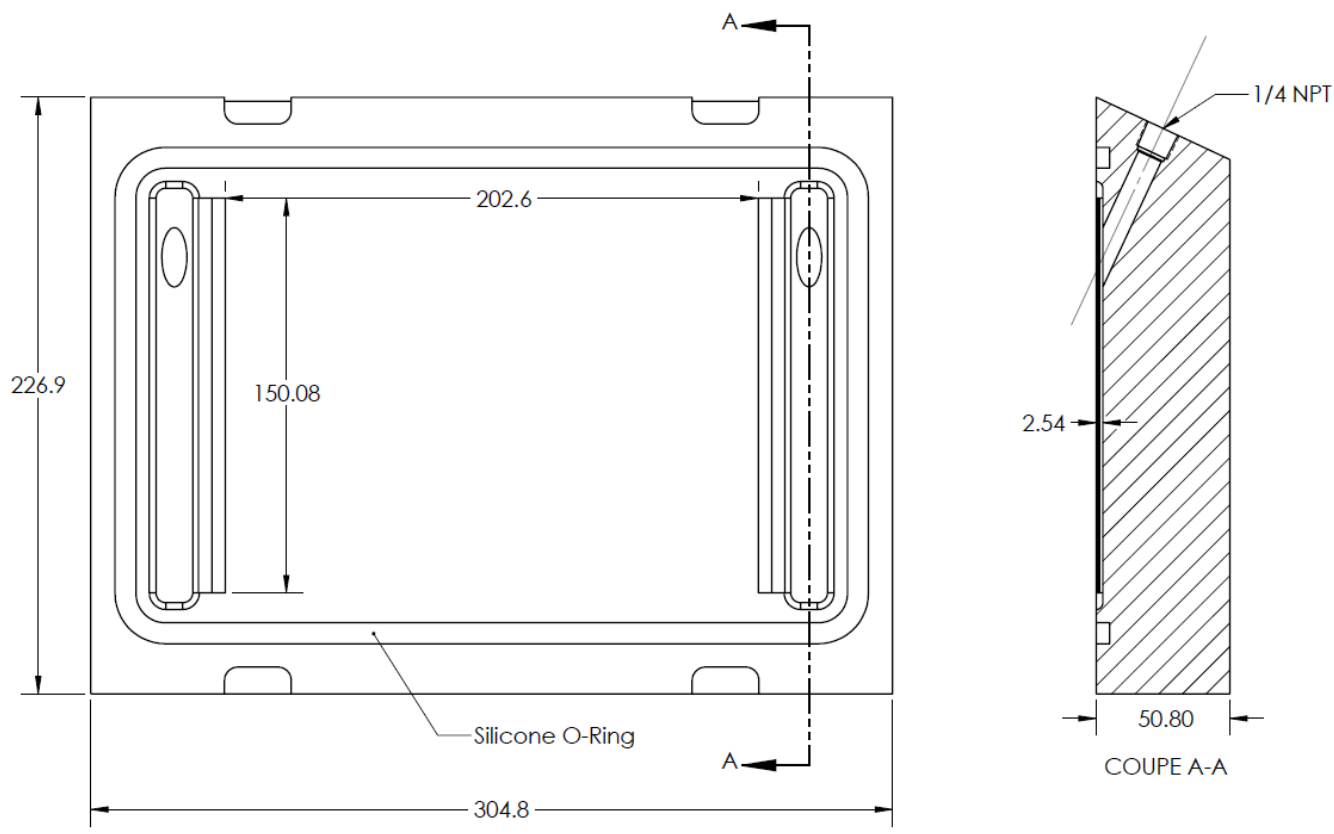

Figure 3-8 Simplified drawing of the bottom part of the RTM tool - top and side view. Dimensions are in millimetres

On the bottom part, two cavities, located near the short sides of the mould, were machined so that the resin would first fill these cavities and then impregnate the fibres. The cavities have two different thicknesses, each with a different depth (Figure 3-9). The section of the cavity that is directly in contact with the tubing is $2.54 \mathrm{~mm}$ deep (Figure 3-9, (b)) whereas the other section has a depth of $0.76 \mathrm{~mm}$ (Figure 3-9 (a)). When the spacer is placed on top of the bottom part on the mould, it only covers the deepest section of the cavities, leaving only the thin section in contact with the preform. Therefore, the injected resin first fills the deep section of the cavity and then starts flowing through the fibres along the line formed by the thin section of the cavity. 
Because the composite panels are rectangular, creating a linear flow front instead of a circular one lead to a better and faster wetting of the preform. A hole was drilled in each cavity to connect the inlet and the outlet tubing (Figure 3-8).

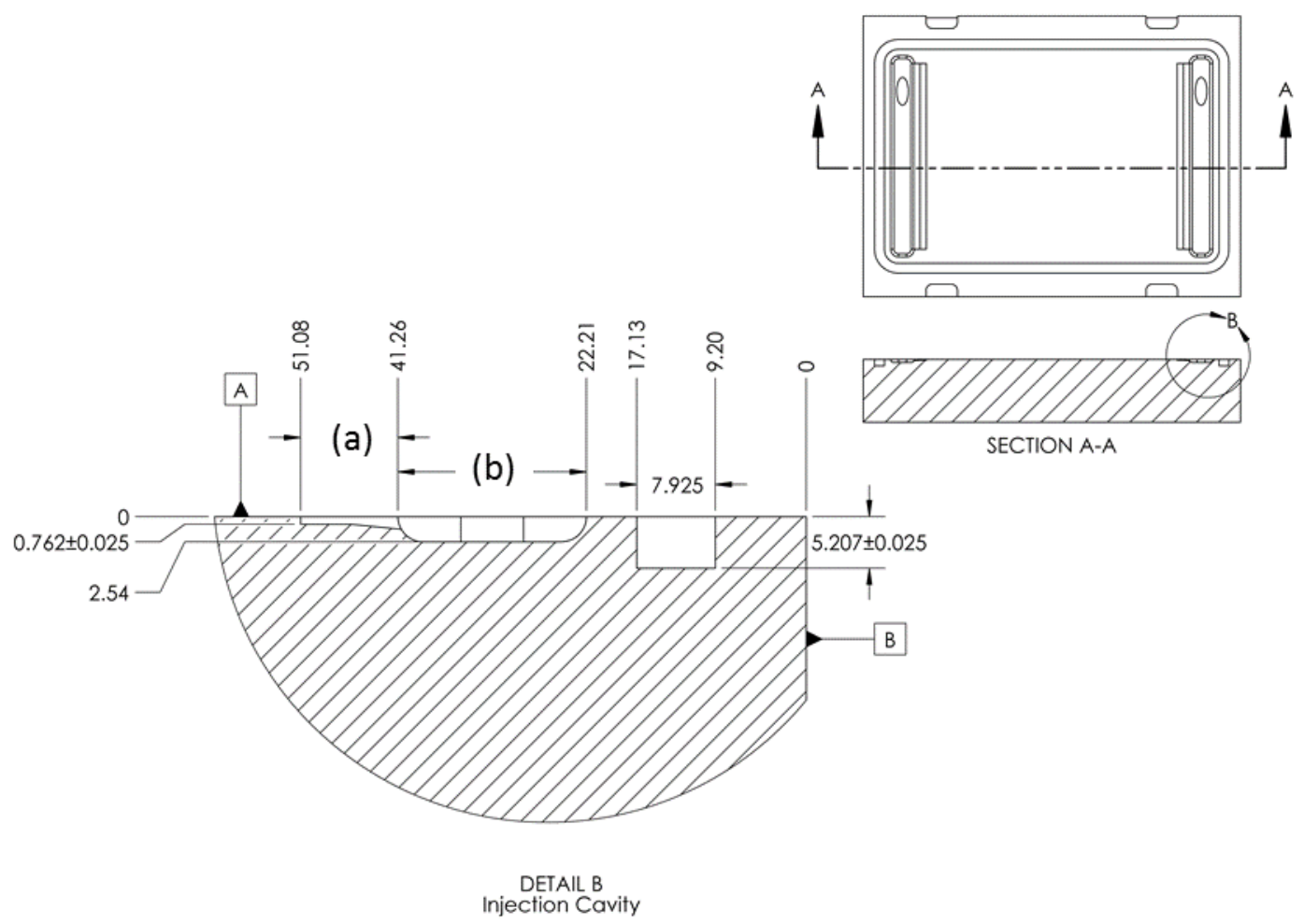

Figure 3-9 Detailed view of the mould injection cavities (a) thin section (b) deep section. Dimensions are in millimetres

\subsection{MATERials}

The same flax woven fabric was used for both polyurethane (PU) and epoxy composites. The reinforcement was a twill 2x2 (ELINT58) with an areal weight of $245 \mathrm{~g} / \mathrm{m}^{2}$ that was provided by TEXONIC (Canada). A two-part SUPER SAP CLR/INS bio-based epoxy resin from Entropy Resin (Spain) was used to manufacture the bio-epoxy composites (Table 3-1). According to the supplier, $18 \%$ of the mixed resin weight is bio-based (Biobased carbon content, ASTM D6866) and the mixed viscosity of the resin is $280 \mathrm{cPs}$. The polyurethane was a two-part LOCTITE MAX 3 thermoset resin that was provided by HENKEL (Germany) (Table 3-1). 
Table 3-1 Main physical and mechanical properties of the bio-epoxy and the polyurethane resin

\begin{tabular}{lcc} 
& $\begin{array}{c}\text { Bio-Epoxy CLR/INS } \\
\text { Entropy [86] }\end{array}$ & $\begin{array}{c}\text { Loctite Polyurethane MAX 3 } \\
\text { Henkel [87] }\end{array}$ \\
\hline Density at $25^{\circ} \mathrm{C}$ (mixed) & 1.098 & 1.16 \\
Viscosity (cPs) & 280 at $25^{\circ} \mathrm{C}$ & 190 at $30^{\circ} \mathrm{C}$ \\
Tensile modulus (MPa) & 3089 & $>3000$ \\
Tensile strength (MPa) & 56.12 & $>84$ \\
Compression strength (MPa) & 85.36 & - \\
Bending modulus (MPa) & 2689 & $>2800$ \\
Bending strength (MPa) & 81.7 & $>97$ \\
Elongation at break (\%) & 6 & 3.5 \\
Pot Life (minutes) & 90 & 15 \\
Glass transition temperature $\left({ }^{\circ} \mathrm{C}\right)$ & 48.3 & $>125$ \\
\hline
\end{tabular}

\subsection{Procedures}

\subsubsection{Mould Filing Time}

Darcy's Law can be used to obtain a 1D approximation of the time required to fill the mould cavity and to wet the entire preform.

$u=\frac{d x}{d t}=-\frac{k}{\mu\left(1-V_{f}\right)} \nabla p$

where

- $\quad u$ is the superficial velocity $(\mathrm{m} / \mathrm{s})$

- $\quad \nabla p$ is the pressure gradient at the flow front $(\mathrm{Pa} / \mathrm{m})$

- $\quad \mu$ is the dynamic viscosity (Pa.s)

- $\quad k$ is the permeability $\left(\mathrm{m}^{2}\right)$

- $\quad V_{f}$ is the fibre volume fraction of the composite

- $\quad x$ is the position of the flow front (m)

- $\quad t$ is the time (s) 
For a frontal injection with a saturated flow and a constant inlet pressure

$$
\begin{aligned}
& \frac{d x}{d t}=-\frac{k}{\mu\left(1-V_{f}\right)} \frac{\Delta P}{x} \\
& \Delta P=P_{\text {front }}-P
\end{aligned}
$$

Therefore

$$
\begin{aligned}
& x^{2}(t)=-2 t \frac{k}{\mu\left(1-V_{f}\right)} \Delta P \\
& t=-\frac{\mu\left(1-V_{f}\right) x^{2}(t)}{2 k \Delta P}
\end{aligned}
$$

$t_{\text {filling }}=-\frac{\left(1-V_{f}\right) \mu \cdot L^{2}}{2 k \Delta P} \approx 25 s$

- $\quad t_{\text {filling }}$ is the time necessary to fill the entire mould (s)

- $\quad \Delta P$ is the pressure difference between the inlet and the flow front $(\sim 483 \mathrm{kPa})$

- $\quad P$ is the inlet pressure $(483 \mathrm{kPa})$

- $\quad \mu$ is the dynamic viscosity (0.100 Pa.s)

- $\quad k$ is the permeability $\left(1,0.10^{-10} \mathrm{~m}^{2}\right)$

- $\quad L$ is the length of the preform $(0.2026 \mathrm{~m})$

- $\quad V_{f}$ is the fibre volume fraction of the composite $(0.4)$

The result in Eq. (10) is calculated for the polyurethane resin. S. Phillips et al. measured the permeability for a similar reinforcement as the one used for this thesis. They found an equivalent unsaturated permeability of $9,42.10^{-11}$ and a saturated permeability of $\sim 1,0.10^{-10}$ for $V_{f}=30 \%$ [54]. Therefore, a value of $k=1,0.10^{-10}$ was used as a first approximation.

The polyurethane resin has a very low viscosity and fills the cavity very quickly, in less than a minute, which is in agreement with the $t_{\text {filling }}=25 \mathrm{~s}$ calculated using Eq. (10). 
The bio-epoxy resin has a higher viscosity and takes much more time to fill the cavity, around 20 minutes experimentally. It can be explained by the higher viscosity of the bio-epoxy and the lower permeability of the preform. In fact, at a fibre volume fraction of $40 \%$ the actual permeability is very likely to be lower. In addition, the viscosity increases significantly with time as the injection progresses, moving far from the value given by the supplier, $\mu_{\text {epoxy }}=0.280 \mathrm{~Pa} . \mathrm{S}$ (Table 3-1). The experimental filling time is therefore quite higher than the $t_{\text {fillingepoxy }}=99 \mathrm{~s}$ that can be calculated using Eq. (10) with a viscosity $\mu_{\text {epoxy }}=0.280 \mathrm{~Pa}$.s and an injection pressure $P=3.45$ bars.

\subsubsection{Process Parameters}

Table 3-2 Process parameters for both resin systems

\begin{tabular}{|c|c|c|}
\hline & $\begin{array}{c}\text { Epoxy Resin } \\
\text { SUPER SAP - CLR/INS }\end{array}$ & $\begin{array}{c}\text { Polyurethane Resin } \\
\text { LOCTITE MAX } 3\end{array}$ \\
\hline Injection Pressure & 3.45 bars & 4.83 bars \\
\hline Injection Temperature & $25^{\circ} \mathrm{C}$ & $50^{\circ} \mathrm{C}$ \\
\hline Resin viscosity in the mold & $\approx 280 \mathrm{cPs}$ & $\approx 100 \mathrm{cPs}$ \\
\hline Injection Time & $\approx 20 \mathrm{~min}$ & $\approx 1 \min 30 \mathrm{~s}$ \\
\hline Pot Life & $90 \min$ & $15 \mathrm{~min}$ \\
\hline Final Pressure & 4.83 bars & 4.83 bars \\
\hline Air removal & Clamping/Unclamping $3 x$ & Clamping/Unclamping $1 x$ \\
\hline Cure Temperature & $50^{\circ} \mathrm{C}(6 \mathrm{~h})$ & $50^{\circ} \mathrm{C}(\approx 5 \mathrm{~h})$ \\
\hline
\end{tabular}

The vacuum pressure is applied as in Figure 3-2. The pressure difference between the inlet and the outlet is therefore equals to the injection pressure shown in Table 3-2. 


\subsubsection{InJECTION Procedure}

First, the three parts of the mould were coated with a Zivax Enviroshield release agent. Before manufacturing the first part, the mould was cleaned using Zivax Fresh Start and sealed using Zyvax Sealer GP. The polyethylene tubing was then connected to the bottom part of the mould via brass compression fitting. The O-rings were then greased and positioned in their cavity (Figure 3-10).

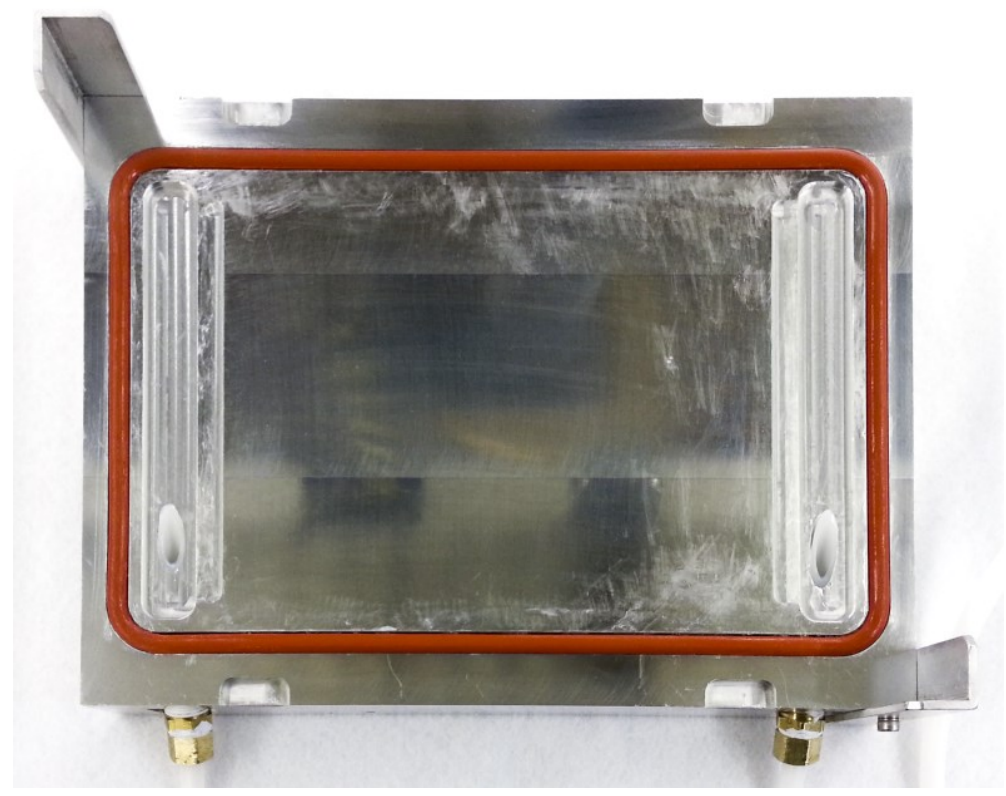

Figure 3-10 Bottom part of the RTM mould with its O-ring and tubing

After placing the spacer on top of the bottom part of the mould, two length of tacky tape were applied on the long sides of the cavity (Figure 3-11). This eliminates the possible gaps between the picture frame and the preform in order to avoid race tracking. Fourteen layers of the flax woven fabric were cut to dimensions $(200 \mathrm{~mm} \times 160 \mathrm{~mm})$, before being stacked and dried under a vacuum bag in an oven at $140^{\circ} \mathrm{C}$ for $8 \mathrm{~h}$. All the reinforcements came from the same roll. The textile preform was laid in the cavity and the mould was closed using a small hydraulic press equipped with heating platens (Figure 3-2) and a clamping force of $5 \mathrm{~T}(49050 \mathrm{~N})$. 


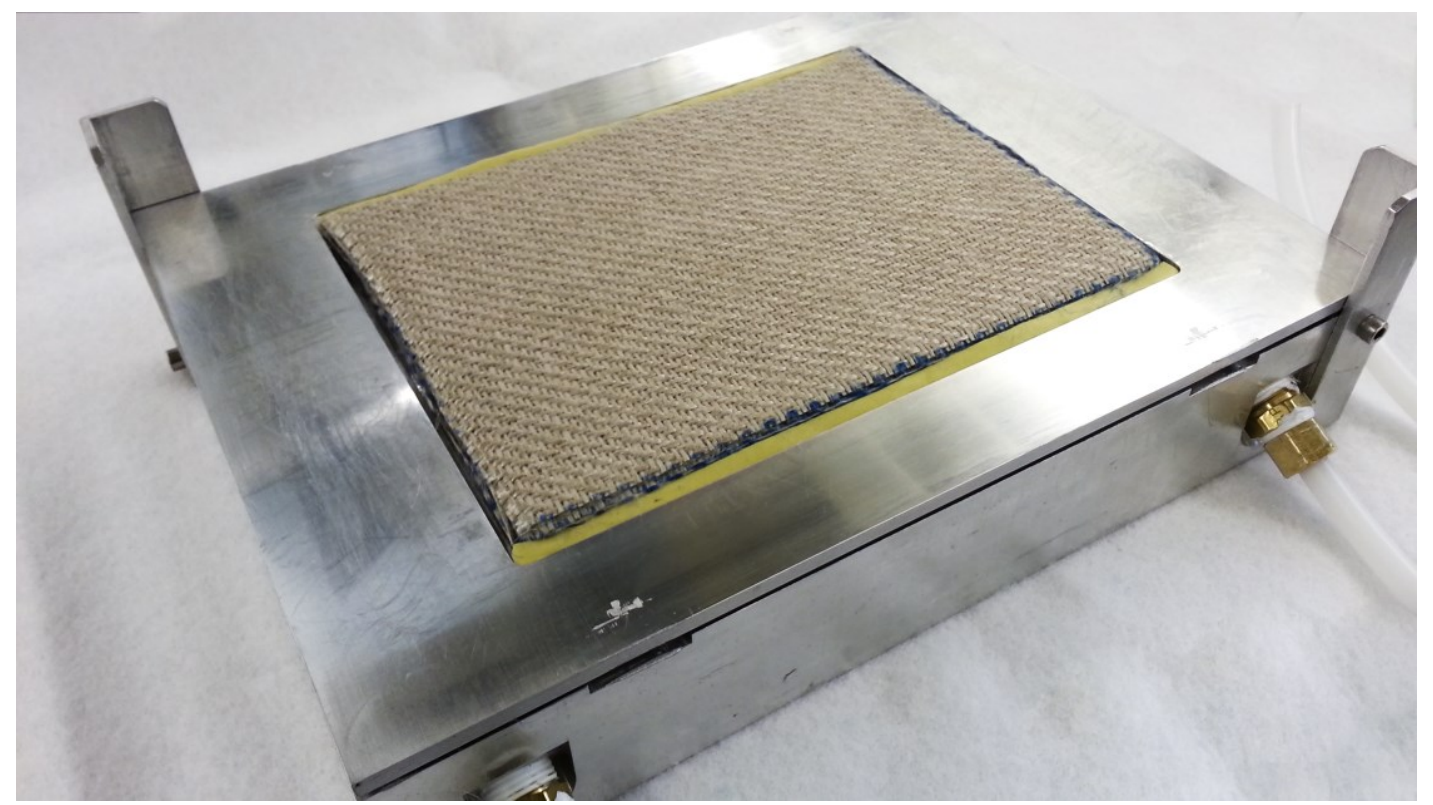

Figure 3-11 RTM mould - bottom part, spacer and preform. The fibre reinforcement is placed in the mould cavity with tacky tape on the edges to avoid race tracking

Once the mould is closed, the outlet was connected to the vacuum trap. The outlet tubing went at least one meter above the mould before coming down to the resin trap (Figure 3-12). This helped the escape of the entrapped air and avoided a resin flow driven by gravity and capillarity. The inlet was connected to a pressure tank. The seal was tested each time and was able to maintain $29 \mathrm{in} . \mathrm{Hg}$ for 5 minutes. Prior to the injection, the tool temperature was brought to $50{ }^{\circ} \mathrm{C}$ and 25 ${ }^{\circ} \mathrm{C}$ for the epoxy and the polyurethane respectively (Table 3-2). Afterward, the resin was mixed, degassed for 4 minutes at $-28 \mathrm{in.Hg}$ and placed in the pressure tank. For both resin systems, the pressure tank remained at $25^{\circ} \mathrm{C}$ during the entire procedure.

Using compressed air, the injection pressure was gradually applied for 1 min. For the epoxy resin, an injection pressure of 3.45 bars was used and the remaining voids were collapsed by increasing the pressure to 4.8 bars once the infusion was finished (Table 3-2). The polyurethane resin was injected at 4.8 bars and was not increased after the infusion. The polyurethane resin was injected at $50^{\circ} \mathrm{C}$. When the resin reached the preheated tool, its viscosity rapidly increased 
from $100 \mathrm{cPs}$ to $200 \mathrm{cPs}$ in 8 minutes (Figure 7-3). In the case of the bio-epoxy the viscosity started at $280 \mathrm{cPs}$ and slowly increased throughout the process (Table 3-2).

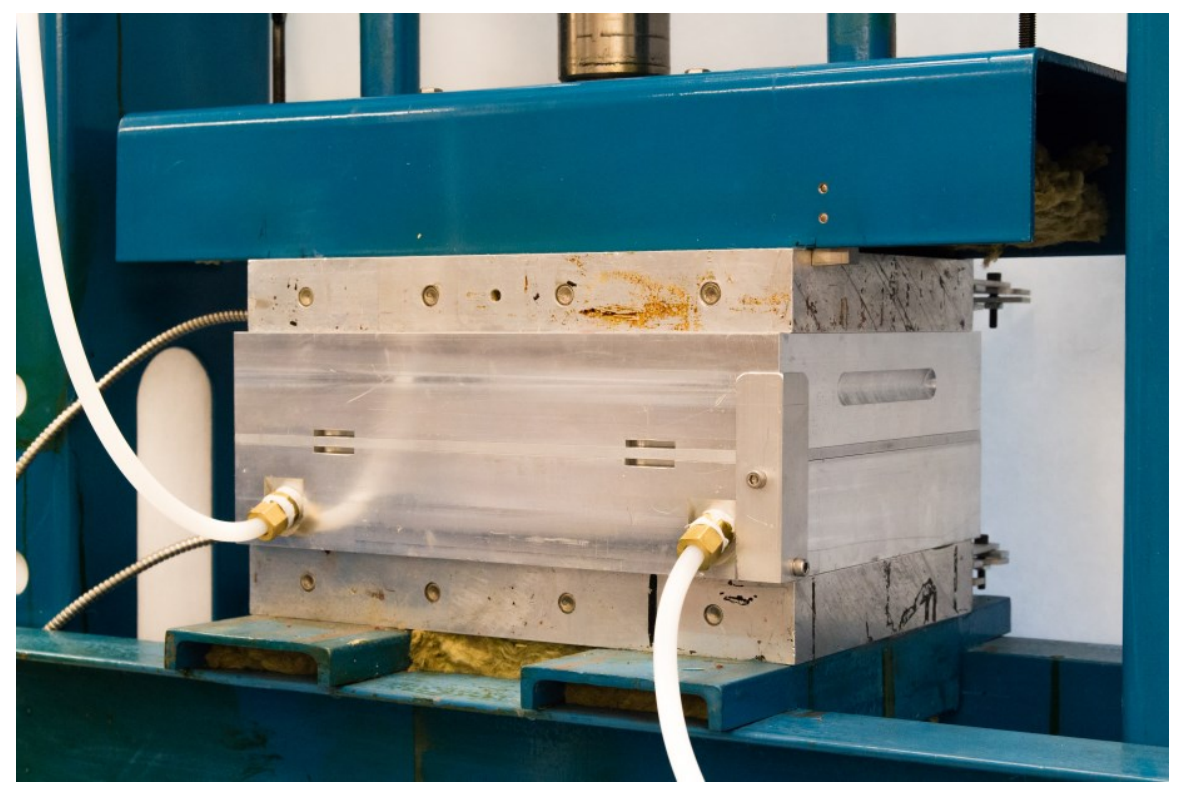

Figure 3-12 RTM tool under the press. The outlet tubing is going up, on the left side of the mould

When the fibres were completely impregnated and the resin flow coming out of the mould was stabilized, i.e. no more air bubbles were coming out of the mould, the outlet tubing was clamped and unclamped 2-3 times in order to generate a brief pressure gradient. This was done to remove the remaining entrapped air bubbles. In the case of the epoxy, the tool was then heated to $50^{\circ} \mathrm{C}$ for six hours. For the polyurethane, the mould temperature was held at $50{ }^{\circ} \mathrm{C}$ for five hours. The mould was cooled to room temperature before demoulding the biocomposites panels. Six polyurethane and twelve epoxy composites panels were made. Excellent panel quality was obtained. All panels had a smooth surface finish, a homogenous thickness and no visible macrovoids. The average fibre volume fraction was $42.4 \pm 1.5 \%$ and $38.9 \pm 1.4 \%$ for the epoxy and polyurethane panels respectively. The difference in the fibre volume fraction can be explained by the variability of the preform weight, ranging from $96.5 \mathrm{~g}$ to $102.2 \mathrm{~g}$. Even if the same number of plies was used, flax fabrics are subjected to variability. The average weight of the preform was $98.1 \mathrm{~g}$ for the polyurethane panels and $99.4 \mathrm{~g}$ for the epoxy panels. The fibre 
volume fraction was calculated using the mass of the reinforcement, the mass of the final part and the density of the fibres and the resins (Eq. (12)) The fibre density was estimated at 1.40 $\mathrm{kg} / \mathrm{m}^{3}$ (Table 2-1). The final thickness of the composite panels was slightly above the spacer thickness. The spacer has a thickness of $5 \mathrm{~mm}$ and the composite panels were $5.3 \mathrm{~mm}$ thick. This added thickness can be explained by extra space taken by the O-rings when they were compressed between the spacer and the mould to create an adequate seal.

$w t \%=\frac{m_{f}}{m_{\text {part }}}$

$w t \%$ is the fibre weight fraction, $m_{f}$ is the mass of the dry reinforcement and $m_{\text {part }}$ is the mass of the composite panel.

$V_{f}=\frac{1}{1+\frac{(1-w t \%) \times \rho_{f}}{w t \% \times \rho_{r}}}$

$V_{f}$ is the fibre volume fraction, $\rho_{f}$ is the fibre density and $\rho_{r}$ is the density of the resin.

\subsection{COMPOSITE MACHINING}

The composite panels were machined to the proper dimensions and tolerances using a Bridgeport Vertical 2-axis milling machine with a diamond coated carbide end mill. Six flax/polyurethane and twelve flax/bio-epoxy panels were machined. In each panels, 7 short beam shear test coupons and 7 shear loading compression coupons were machined. First, a rectangle containing the 7 test coupons was cut roughly using a band saw (in red, Figure 3-13). This rectangle was then machined to dimensions and its edges made parallel using the Bridgeport milling machine. One by one, the test coupons were cut from the rectangle using the band saw and machined to dimensions with the milling machine. 


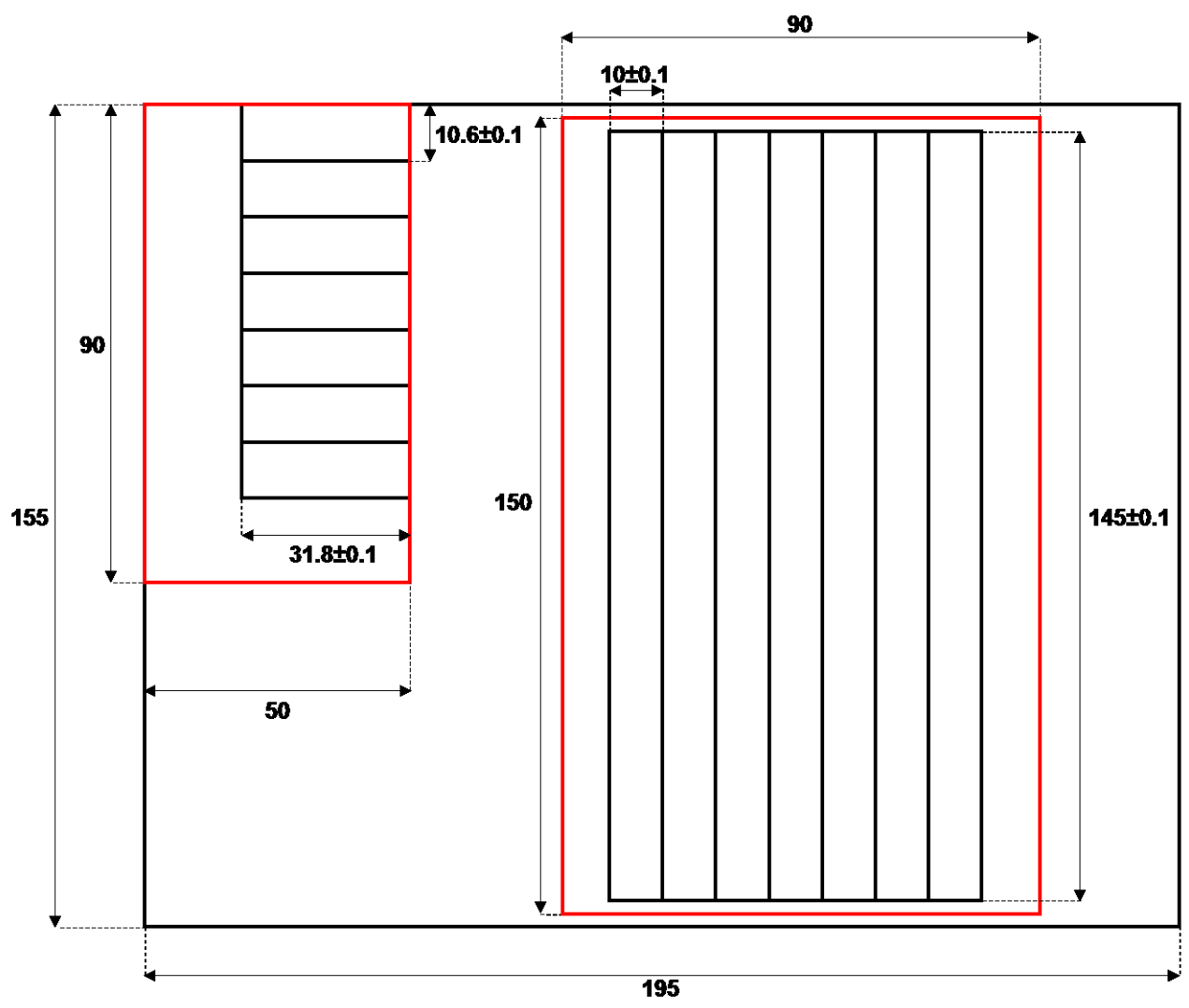

Figure 3-13 Drawing indicating the locations and dimensions of the test coupons machined in the composite panels. The red areas were roughly cut using a band saw. All dimensions are in $\mathrm{mm}$.

The short beam shear coupon dimensions were $31.8 \mathrm{~mm} \times 10.6 \mathrm{~mm}$ and the shear load compression coupons were $145 \mathrm{~mm} \times 10 \mathrm{~mm}$ (Figure 3-13). For each resin systems, nine test coupons were also machined for dynamic mechanical analysis (DMA) tests. The DMA test coupons were $60 \mathrm{~mm} \times 10 \mathrm{~mm}$. No water or cutting fluid was used in order to avoid wetting the samples before ageing. The samples were held in the vise of the milling machine. When the composites were machined using the end of the mill, i.e. for face milling, the samples were sandwiched between sheets of acrylic to minimize fibre tear out and delamination at the edges. It is a very common practice to "support" composite parts when they are machined. When the side of the end mill was used, i.e. for shoulder milling, using acrylic sheet was not necessary. Once machined, the test coupons were put in sealed bags with desiccant. 


\section{CHAPTER 4: WATER ABSORPTION AND GRAVIMETRIC ANALYSIS}

\subsection{SAMPles CONDITIONING}

All the test coupons were stored in sealed bags with desiccant immediately after manufacturing and machining. The first batch of coupons was dried under vacuum at $40^{\circ} \mathrm{C}$ for $24 \mathrm{~h}$ but no weight reduction was observed. Therefore, the desiccant method was considered sufficient to dry the test coupons before ageing, i.e. no samples were dried in an oven after the first batch. All the samples were weighted on a Sartorius entris244-1s scale with a precision of $1 \mathrm{mg}$. The water absorption characteristics of the composites were evaluated by the relative weight gain $M_{t}$ (2.4.2).

\subsubsection{MOISTURE CONDITIONING BEFORE MECHANICAL TESTING}

The short beam shear and shear loading compression test coupons were conditioned at $30{ }^{\circ} \mathrm{C}$ and 90\% RH in a Conviron E7 environmental chamber. The ageing conditions were monitored using the environmental chamber sensors. In most studies [11, 16, 17, 26, 28, 29], Fick's second law of diffusion is used to model the global water absorption behaviour of the composites and gives accurate results (2.4.2). The times at which the samples were tested were therefore determined according the square root of time. Test coupons were conditioned for the following periods of time: $0 \mathrm{~h}, 6 \mathrm{~h}, 23 \mathrm{~h}, 91 \mathrm{~h}, 336 \mathrm{~h}$ and $720 \mathrm{~h}$. For each period of time, 2 flax/bio-epoxy panels and 1 flax/polyurethane panel were tested. For the short beam shear and the shear load compression tests, 7 coupons were cut from the same panel (Figure 3-13). The test coupons were weighted before conditioning and within the 5 minutes following their conditioning. They were then placed in a sealed bag to limit the contact with the ambient air and were removed from the bag just before their mechanical testing. 


\subsubsection{Water ImMersion before Dynamic Mechanical ANALysis}

The DMA test coupons were immerged in distilled water at $30{ }^{\circ} \mathrm{C}$ in an environmental chamber. The temperature was monitored using the environmental chamber thermocouples. The DMA tests were performed to assess the influence of water absorption on the glass transition temperature $\left(T_{g}\right)$ of the composites. For each resin system, a total of 9 DMA coupons were machined from the same panel. The samples were conditioned for the following periods of time: 0h, 216h and 432h. Each period of time corresponds to 3 flax/bio-epoxy and 3 flax/polyurethane test coupons. The test coupons were weighted before conditioning and within the 3 minutes following their conditioning. The droplets of water were wiped from the surface of the samples before the weight measurement was taken. They were then placed in the DMA environmental chamber and tested.

\subsection{WATER ABSORPTION OF THE LAMINATES}

The moisture content of the composites corresponds to the weight gain defined in Eq. (1). Figure 4-1 shows the percentage of water absorbed for the samples after $90 \% \mathrm{RH}$ ageing at $30{ }^{\circ} \mathrm{C}$, as a function of square root of ageing time. Each data point corresponds to the average water uptake of 7 short beam shear or shear loading compression test coupons cut from the same composite panel. In the case of a one-dimensional approach of Fick's law, the water uptake increases linearly with the square root of time, and then gradually slows until an equilibrium plateau is reached, typically after a month for flax composite exposed to $90 \% \mathrm{RH}[16]$. Between $0 \mathrm{~h}^{1 / 2}$ to $20 \mathrm{~h}^{1 / 2}$, the samples had not reach saturation but followed the expected linear trend. A linear regression was fitted for the first part of the curve, i.e. before the equilibrium plateau, and a relatively good fit was obtained (Figure 4-1). After $720 \mathrm{~h}$ of ageing, i.e. the last data points in Figure 4-1, the bio-epoxy samples were reaching equilibrium and it is difficult to determine if the polyurethane samples were still absorbing moisture. More test coupons and a longer ageing period would have been required to clearly determine if the composites have reached equilibrium for these given environmental conditions. 


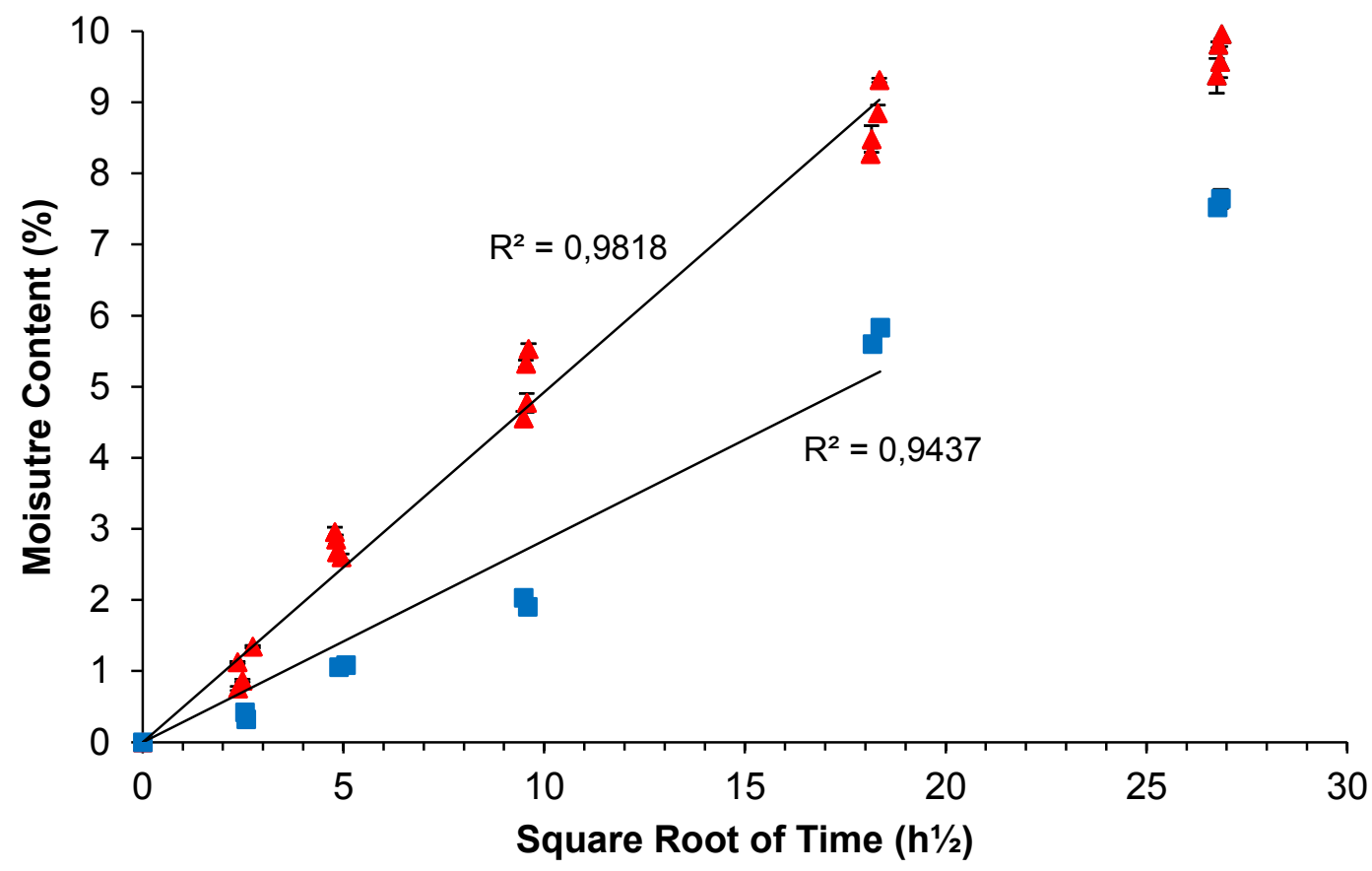

$\Delta$ Flax/Bio-based Epoxy $\quad$ Flax/Polyurethane

Figure 4-1 Water uptake of flax fibre reinforced composites after $90 \% \mathrm{RH}$ ageing at $30^{\circ} \mathrm{C}$

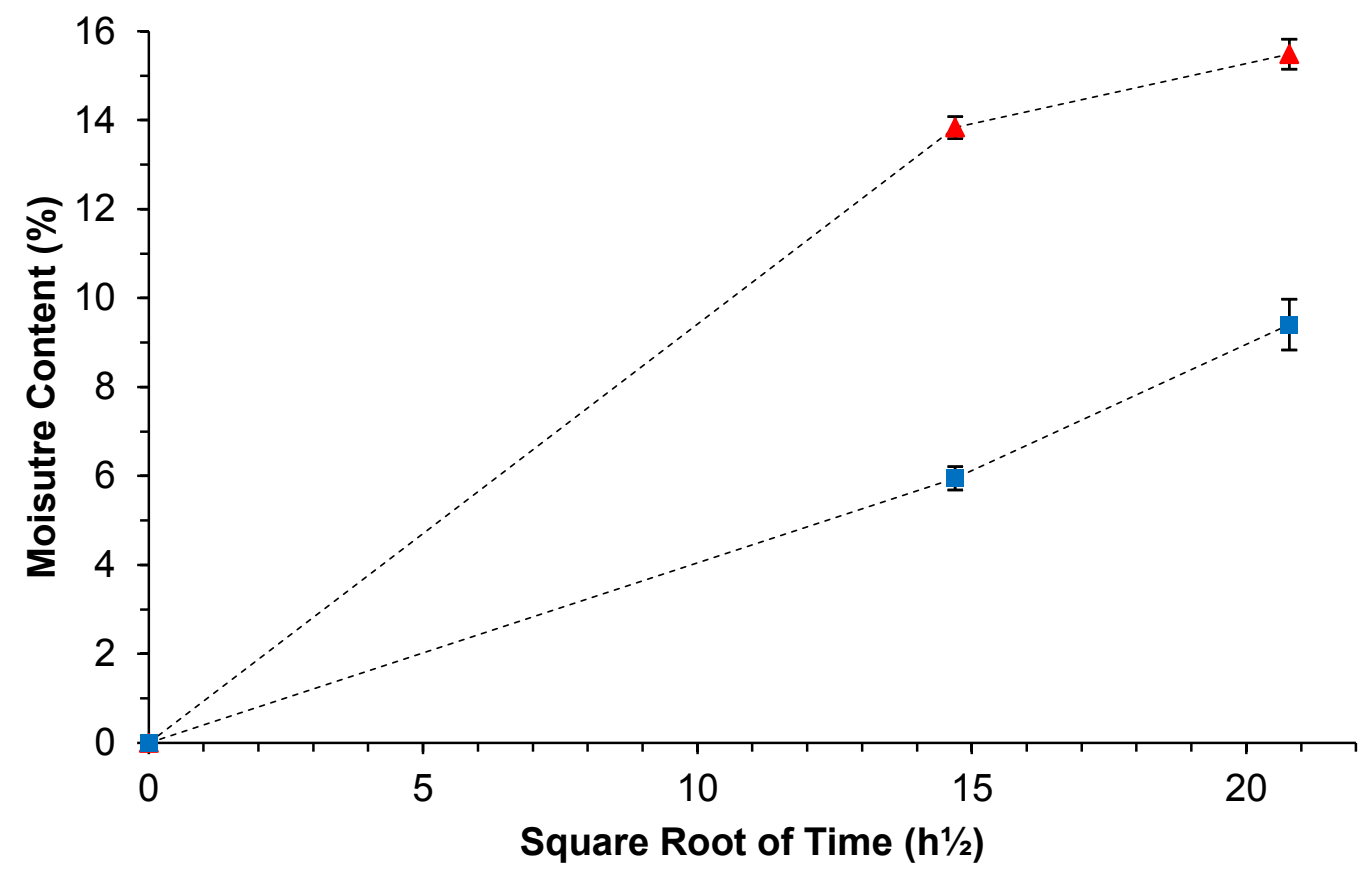

$\triangle$ Flax/Bio-based Epoxy $\quad$ Flax/Polyurethane

Figure 4-2 Water uptake of flax fibre reinforced composites after immersion in distilled water at $30^{\circ} \mathrm{C}$ 
Figure 4-2 shows the percentage of water absorbed for the samples immerged in distilled at $30^{\circ} \mathrm{C}$, as a function of square root of ageing time. In Figure 4-2, each data point corresponds to the average water uptake of 3 DMA samples. After 432h (18 days) of conditioning, the surfaces of the immerged composites were starting to show sign of fungal growth.

In both Figure 4-1 and Figure 4-2, the polyurethane composites do not reached equilibrium or saturation, whereas the moisture or water uptake of the bio-epoxy composites clearly slows down. The beginning of an absorption plateau can even be seen in the case of the flax/bio-epoxy samples. This clearly shows that polyurethane composites have a much slower absorption rate than the bio-epoxy composites, $0.284 \mathrm{~h}^{-1 / 2}$ and $0.493 \mathrm{~h}^{-1 / 2}$ respectively.

The polyurethane composites also absorb less moisture (Figure 4-1 and Figure 4-2). After 432h of immersion, the flax/bio-epoxy and the flax/polyurethane samples have absorbed $15.5 \%$ and $9.4 \%$ respectively. After $720 \mathrm{~h}$ of $90 \% \mathrm{RH}$ ageing at $30^{\circ} \mathrm{C}$, the flax/bio-epoxy and the flax/polyurethane samples did absorb $9.7 \%$ and $7.6 \%$ respectively. Epoxy resins absorb between $1 \%$ to $5 \%$ at saturation, depending on their formulations [88]. Polyurethane resins absorb around $0.5 \%$ to $2 \%$ [88]. Once again, these numbers depend on the ageing temperature and conditions. However, when used in a laminate, the contribution of the resin to the global water uptake behaviour of the composite does not exceed 1\% [59].

The flax fibres are mainly responsible for the water absorption of the composite due to their hydrophilicity $[11,17]$. A smaller water absorption rate therefore indicates that the fibres/matrix interaction is different $[59,62,63]$. This can be explained by the formation of bonds between the urethane pre-polymer and the hydroxyl group of the flax fibres. A reduction in the available hydroxyl groups would lead to a reduction in the moisture absorption rate. In addition, an improved fibre/matrix interaction may also lead to a reduction of the matrix microvoids which would significantly decrease the moisture absorption rate. 


\section{Chapter 5: Mechanical Testing Results}

\section{AND DISCUSSION}

\subsection{Mechanical Testing}

There is no commonly used tests to characterize the fibre/matrix interface in a cured composite laminate [84]. Therefore, two different tests were selected to measure mechanical properties that are closely related and sensitive to the fibre/matrix adhesion. Short beam shear tests (ASTM D2344) were performed to measure the interlaminar shear strength, a property directly affected by the bond quality between the fibres and the matrix. Shear-loading compression tests (ASTM D3410) were also performed. In fact, the compressive strength of a laminate containing interlaminar damages is likely to be degraded because individual plies are free to exhibit local instabilities [84]. Therefore, the evolution of the compression properties during ageing should be a good indicator of the effects of moisture on the interface and the interlaminar strength of the composite. Both tests were performed on a $10 \mathrm{kN}$ Instron model 4502 testing system equipped with a $50 \mathrm{kN}$ load cell. The test fixtures were made by Wyoming Test Fixtures.

\subsubsection{SHORT BEAM SHEAR}

Short beam shear tests determine the interlaminar short-beam strength of high-modulus fibrereinforced composite materials. The beam is loaded in three-point bending (Figure 5-1). The failures are normally dominated by the resin and the interlaminar properties. The results can be used to compare different composites, provided that the failures occur consistently in the same mode [89]. The average specimen thickness of the panels is $5.3 \mathrm{~mm}$. Therefore, the loading span length was set to $21.2 \mathrm{~mm}$ in order to obtain a loading span length-to-specimen thickness width ratio of 4.0. The test coupons were machined to be $31.8 \mathrm{~mm}$ long and $10.6 \mathrm{~mm}$ wide (Figure 3-13). 


\subsubsection{FAILURE MODES}

Before ageing, both epoxy and polyurethane composites failed in a combination of interlaminar shear and tension failure modes (Figure 5-1 a)), allowing the determination of the apparent short beam strength of the material (Figure 5-4). After 23h of ageing, the flax/bio-epoxy samples no longer failed, they deformed plastically at a much lower load than initially (Figure 5-1 b)). No apparent short beam strength could therefore be calculated for the flax/epoxy composite after $23 \mathrm{~h}$ of ageing. The presence of water in the fibres increased the mobility between the microfibrils and resulted in a plasticizing effect $[17,81]$. With water acting as a plasticizer, the internal bonds between microfibrils are softened, thus weakening the composite reinforcement and modifying its behaviour.

a)

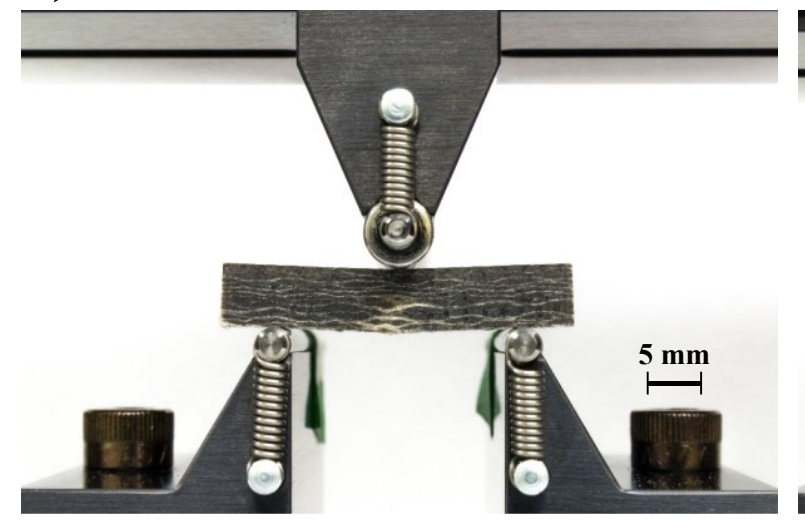

b)

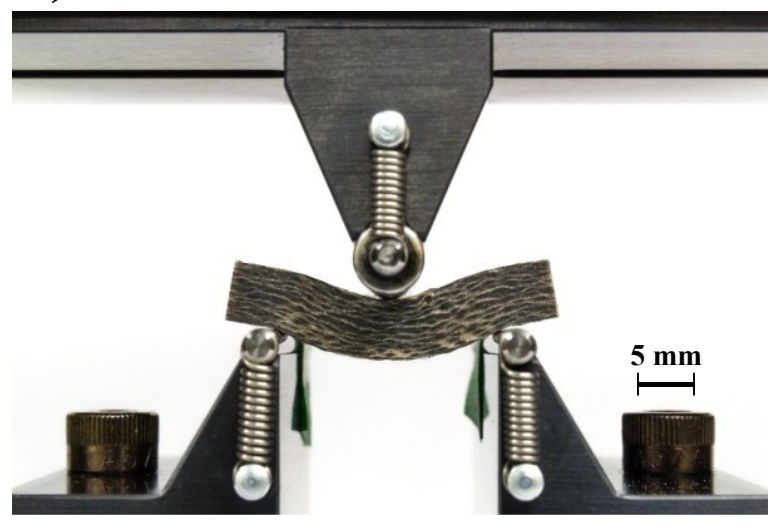

Figure 5-1 Typical fracture modes of flax composites tested in short beam shear (ASTM D2344)

a) Interlaminar Shear/Tension (flax/PU, 23h) b) Inelastic Deformation (flax/bio-epoxy, 336h)

\subsubsection{RESULTS}

The influence of humidity on the mechanical behaviour during the short beam shear tests is shown in Figure 5-2 and Figure 5-3. Bio-Epoxy panels are labelled A, B, C, D and E. Polyurethane panels were labelled $\alpha, \beta, \gamma, \delta$ and $\varepsilon$. Each panel corresponds to one ageing time. The percentage in the legend of Figure 5-2 and Figure 5-3 is the average moisture uptake of the 7 
short beam shear test coupons machined from the composite panel. At the beginning of the conditioning, both composites failed in a combination of interlaminar shear and tension (Figure 5-1). Some samples failed in pure interlaminar shear whereas for others it was more difficult to determine which of the tension or interlaminar shear failure mode was predominant. After ageing for a certain period of time, $91 \mathrm{~h}$ in the case of the flax/bio-epoxy composites and $336 \mathrm{~h}$ for the flax/polyurethane composites, the failure mode changed to an inelastic deformation failure mode. The test coupons no longer broke but deformed plastically when loaded. It is interesting to notice that both composites started to deform plastically for approximately the same amount of absorbed water. In fact, both composites had absorbed around 5\% of their weight in water when their short beam shear failure mode changed. This change of failure mode occurred at a moisture content of $4.55 \%$ and $5.60 \%$ for the bio-epoxy and the polyurethane respectively.

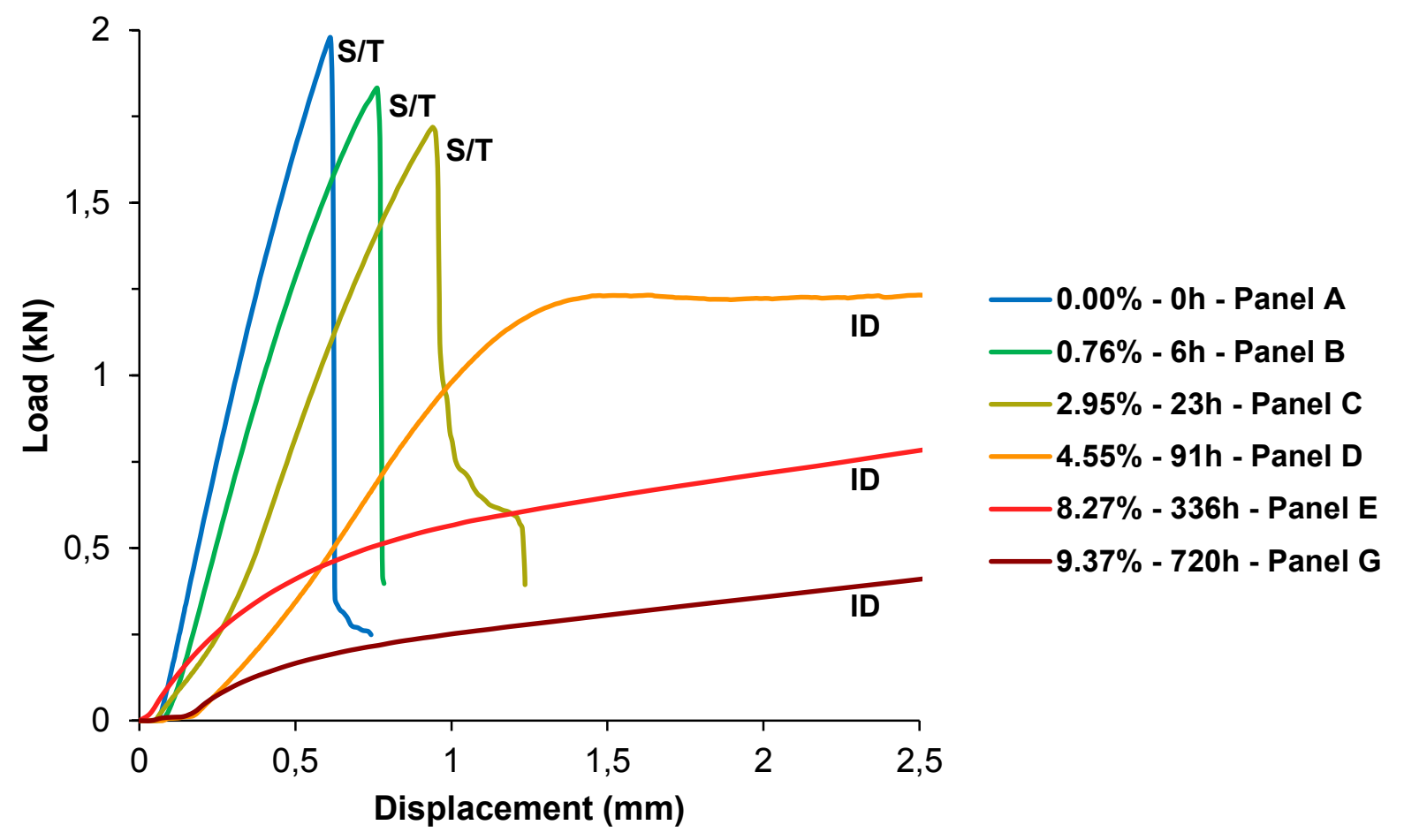

Figure 5-2 Short beam shear tests after $90 \% \mathrm{RH}$ ageing at $30^{\circ} \mathrm{C}$ - flax/bio-epoxy

Failure mode: S/T Interlaminar Shear/Tension ; ID Inelastic Deformation. The percentage in the legend is the average water uptake of the sample 
The flax/polyurethane composite took a much longer time to reach a water uptake of $5 \%$ (336h against $91 \mathrm{~h}$ for the flax/bio-epoxy), indicating that the polyurethane matrix offers a better protection than the bio-epoxy. The chemical bonds between the surface of the fibres and the polyurethane matrix slow down the absorption process but when the water eventually reaches the fibres, it starts degrading the mechanical performance of the composite [11]. For a water uptake of $5 \%$, the composite were similarly affected in term of failure mode. The polyurethane composites retained their short beam strength over longer periods of time (Figure 5-4).

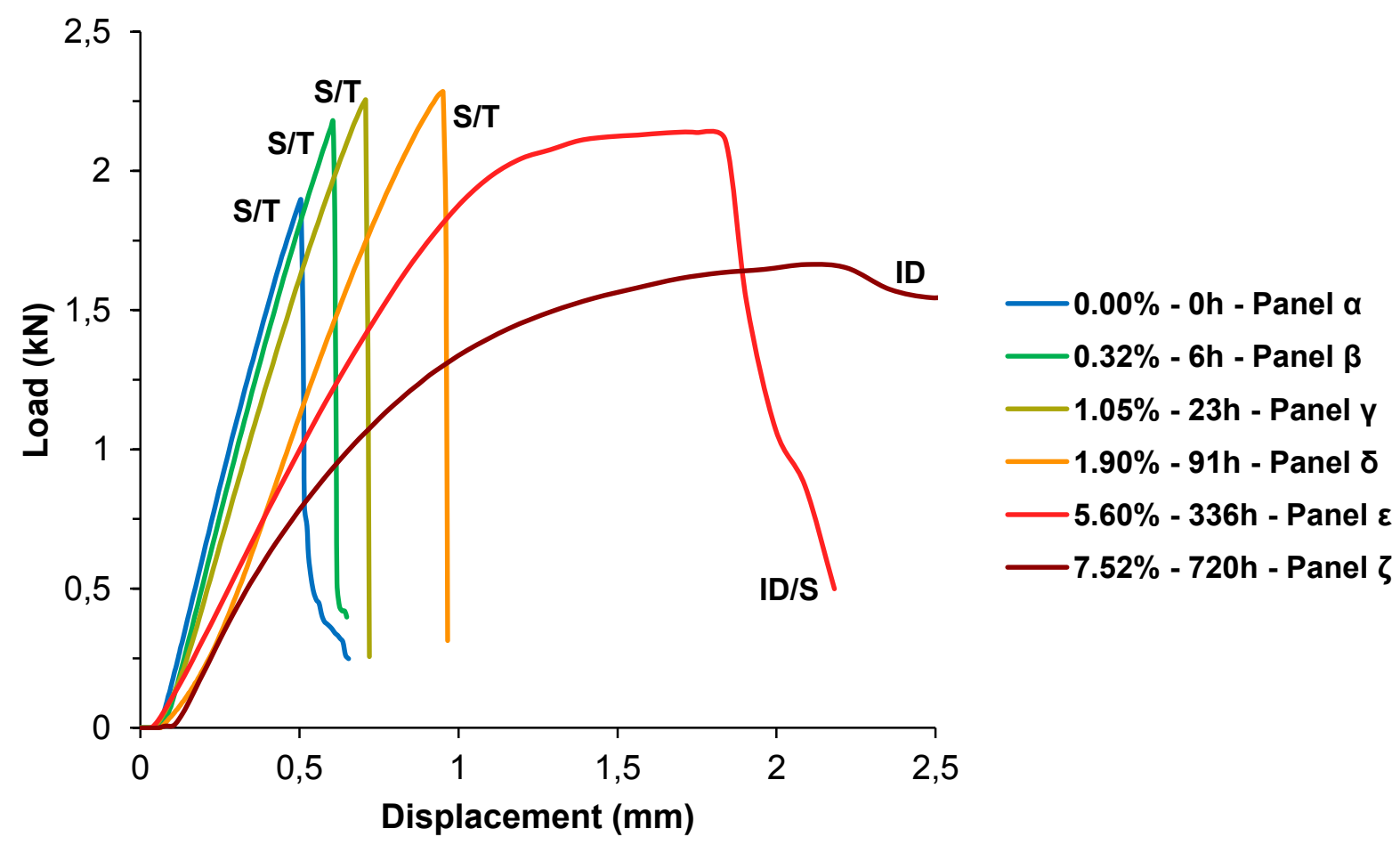

Figure 5-3 Short beam shear tests after $90 \% \mathrm{RH}$ ageing at $30^{\circ} \mathrm{C}$ - flax/polyurethane

Failure mode: S/T Interlaminar Shear/Tension ; ID Inelastic Deformation. The percentage in the legend is the average water uptake of the sample

As shown in Figure 5-4, the absorbed water had a significant impact on the short beam strength of the flax/bio-epoxy composite as it dropped by $17.6 \%$ in $23 \mathrm{~h}$. Afterward the material started to deform plastically. It was also the case for the flax/polyurethane composite since after $336 \mathrm{~h}$ the short beam strength can no longer be measured. 
However, there is an increase in the short beam strength of the flax/polyurethane samples right after the beginning of the ageing. After $91 \mathrm{~h}$ of conditioning, the short beam strength of the polyurethane composites had increased by $23 \%$ with a corresponding water uptake of $1.90 \%$. The plasticizing effect of water can be seen for both resin systems; as the composites absorbed moisture, they failed at a bigger displacement, i.e. the slope of the load-displacement curve decreased with the conditioning time and the water uptake (Figure 5-2 and Figure 5-3). Thus, the plasticization cannot entirely explain the two different evolutions of the short beam strengths, even if the plasticizing effect is more important for the flax/bio-epoxy composite than the flax/polyurethane composite when exposed to moisture.

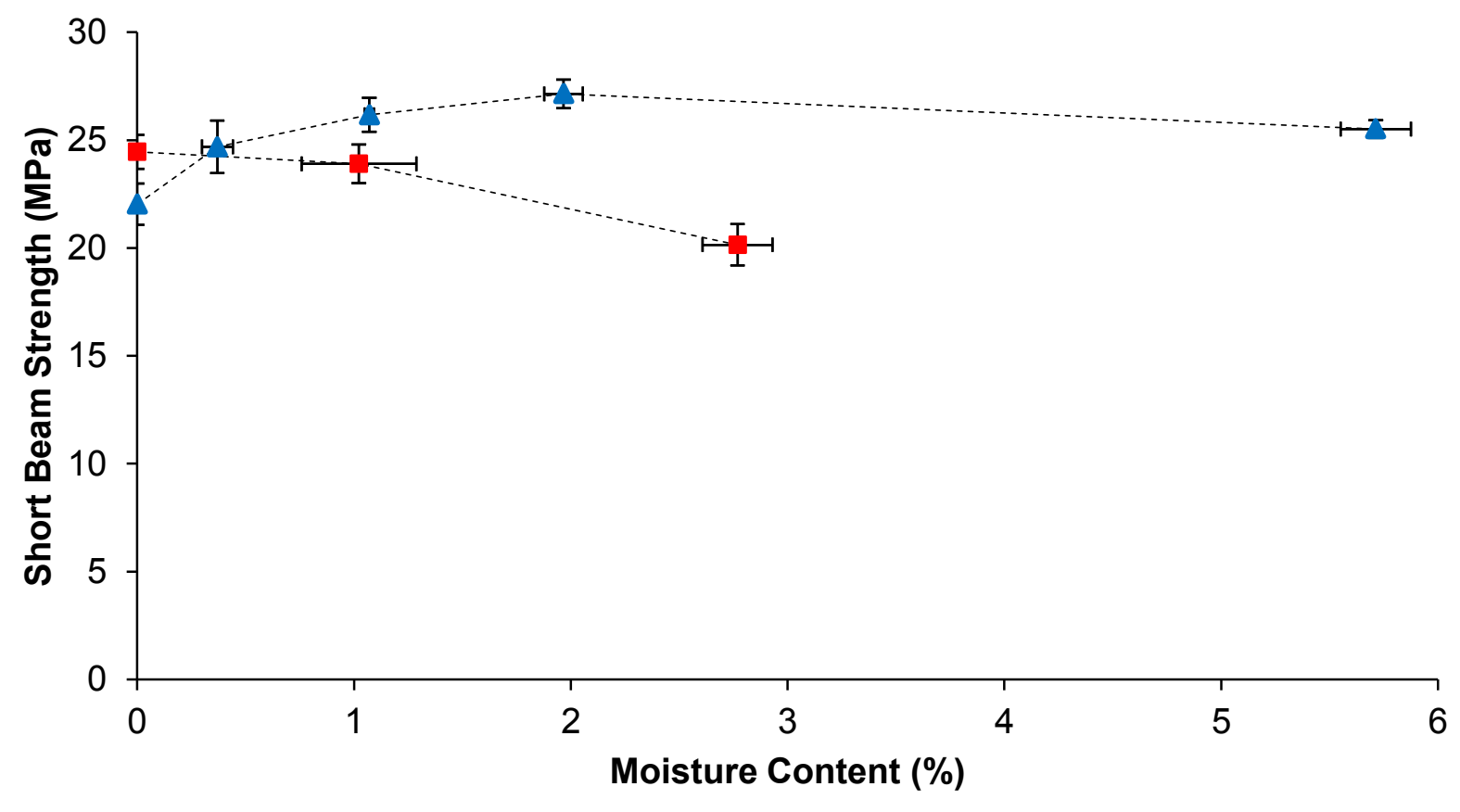

- Flax/Bio-Epoxy $\triangle$ Flax/Polyurethane

Figure 5-4 Evolution of the short beam strength of flax/bio-epoxy and flax/polyurethane composites with the water uptake 
A polyurethane matrix is more polar than an epoxy resin. At low level of absorbed water, the higher polarity of the polyurethane could lead to stronger polar-polar interactions between the water molecules, the polymer chains and the cellulose contained in the flax fibres. This would create stronger intermolecular forces in the matrix and at the fibre/matrix interface that could explain why there is an increase in short beam strength for the polyurethane matrix and not for the bio-epoxy matrix (Figure 5-4). The small swelling of the fibres caused by water absorption could potentially improve the interface strength and the load transfer between the matrix and the fibres (Figure 2-4 (e)), but this increase in short beam strength would have to be observed for both the bio-epoxy and the polyurethane composites it is not the case (Figure 5-4). Nevertheless, the results shown in Figure 5-4 clearly indicate that absorbed moisture does not affect the fibres and the interface bonds in the polyurethane composite the same way it does in the bio-epoxy composites.

\subsubsection{SHEAR LOADING COMPRESSION}

Shear loading compression tests determine the in-plane compressive properties of high-modulus fibre-reinforced composite materials. The compressive force is introduced into the specimen through shear at wedge grip interfaces (Figure 5-5) [90].

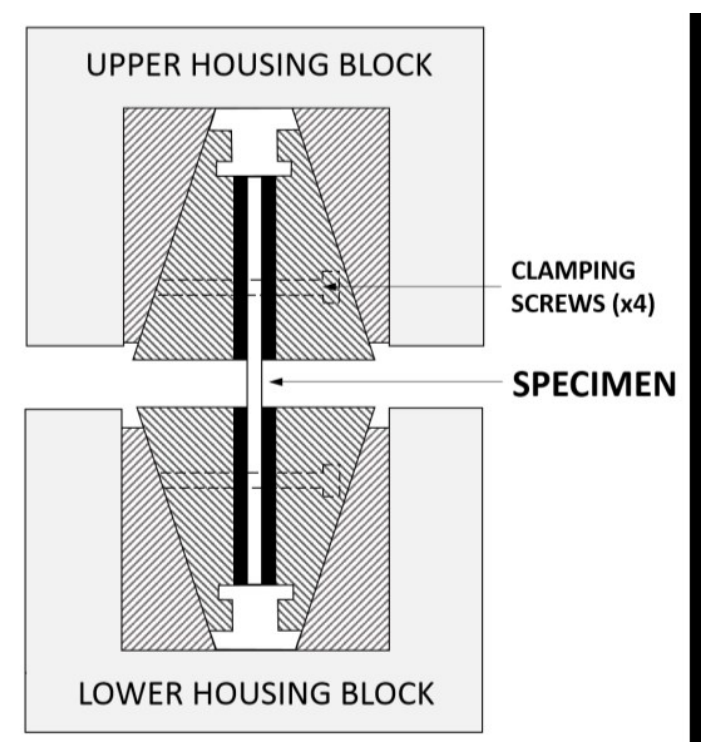

Figure 5-5 Schematic of a compression test fixture. Alignment rods in linear bearings are used to keep the housing blocks aligned 
Compression tests are very sensitive to interlaminar damage. The measured compressive properties and their evolution with moisture absorption can therefore be related to some extent to the fibre/matrix interface. The average specimen thickness of the panels is $5.3 \mathrm{~mm}$. No buckling or bending of the test coupons was observed during the tests. The test coupons were machined to be $145 \mathrm{~mm}$ long and $10 \mathrm{~mm}$ wide (Figure 3-13). The displacement of the electromechanical Instron testing system was used to calculate the compressive modulus.

\subsubsection{FAILURE MODES}

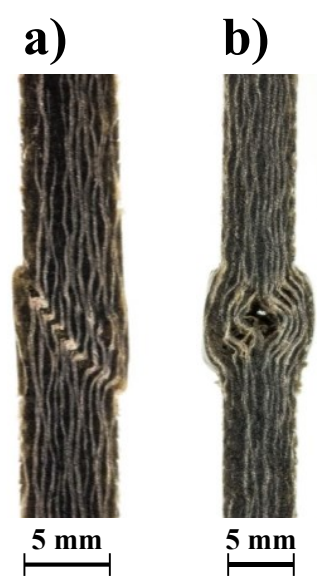

Figure 5-6 Typical fracture modes of flax composites tested in shear loading compression (ASTM D3410) a) Through-the-thickness (flax/PU, 23h) b) Brooming (flax/bio-epoxy, 91h)

At the beginning of the conditioning, all the samples failed according to a through-thickness failure mode in the gauge section (Figure 5-6 a)). In the case of the bio-epoxy matrix, the plasticizing effect of water affected the material rapidly. After $23 \mathrm{~h}$ of hygrothermal ageing, the failure mode changed to brooming, a plastic failure mode in which the sample expand perpendicularly to the loading axe (Figure 5-6 b)). The same change was observed for the flax/polyurethane composites after $91 \mathrm{~h}$ of conditioning. In the brooming failure mode, no clear fracture was observed and the sample deformed at a much lower load than initially. 


\subsubsection{RESULTS}

Figure 5-7 and Figure 5-8 show the influence of humidity on the mechanical behaviour during the shear loading compression tests. Each panel corresponds to one ageing time. The percentage in the legend of Figure 5-7 and Figure 5-8 is the average moisture content of the 7 shear loading compression test coupons machined from the same composite panel. At low level of water uptake, i.e. under 5\%, all the samples failed in a through-the-thickness failure mode (Figure 5-6 a)). The fractures were clean, located in the gauge section and form a $45^{\circ}$ angle. The compressive failure mode changed when the water uptake exceeded $5 \%$, more precisely $5.32 \%$ and $5.83 \%$ for the bio-epoxy and the polyurethane respectively. The absorbed water also affected the displacement at peak load, especially in the case of the flax/bio-epoxy composites (Figure $5-7)$.

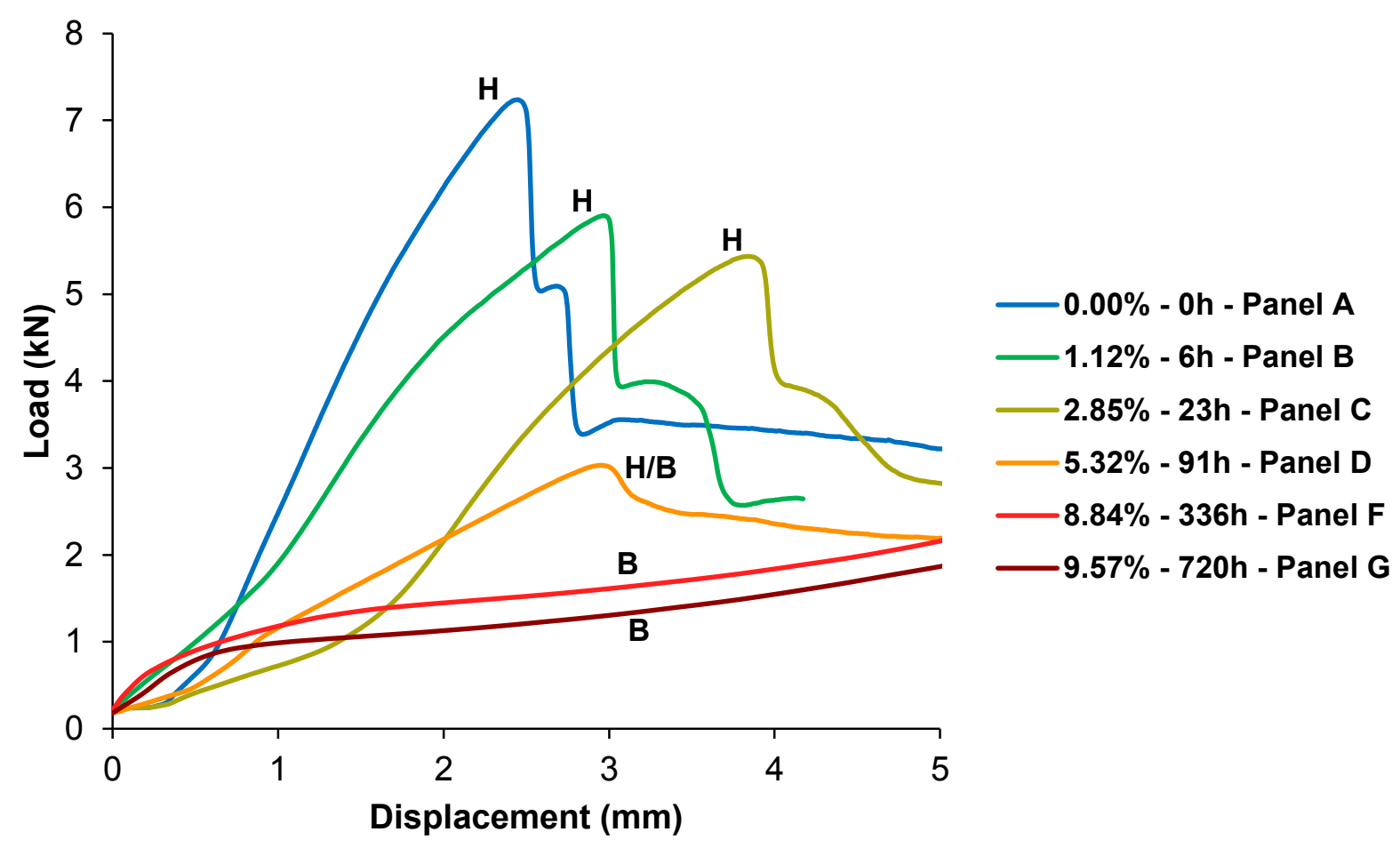

Figure 5-7 Shear loading compression tests after $90 \% \mathrm{RH}$ ageing at $30^{\circ} \mathrm{C}$ - flax/bio-epoxy

Failure Mode: H Through-the-Thickness ; H/B Through-the-Thickness then Brooming. The percentage in the legend is the average water uptake of the sample 
This change in the ductility of the composite is likely to be caused by the effect of water on the epoxy matrix. In fact, the absorbed water can reduce the modulus and also increase the ductility of epoxy resins [91]. This phenomenon highly depends on the chemistry of the resin. This $5 \%$ threshold is the same as the one observed for the short beam shear tests (5.1.1.2). This confirms that the polyurethane matrix offered a better protection than the bio-epoxy and that the water induced degradations became critical when the composites reached a water uptake of $5 \%$. However, flax/polyurethane composites retained their mechanical performance for a longer period of time and did not plasticize as much as the flax/bio-epoxy composite, even after absorbing more than 5\% of moisture (Figure 5-7 and Figure 5-8). It confirmed once again that the absorbed water did not affect the two composites in the same fashion.

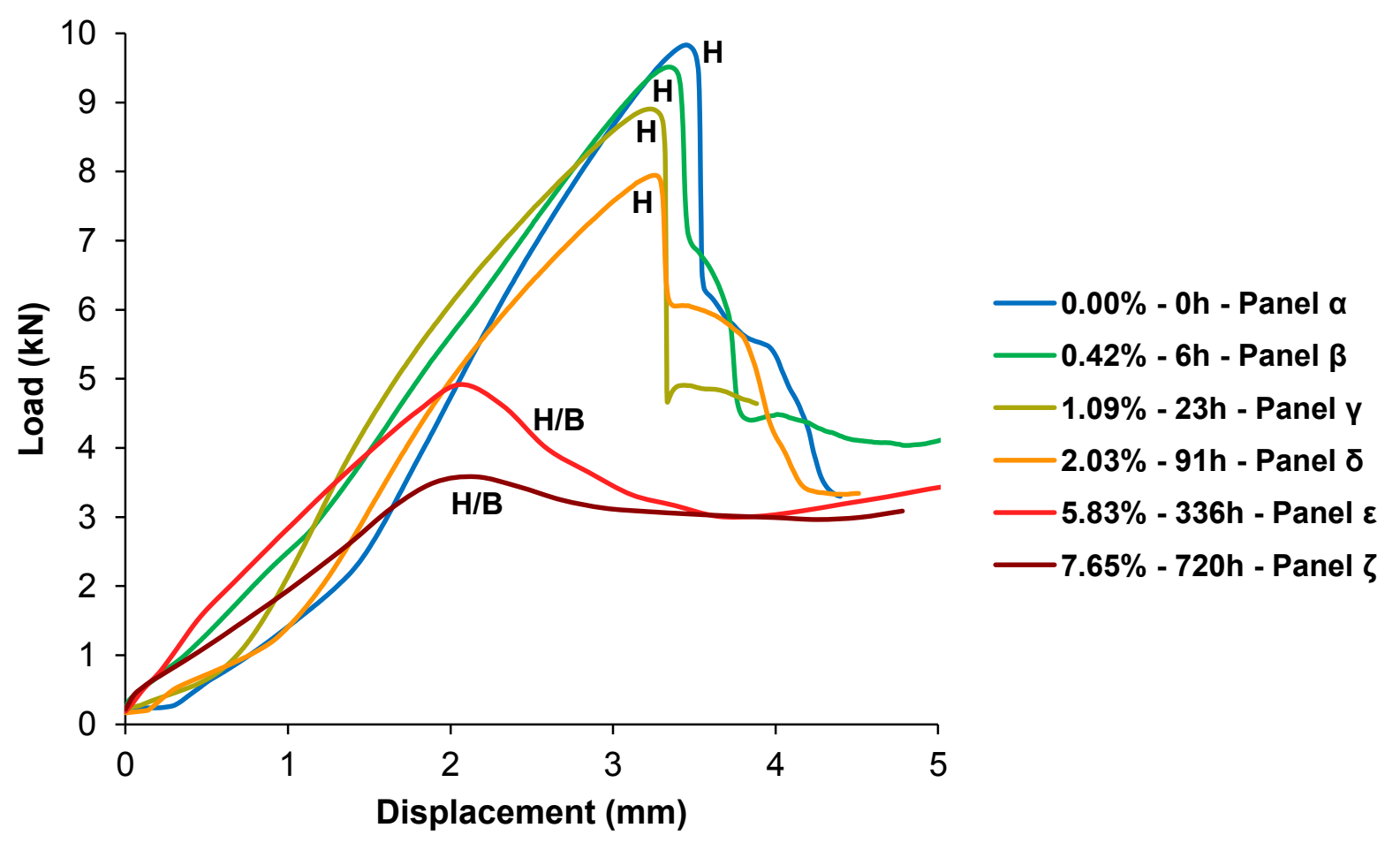

Figure 5-8 Shear loading compression tests after $90 \% \mathrm{RH}$ ageing at $30^{\circ} \mathrm{C}$ - flax/polyurethane

Failure Mode: H Through-the-Thickness ; H/B Through-the-Thickness then Brooming. The percentage in the legend is the average water uptake of the sample 
After $91 \mathrm{~h}$ of conditioning, both the ultimate compressive strength and the compressive modulus of elasticity of the bio-epoxy composites were reduced by $61.7 \%$ and $69.7 \%$ respectively (Figure 5-9 and Figure 5-10). In addition, according to the bio-epoxy manufacturer, the ultimate compressive strength of the neat resin is 85.4 MPa (ASTM D695, Table 3-1), which is higher than the compressive strength of 51.6 MPa measured for the flax/bio-epoxy composite after $91 \mathrm{~h}$ (Appendices). The increased mobility between the flax microfibrils [17, 81] reduced significantly the load that the fibres can carry in compression. As the load cannot be efficiently transferred to the fibres, the sample failed when the matrix failed. In this case, the wet fibres actually weakened the compressive properties of the bio-epoxy composites.

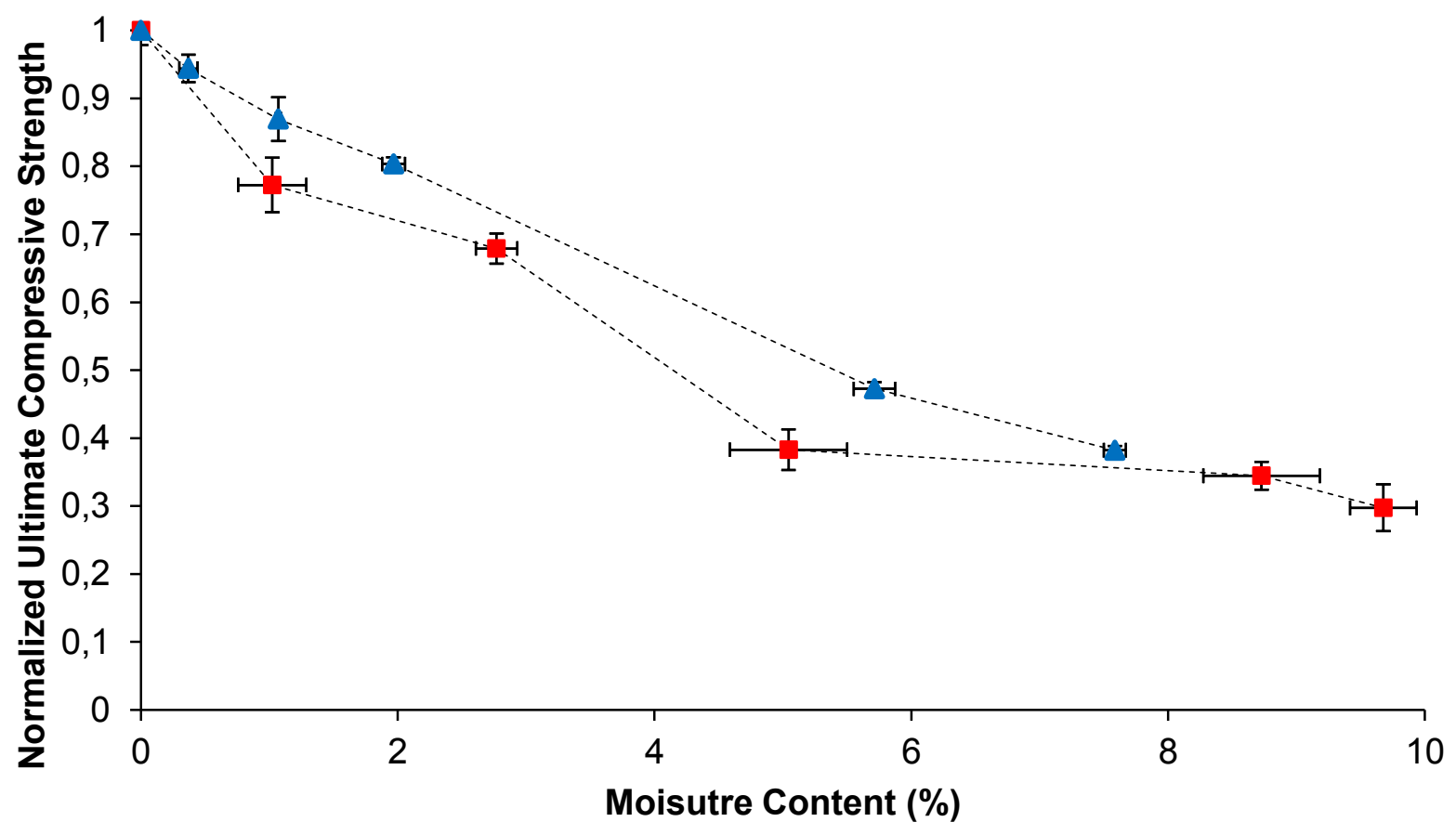

- Flax/Bio-Epoxy $\Delta$ Flax/Polyurethane

Figure 5-9 Normalized compressive strength of flax/bio-epoxy and flax/polyurethane composites 
After 336h of conditioning, the compressive modulus and the compressive strength of the flax/polyurethane samples are reduced by $52.8 \%$ and 35.5\% respectively (Figure 5-9 and Figure 5-10). Figure 5-10 shows the evolution of the modulus with the moisture uptake. The modulus was determine using the displacement of the INSTRON testing machine and the longest linear part of the load-displacement curves (Figure 5-7 and Figure 5-8). No standards were used. This method did not give very precise results. However, different trends were observed for the two resin systems and can be used to explain the behaviour of the composites. There was almost no plasticizing effect for the flax/polyurethane composites when the water uptake was under $3 \%$ as opposed to the flax/bio-epoxy composites that plasticized as soon as their moisture content increased. Epoxy matrices are known to plasticize when they absorb moisture [92] and it could explain the compressive modulus behaviour when the amount of absorbed water was below $2 \%$ 3\% (Figure 5-10). After a water uptake 3\%, both composites lost their compressive modulus progressively and this was likely to be caused by fibre plasticization.

For the same amount of absorbed moisture, the flax/polyurethane composites are clearly superior to flax/bio-epoxy composites at retaining their compressive strength and modulus. The polyurethane composites are less affected by moisture and broke through the thickness in a consistent manner, showing that the fibre/matrix interface is stronger because of the covalent bonds created between the hydroxyl groups of the cellulosic fibres and the polyurethane matrix. These results are consistent with the one obtained with the short beam shear tests (5.1.1.2). 


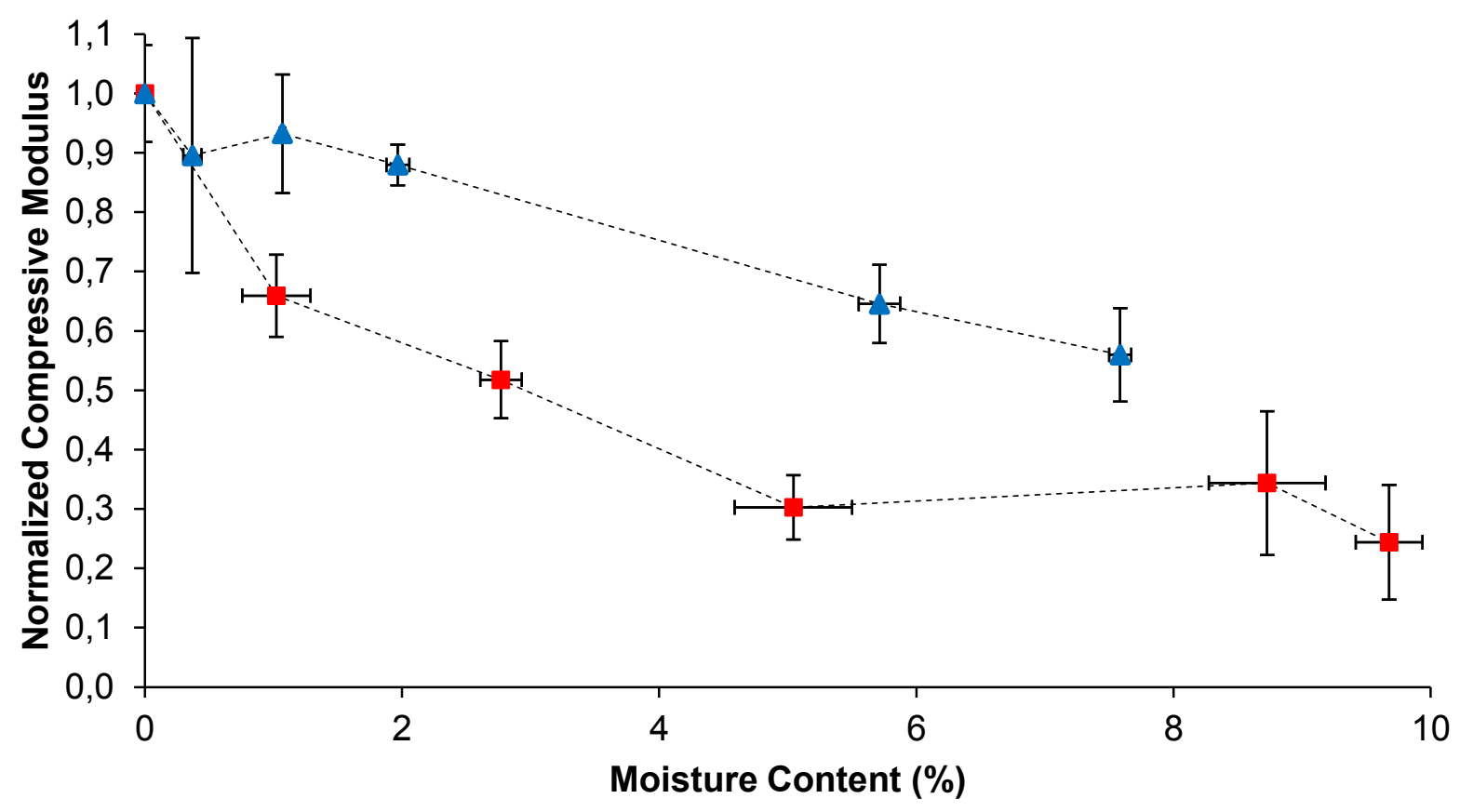

-Flax/Bio-Epoxy $\Delta$ Flax/Polyurethane

Figure 5-10 Normalized compressive modulus of flax/bio-epoxy and flax/polyurethane composites The absorbed water seemed to affect the composites in two different ways. On one hand, water has a plasticizing effect on the composite. The type of matrix highly influences the extent of the plasticization. The absorbed water also increased the mobility and the reorientation of the cellulose microfibrils located at the surface of the flax fibres by softening the internal bonds which result in fibre plasticization. On the other hand, it can lead to stronger polar-polar interactions between the water molecules, the polymer chains and the cellulose contained in the flax fibres. If the polymer chains contain polar group as in the case of the polyurethane resins, the interaction are stronger. This explains the small increase in short beam strength for low level of absorbed moisture. Overall, the better mechanical performance of the flax/polyurethane can be explained by a better fibre/matrix adhesion and a smaller amount of absorbed moisture located at the interface. 


\subsection{Glass Transition TEMPERATURE}

The dry and wet glass transition temperatures were measured using a TA Q800 dynamic mechanical analyser. The DMA $T_{g}$ is frequently used to indicate the upper use temperature of composite materials, as well as for quality control of composite materials [93]. Moisture and hygrothermal ageing can have a significant effect on the DMA $T_{g}[83,93]$. Therefore, wet samples were weighted before and after water immersion and were tested within 3 minutes after removal from the conditioning chamber. All specimens were tested on a three point bending test fixture with a $50 \mathrm{~mm}$ span at frequency of $1 \mathrm{~Hz}$ and a displacement of $15 \mu \mathrm{m}$. The test coupons were machined to be $60 \mathrm{~mm}$ long, $10 \mathrm{~mm}$ wide and had an average thickness of $5.3 \mathrm{~mm}$. The thickness of the composites is relatively big for this kind of tests and that explains why the displacement is so small. The DMA $T_{g}$ were calculated according to the ASTM standard D7028 (Figure 5-12). A heating rate of $5{ }^{\circ} \mathrm{C} / \mathrm{min}$ was used as a compromise between $T_{g}$ measurement accuracy and bias. A slower heating rate would cause the specimen to dry and given the size of the test coupons, a thermal lag is to be expected. Nevertheless, the comparison of the effect of water uptake on the $T_{g}$ remains valid as the same heating rate was used for all samples.

The bio-epoxy resin has a relatively low glass transition temperature of $48.3^{\circ} \mathrm{C}$ compared to the polyurethane $T_{g}$ that could reach $150^{\circ} \mathrm{C}$ (Table $\left.3-1\right)$. It is fairly common for bio-based resins have a low $T_{g}$. In addition, no post cure was performed for both composites and it explains why the polyurethane composites initial had a DMA $T_{g}$ of $86.8^{\circ} \mathrm{C}$.

Figure 5-12 and shows the evolution of the storages modulus $E^{\prime}$ with temperature. These curves were used to determine the DMA $T_{g}$ of the composites. During the glass transition, the storage modulus is significantly reduced and this drop is used to determine $T_{g}$ as the intersection of two tangent lines as shows for the first curve is Figure 5-12. The average of the calculated $T_{g}$ is also plotted on Figure 5-11 and Figure 5-12. 


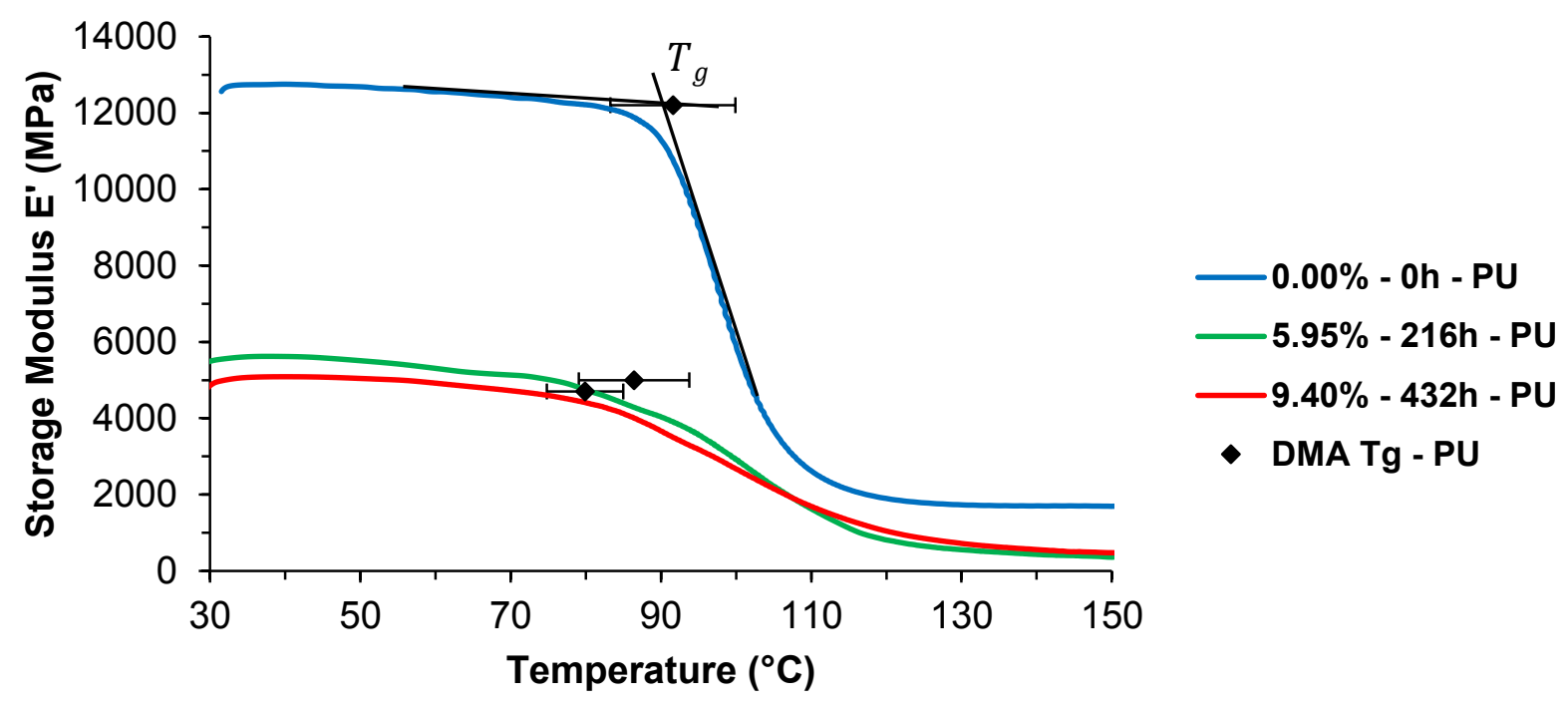

Figure 5-11 Storage modulus of the flax/polyurethane composites measured by DMA for different immersion times. The average calculated $T_{g}$ is plotted for each curve

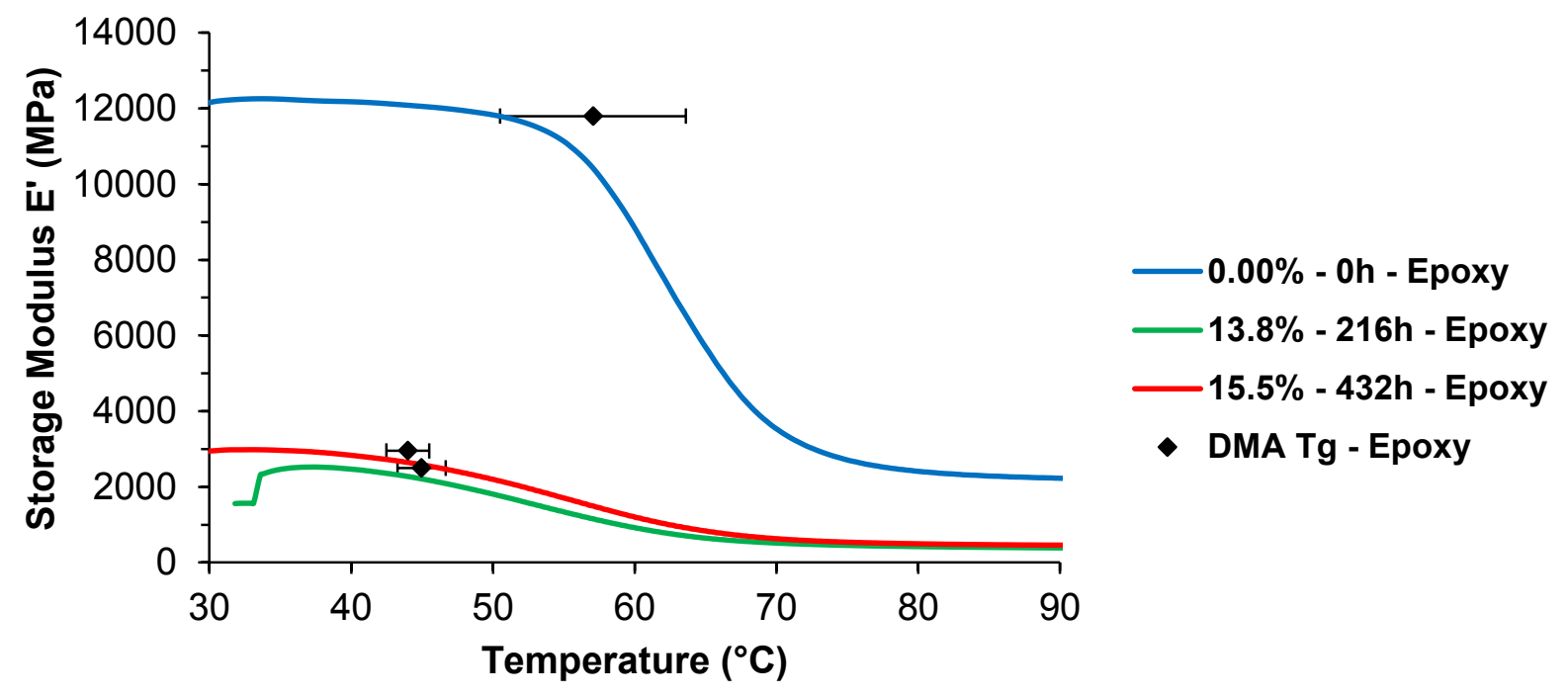

Figure 5-12 Storage modulus of the flax/bio-epoxy composites measured by DMA for different immersion times. The average calculated $T_{g}$ is plotted for each curve 


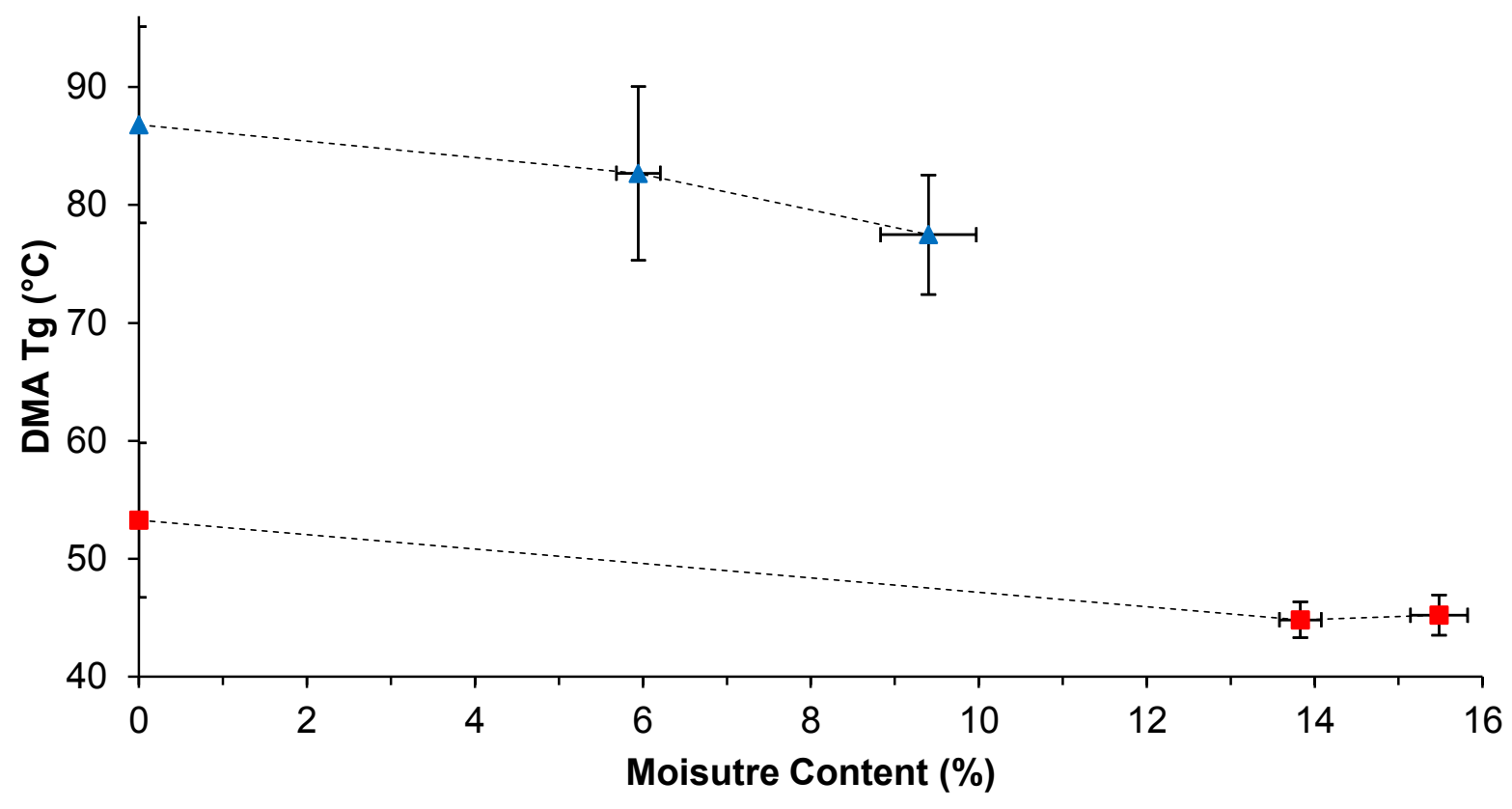

- Flax/Bio-based Epoxy $\Delta$ Flax/Polyurethane

Figure 5-13 Evolution of the glass transition temperature with water uptake for flax/bio-epoxy and flax/polyurethane composites

As expected, the $T_{g}$ was affected by the hygrothermal ageing (Figure 5-13). After 432h (18 days) of immersion in distilled water, the $T_{g}$ was reduced by $8.1{ }^{\circ} \mathrm{C}(15.1 \%)$ and $9.3{ }^{\circ} \mathrm{C}(10.7 \%)$ for the flax/bio-epoxy and the flax/polyurethane composites respectively. Even if the flax/bio-epoxy composites absorbed more moisture, both materials had the same behaviour regarding the evolution of their $T_{g}$ with water absorption.

\subsection{DAMAge Microscopy}

In addition to the mechanical and DMA tests, scanning electron microscopy (SEM) images were taken to visualize the fibre matrix interface and to look at the water induced damages. The samples were dried in sealed bags with desiccant prior to taking the micrographs. Figure 5-14 shows the gauge region of shear loading compression tests coupons that failed in brooming. On these images, the $0^{\circ}$ and $90^{\circ}$ elementary fibres (Figure 2-1) of the woven reinforcement can be seen. For both the polyurethane and the bio-epoxy composite, microbuckling and fibre/matrix 
debonding occurred for the longitudinal fibres. It is also interesting to notice the variability in the elementary fibre diameter, typical of a natural fibre reinforcement.
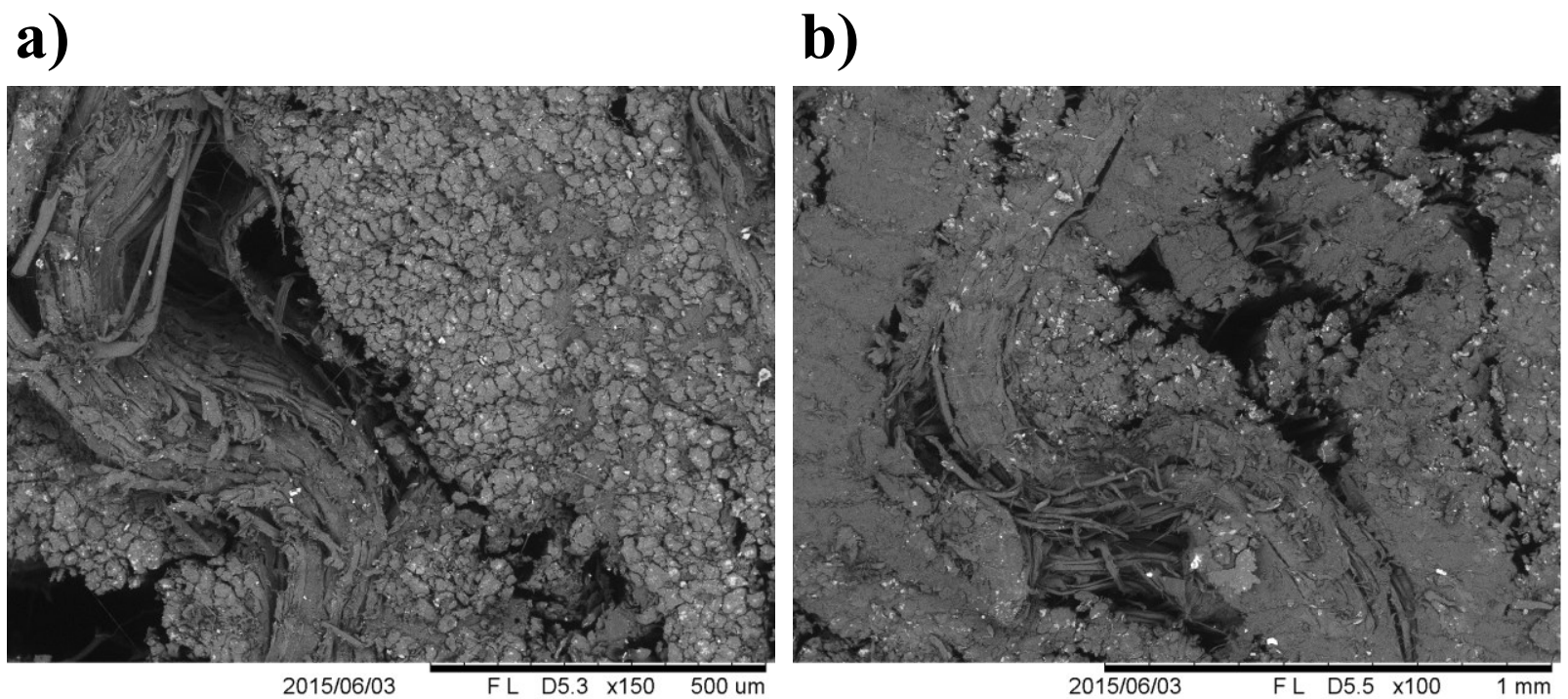

Figure 5-14 SEM images - Side view of shear loading compression test coupons after $720 \mathrm{~h}$ of conditioning. a) flax/bio-epoxy b) flax/polyurethane

Figure 5-15 shows the fibre/matrix interface in an undamaged area of the composites before and after conditioning the samples during $720 \mathrm{~h}$ (30 days) at $90 \% \mathrm{RH}$ and $30^{\circ} \mathrm{C}$. Before ageing, a small gap, i.e. a dark area surrounding the elementary fibres (circled in red), can been observed between the flax fibres and the bio-epoxy matrix (Figure 5-15 a)). There is almost no visible gap in the case of the flax/polyurethane (Figure 5-15 c)), which indicates a better fibre/matrix adhesion. In fact, it is quite difficult to distinguish the elementary fibres and the polyurethane resin in SEM images. After a month of conditioning, the gap is even wider and more visible in the case of the flax/bio-epoxy composites (Figure 5-15 a) and b)). The absorbed water and the swelling of the fibres might be the causes of this change in the interface region. A bigger space between the fibres and the matrix compromises the load transfer, therefore reducing the mechanical performance. The interface of the flax/polyurethane composites does not seem to be affected in the same way, i.e. there is no visible expansion of the area between the fibres and the matrix (Figure 5-15 c) and d)). Matrix cracking can however be noticed after $720 \mathrm{~h}$ of ageing. 
These results are in agreement with the mechanical tests results and indicate a better adhesion between the flax fibres and the polyurethane matrix. The chemical reaction between the cellulose and the isocyanate would explain such differences; It may also explains why the polyurethane interface absorbed less moisture and did not expand as much as the flax/bio-epoxy interface.

a)
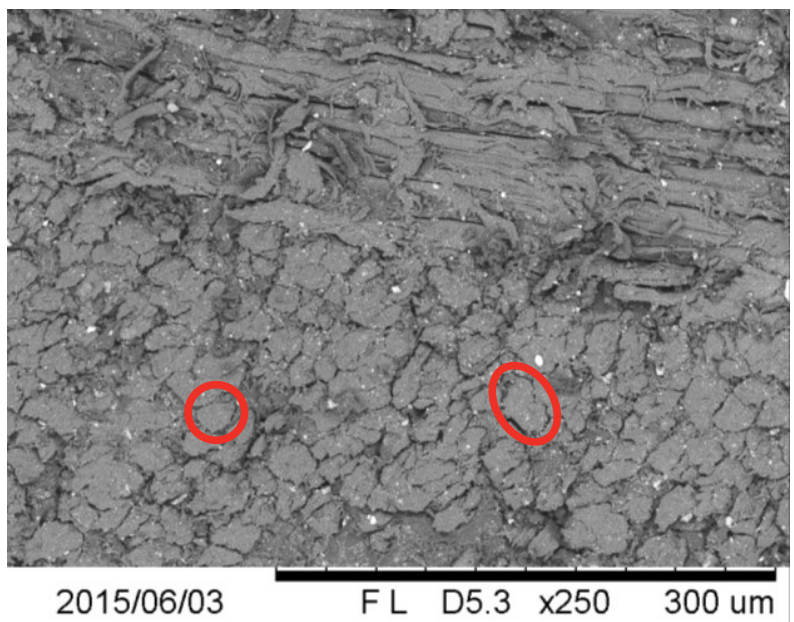

c)

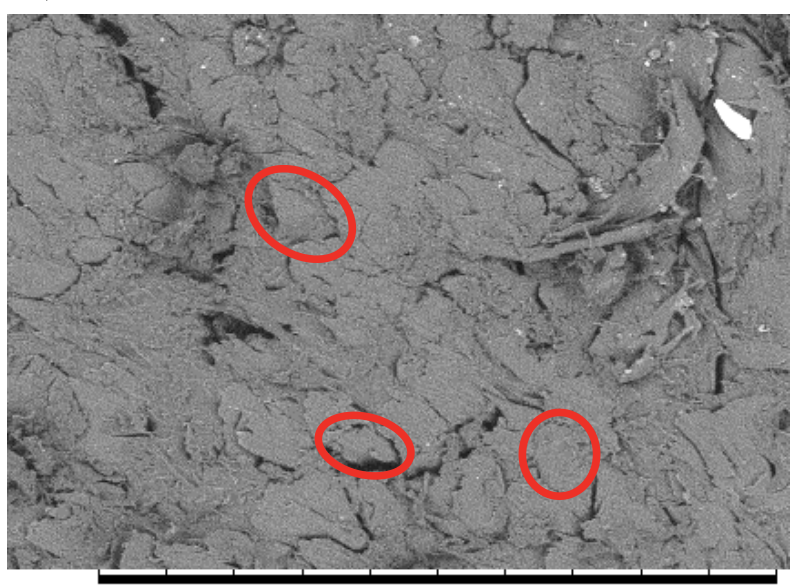

$201 \overline{5 / 06 / 03}$

FL $\quad$ D5.2 $\times 500 \quad 200$ um

\section{b)}

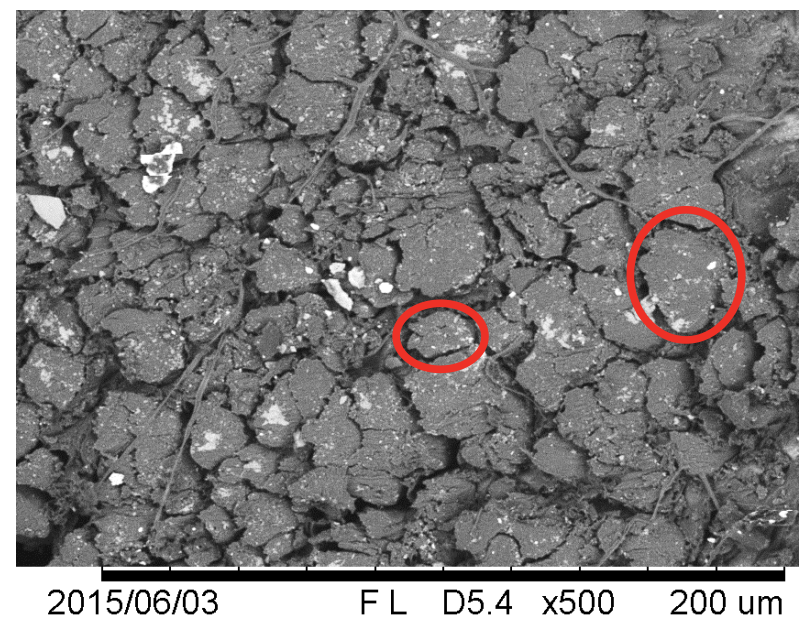

d)

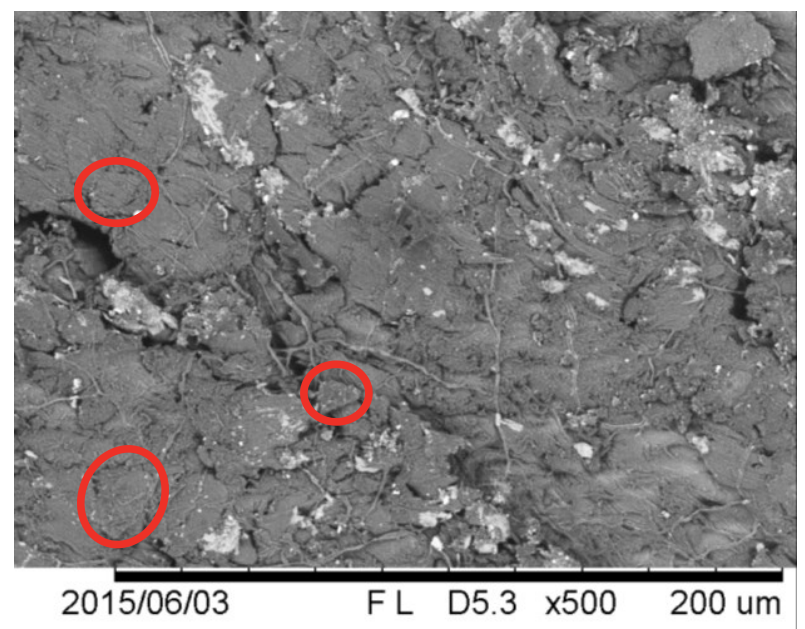

Figure 5-15 SEM images - Fibre/matrix interface in an undamaged area before and after conditioning. Elementary fibres are circled in red. The bright white areas are charge accumulations.

a) flax/bio-epoxy, 0h. b) flax/bio-epoxy, 720h. c) flax/polyurethane, 0h. d) flax/polyurethane, $720 \mathrm{~h}$. 


\section{ChAPTER 6: CONCLUSIONS}

\subsection{CONTRIBUTIONS}

This study aimed at investigating the influence of hygrothermal ageing on the fibre/matrix interface and the mechanical properties of composites laminates reinforced by a woven flax fabric. A bio-based epoxy and a thermoset polyurethane resin were used to manufacture composite panels using a resin transfer moulding process. From this work, the following conclusions can be drawn:

- Moisture absorption follows a Fickian diffusion behaviour for both composites. Polyurethane absorb less moisture and at a slower rate. The chemical bonding between the hydroxyl groups of the cellulosic fibres and the urethane pre-polymer results in a reduction of the available hydroxyl groups. This directly influence the way the composite fibres interact with water and absorb moisture.

- The short beam shear failure of the flax/bio-epoxy changed from an interlaminar shear/tension mode to inelastic deformation mode with the absorption of moisture. This is caused by the plasticizing effect of the absorbed water on the fibres and the matrix. Water also has a plasticizing effect on the polyurethane composites and it changes their failure mode, but it took longer to appear.

- The shear loading compression tests showed the same plasticizing effects of water, with a change in the failure mode happening after $23 \mathrm{~h}$ of ageing for the bio-epoxy composites and after $91 \mathrm{~h}$ for the polyurethane composites. Overall, the mechanical performances of the polyurethane composites are less affected by moisture absorption than those of the bio-epoxy composites. As the two tests performed are very sensitive to the fibre/matrix bonding, this confirmed that the adhesion between the fibres and the matrix is stronger in the case of the polyurethane matrix.

- $\quad$ The SEM images confirmed the mechanical tests results in showing a good adhesion and a tight bond at interface between the flax elementary fibres and the polyurethane matrix. 
- $\quad$ The glass transition temperature slightly decreased with the water uptake. This behaviour is similar for both resin systems.

The results analysis showed that for cellulosic fibres reinforced composites, the use of polyurethane resin is highly beneficial for the environmental stability, the durability and the moisture resistance of the material. It also shows that the nature of the fibre/matrix interface plays a key role in the moisture absorption mechanisms.

\subsection{FUTURE WORK}

The results presented within this thesis could be used for further study such as:

- Maximizing the bio-based content of the composites. Developing a bio-polyurethane using bio-polyols would be a way to move toward a greener biocomposites with the advantages of the stronger flax/polyurethane interactions. These bio-polyurethane would need to the suitable for injection processes, which requires a low viscosity and a decent pot life.

- Using two different types of reinforcement to manufacture bio-composite with improved mechanical performance and environmental resistance. Using layers of E-glass fibres on the outside of the composite could potentially reduce the water absorption rate and increase the mechanical properties, especially in terms of flexural strength and bending stiffness.

- The recovery of the mechanical properties could also be investigated. In this thesis and for fibre volume fractions of around 40\%, a 5\% water uptake lead to significant reductions in terms of mechanical properties for both composites. It would be interesting to study if a similar threshold can be observed for different fibre volume fractions and how drying the composites affects the composites before and after that threshold.

- $\quad$ The chemical bonding between the flax fibres and the polyurethane matrix could be studied in greater details. More specifically, quantifying the amount of the cellulose hydroxyl groups that react with the isocyanate would help to understand the adhesion mechanisms. Using polyurethane with increased hydrophobicity [94] could improve the water resistance of the composites but could also potentially reduce the fibre/matrix compatibility. 


\section{APPENDICES}

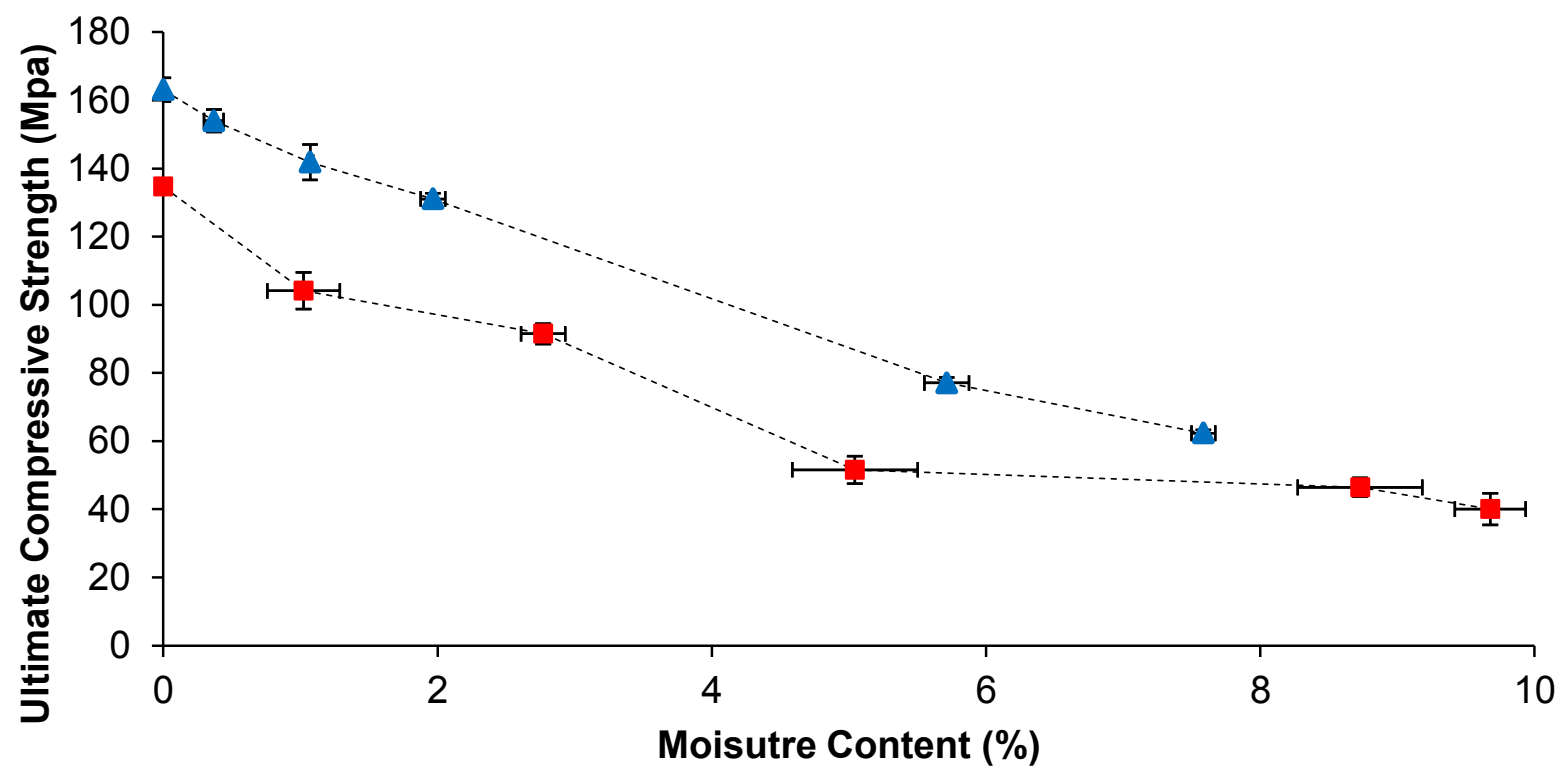

- Flax/Bio-Epoxy $\triangle$ Flax/Polyurethane

Figure 7-1 Ultimate compressive strength of flax/bio-epoxy and flax/polyurethane composites

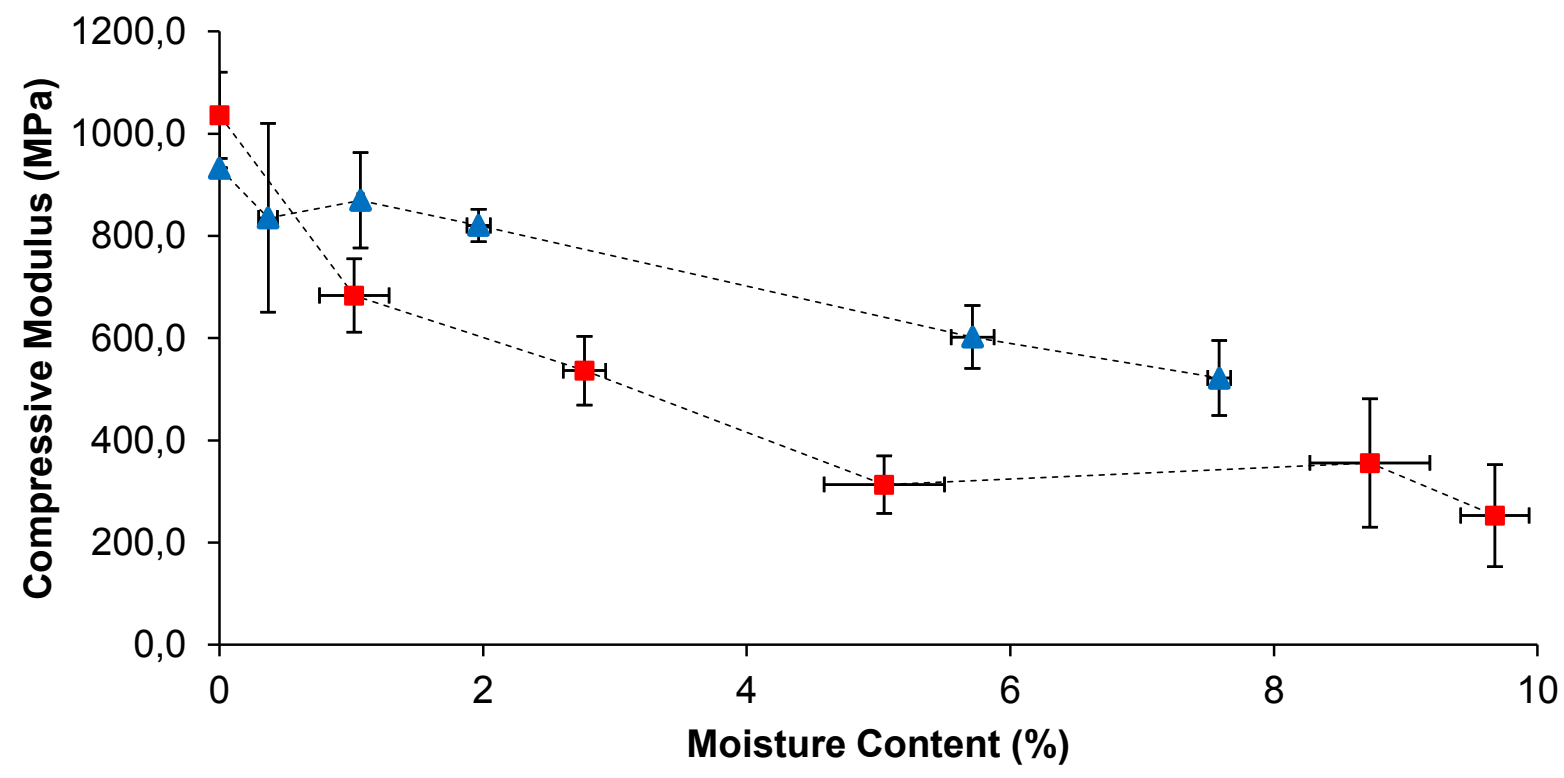

- Flax/Bio-Epoxy $\triangle$ Flax/Polyurethane

Figure 7-2 Compressive modulus of flax/bio-epoxy and flax/polyurethane composites 


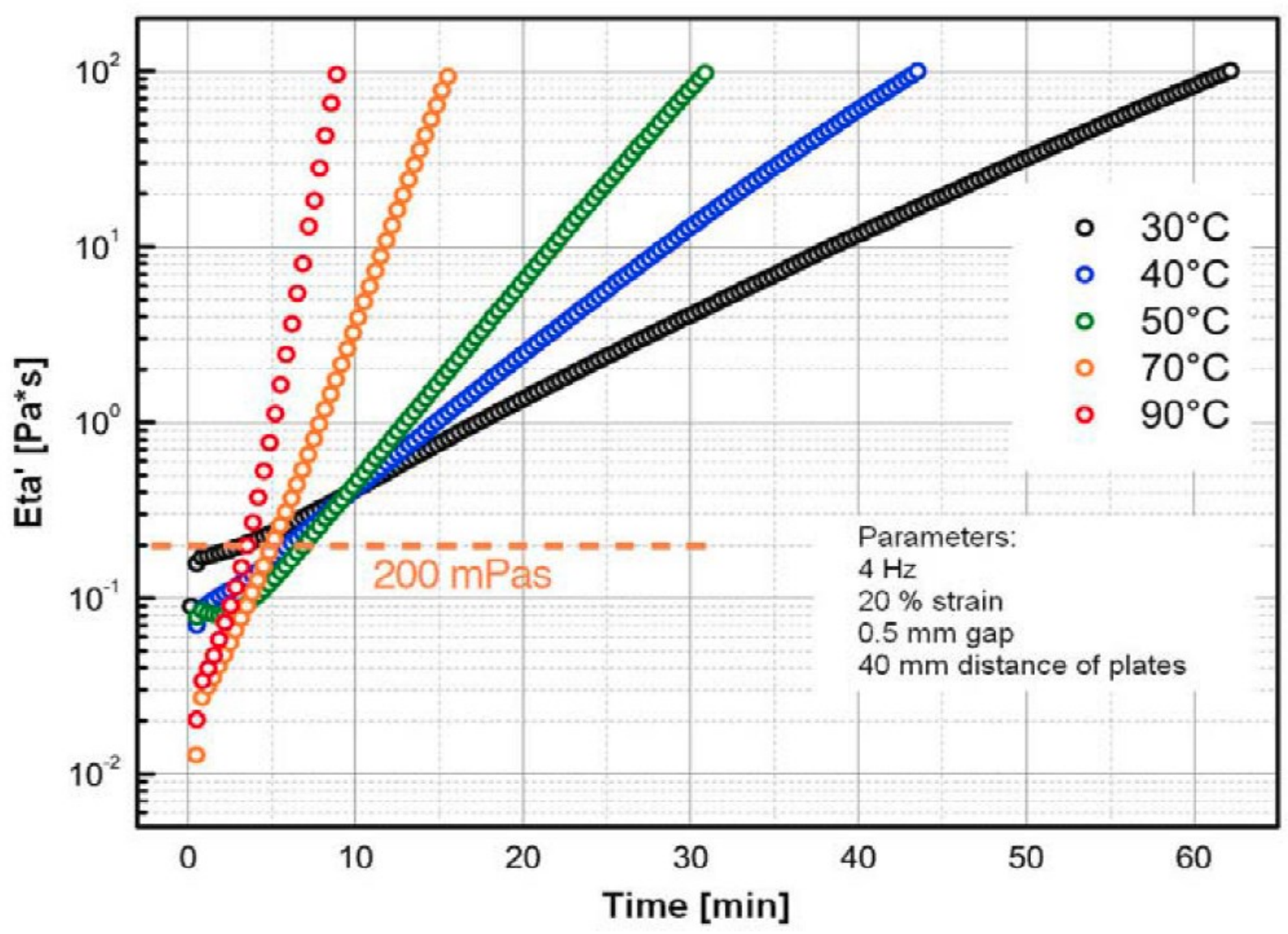

Figure 7-3 Viscosity of the LOCTITE MAX 3 Polyurethane resin for different injection temperatures [95] 


\section{REFERENCES}

[1] A. K. Mohanty, M. Misra, and L. T. Drzal, Natural fibers, biopolymers, and biocomposites: CRC Press, 2005.

[2] H. L. Bos, The potential of flax fibres as reinforcement for composite materials: Technische Universiteit Eindhoven, 2004.

[3] J. Biagiotti, D. Puglia, and J. M. Kenny, "A review on natural fibre-based composites - part I: structure, processing and vegetable fibres," Journal of Natural Fibers, vol. 1, pp. 37-68, / 2004.

[4] A. Arbelaiz, B. Fernandez, J. A. Ramos, A. Retegi, R. Llano-Ponte, and I. Mondragon, "Mechanical properties of short flax fibre bundle/polypropylene composites: Influence of matrix/fibre modification, fibre content, water uptake and recycling," Composites Science and Technology, vol. 65, pp. 1582-92, 08/ 2005.

[5] O. Faruk, A. K. Bledzki, H.-P. Fink, and M. Sain, "Biocomposites reinforced with natural fibers: 2000-2010," Progress in Polymer Science, vol. 37, pp. 1552-1596, 2012.

[6] D. Puglia, J. Biagiotti, and J. M. Kenny, "A review on natural fibre-based composites - part II application of natural reinforcements in composite materials for automotive industry," Journal of Natural Fibers, vol. 1, pp. 23-65, / 2004.

[7] Y. Libo, N. Chouw, and K. Jayaraman, "Flax fibre and its composites - a review," Composites Part B: Engineering, vol. 56, pp. 296-317, 01/2014.

[8] J. Hobson and M. Carus, "Targets for bio-based composites and natural fibres," JEC composites, pp. 31-32, 2011.

[9] J. Gassan and A. K. Bledzki, "Possibilities for improving the mechanical properties of jute/epoxy composites by alkali treatment of fibres," Composites Science and Technology, vol. 59, pp. 13031309, 1999.

[10] K. Van Rijswijk and W. Brouwer, "Cost-effectiveness of composites with natural materials," in Society for the Advancement of Material and Process Engineering. International SAMPE Europe conference, 2002, pp. 287-298.

[11] S. Alix, L. Lebrun, C. Morvan, and S. Marais, "Study of water behaviour of chemically treated flax fibres-based composites: A way to approach the hydric interface," Composites Science and Technology, vol. 71, pp. 893-899, 2011.

[12] M. Assarar, D. Scida, A. El Mahi, C. Poilane, and R. Ayad, "Influence of water ageing on mechanical properties and damage events of two reinforced composite materials: Flax-fibres and glass-fibres," Materials and Design, vol. 32, pp. 788-795, 2011.

[13] A. Le Duigou, P. Davies, and C. Baley, "Seawater ageing of flax/poly(lactic acid) biocomposites," Polymer Degradation and Stability, vol. 94, pp. 1151-1162, 2009. 
[14] P. Mannberg, "Non-linear behaviour of polymer composites, moisture effects and accelerated testing," Doctoral Thesis, Division of Material Science, Luleå University of Technology, Luleå, Sweden, 2013.

[15] L. Pupure, N. Doroudgarian, and R. Joffe, "Moisture uptake and resulting mechanical response of biobased composites. I. constituents," 2013.

[16] W. Qiu-hong and H. Gu, "Tensile property of the flax/polyester composites after water treatment," Advanced Materials Research, vol. 194-196, pp. 1740-4, / 2011.

[17] D. Scida, M. Assarar, C. Poilane, and R. Ayad, "Influence of hygrothermal ageing on the damage mechanisms of flax-fibre reinforced epoxy composite," Composites Part B: Engineering, vol. 48, pp. 51-58, 2013.

[18] A. Stamboulis, C. A. Baillie, S. K. Garkhail, H. G. H. van Melick, and T. Peijs, "Environmental durability of flax fibres and their composites based on polypropylene matrix," Applied Composite Materials, vol. 7, pp. 273-94, 11/ 2000.

[19] N. Doroudgarian, L. Pupure, and R. Joffe, "Moisture uptake and resulting mechanical response of bio-based composites. II. composites," 2014.

[20] I. O. Bakare, F. E. Okieimen, C. Pavithran, H. P. S. Abdul Khalil, and M. Brahmakumar, "Mechanical and thermal properties of sisal fiber-reinforced rubber seed oil-based polyurethane composites," Materials \& Design, vol. 31, pp. 4274-4280, 10// 2010.

[21] H. Dhakal, Z. Zhang, N. Bennett, A. Lopez-Arraiza, and F. Vallejo, "Effects of water immersion ageing on the mechanical properties of flax and jute fibre biocomposites evaluated by nanoindentation and flexural testing," Journal of Composite Materials, vol. 48, pp. 1399-1406, 2014.

[22] A. Le Duigou, A. Bourmaud, and C. Baley, "In-situ evaluation of flax fibre degradation during water ageing," Industrial Crops and Products, vol. 70, pp. 204-210, 2015.

[23] A. Le Duigou, A. Bourmaud, P. Davies, and C. Baley, "Long term immersion in natural seawater of Flax/PLA biocomposite," Ocean Engineering, vol. 90, pp. 140-148, 2014.

[24] J. Moothoo, S. Allaoui, P. Ouagne, D. Soulat, and B. Guilleminot, "Effect of uptake behaviour on tensile properties of flax fibre reinforced composites," in ECCM15-15TH EUROPEAN CONFERENCE ON COMPOSITE MATERIALS, 2012, p. 8.

[25] R. Silva, M. Ueki, D. Spinelli, W. Bose Filho, and J. Tarpani, "Thermal, mechanical, and hygroscopic behavior of sisal fiber/polyurethane resin-based composites," Journal of Reinforced Plastics and Composites, vol. 29, pp. 1399-1417, 2010.

[26] P. Domone and J. Illston, Construction materials: their nature and behaviour: Taylor \& Francis, 2010 .

[27] N.-L. M. Robertson, J. A. Nychka, K. Alemaskin, and J. D. Wolodko, "Mechanical performance and moisture absorption of various natural fiber reinforced thermoplastic composites," Journal of Applied Polymer Science, vol. 130, pp. 969-980, 2013. 
[28] C. Baley, T. D'Anselme, and J. Guyader, "Composite materials reinforced with natural fibres," Composites (Paris), vol. 37, pp. 28-34, 1997.

[29] L. U. Devi, S. Bhagawan, and S. Thomas, "Mechanical properties of pineapple leaf fiber-reinforced polyester composites," Journal of Applied Polymer Science, vol. 64, pp. 1739$1748,1997$.

[30] V. G. Geethamma, K. Thomas Mathew, R. Lakshminarayanan, and S. Thomas, "Composite of short coir fibres and natural rubber: effect of chemical modification, loading and orientation of fibre," Polymer, vol. 39, pp. 1483-1491, // 1998.

[31] G. Kalaprasad, K. Joseph, S. Thomas, and C. Pavithran, "Theoretical modelling of tensile properties of short sisal fibre-reinforced low-density polyethylene composites," Journal of Materials Science, vol. 32, pp. 4261-4267, 1997.

[32] M. K. M. K. D. Lohmeyer, "Study of Markets and Price Situation of Natural Fibres (Germany and EU)," 2000.

[33] H. Saechtling, "Book review: International Plastics Handbook: for the Technologist, Engineer and User," Polymer News, vol. 21, pp. 219-219, 1996.

[34] D. N. Saheb and J. Jog, "Natural fiber polymer composites: a review," Advances in Polymer Technology, vol. 18, pp. 351-363, 1999.

[35] K. Satyanarayana, K. Sukumaran, P. Mukherjee, C. Pavithran, and S. Pillai, "Natural fibrepolymer composites," Cement and Concrete composites, vol. 12, pp. 117-136, 1990.

[36] A. Vázquez, V. A. Domínguez, and J. M. Kenny, "Bagasse Fiber-Polypropylene Based Composites," Journal of Thermoplastic Composite Materials, vol. 12, pp. 477-497, November 1, 19991999.

[37] S. Phillips, "Bio-Composite Material Applications to Musical Instruments," Master of Engineering, Mechanical Engineering, McGill University, Montreal, McGill University, Montreal, 2009.

[38] M. Lewin, Handbook of fiber chemistry: CRC Press, 2010.

[39] A. Thuault, S. Eve, D. Blond, J. Bréard, and M. Gomina, "Effects of the hygrothermal environment on the mechanical properties of flax fibres," Journal of Composite Materials, p. $0021998313490217,2013$.

[40] www.agrofibrecomposites.com. (2004). Flax Fibre Structure. Available: http://www.agrofibrecomposites.com/process.htm

[41] Bowes, 1966.

[42] http://laled.fotomaps.ru/flax-plant.php.

[43] S. Goutianos, T. Peijs, B. Nystrom, and M. Skrifvars, "Development of flax fibre based textile reinforcements for composite applications," Applied Composite Materials, vol. 13, pp. 199-215, 2006 . 
[44] A. Bismarck, I. Aranberri-Askargorta, J. Springer, T. Lampke, B. Wielage, A. Stamboulis, et al., "Surface characterization of flax, hemp and cellulose fibers; Surface properties and the water uptake behavior," Polymer Composites, vol. 23, pp. 872-894, 2002.

[45] S. Kalia, B. S. Kaith, and I. Kaur, "Pretreatments of natural fibers and their application as reinforcing material in polymer composites-a review," Polymer Engineering and Science, vol. 49, pp. 1253-1272, 2009.

[46] K. G. Satyanarayana, G. G. Arizaga, and F. Wypych, "Biodegradable composites based on lignocellulosic fibers - an overview," Progress in Polymer Science, vol. 34, pp. 982-1021, 2009.

[47] J. M. Yatim, N. H. B. A. Khalid, and R. Mahjoub, "Biocomposites for the Construction Materials and Structures," CIDB Seminar, Sarawak, Faculty of Civil Enginnering, Universiti Teknologi Malaysia, 2011.

[48] W. Wake, "Theories of adhesion and uses of adhesives: a review," Polymer, vol. 19, pp. 291-308, 1978.

[49] D. Hull and T. W. Clyne, An Introduction to Composite Materials: Cambridge University Press, 1996.

[50] C. Hill and M. Hughes, "Natural fibre reinforced composites opportunities and challenges," 26650 The Old Road, Valencia, California, 91381-0751, United States, 2010, pp. 148-158.

[51] B. S. Kaith and S. Kalia, "Grafting of flax fiber (Linum usitatissimum) with vinyl monomers for enhancement of properties of flax-phenolic composites," Polymer Journal, vol. 39, pp. 13191327, 2007.

[52] B. S. Kaith, A. S. Singha, S. Kumar, and S. Kalia, "Mercerization of flax fiber improves the mechanical properties of fiber-reinforced composites," International Journal of Polymeric Materials and Polymeric Biomaterials, vol. 57, pp. 54-72, 2008.

[53] D. Xue and M. Miao, "Influences of moisture absorption and chemical treatments on the resin flow characteristics of natural fibre nonwoven mats," Journal of the Textile Institute, vol. 103, pp. 1024-1030, 2012.

[54] L. L. Steven Philips, "Characterization of flax fibres for application in the resin infusion process," PhD Thesis, McGill University, 2013.

[55] T. Stuart, Q. Liu, M. Hughes, R. D. McCall, H. S. S. Sharma, and A. Norton, "Structural biocomposites from flax - Part I: Effect of bio-technical fibre modification on composite properties," Composites Part A: Applied Science and Manufacturing, vol. 37, pp. 393-404, 3// 2006.

[56] N. Graupner, J. Rocler, G. Ziegmann, and J. Mussig, "Fibre/matrix adhesion of cellulose fibres in PLA, PP and MAPP: A critical review of pull-out test, microbond test and single fibre fragmentation test results," Composites Part A: Applied Science and Manufacturing, vol. 63, pp. 133-148, 2014.

[57] R. Heijenrath and T. Peijs, "Natural-fibre-mat-reinforced thermoplastic composites based on flax fibres and polypropylene," Advanced composites letters, vol. 5, pp. 81-86, 1996. 
[58] R. Crossley, P. Schubel, and A. Stevenson, "Furan matrix and flax fibre as a sustainable renewable composite: Mechanical and fire-resistant properties in comparison to phenol, epoxy and polyester," Journal of Reinforced Plastics and Composites, vol. 33, pp. 58-68, 2014.

[59] Y. Perrot, "Influence of the matrix properties on the mechanical behaviour of glass/polyester composites used in yacht building," PhD thesis, Université de Bretagne Sud, 2006.

[60] B. Harris, Fatigue in composites: science and technology of the fatigue response of fibrereinforced plastics: Woodhead Publishing, 2003.

[61] B. Masseteau, F. Michaud, M. Irle, A. Roy, and G. Alise, "An evaluation of the effects of moisture content on the modulus of elasticity of a unidirectional flax fiber composite," Composites Part A: Applied Science and Manufacturing, vol. 60, pp. 32-37, 2014.

[62] E. Gellert and D. Turley, "Seawater immersion ageing of glass-fibre reinforced polymer laminates for marine applications," Composites Part A: Applied Science and Manufacturing, vol. 30, pp. 1259-1265, 1999.

[63] P. Davies, F. Mazeas, and P. Casari, "Sea water aging of glass reinforced composites: shear behaviour and damage modelling," Journal of composite materials, vol. 35, pp. 1343-1372, 2001.

[64] A. Celino, F. Jacquemin, S. Fréour, and P. Casari, "Study of the diffusion behavior of natural fibers," in 15th European Conference on Composite Materials.

[65] C.-H. Shen and G. S. Springer, "Moisture absorption and desorption of composite materials," Journal of Composite Materials, vol. 10, pp. 2-20, 1976.

[66] L.-R. Bao and A. F. Yee, "Moisture diffusion and hygrothermal aging in bismaleimide matrix carbon fiber composites-part I: Uni-weave composites," Composites Science and Technology, vol. 62, pp. 2099-2110, 2002.

[67] E. Sparnin, A. Pupurs, J. Varna, R. Joffe, K. Nattinen, and J. Lampinen, "The moisture and temperature effect on mechanical performance of flax/starch composites in quasi-static tension," Polymer Composites, vol. 32, pp. 2051-2061, 2011.

[68] S. Alix, E. Philippe, A. Bessadok, L. Lebrun, C. Morvan, and S. Marais, "Effect of chemical treatments on water sorption and mechanical properties of flax fibres," Bioresource Technology, vol. 100, pp. 4742-4749, 2009.

[69] A. Karmaker and G. Hinrichsen, "Processing and characterization of jute fiber reinforced thermoplastic polymers," Polymer-Plastics Technology and Engineering, vol. 30, pp. 609-629, 1991.

[70] A. C. Karmaker, "Effect of water absorption on dimensional stability and impact energy of jute fibre reinforced polypropylene," Journal of Materials Science Letters, vol. 16, pp. 462-4, 03/15 1997.

[71] A. C. Karmaker and C. M. Clemons, "Water absorption and load transferring mechanisms in polypropylene reinforced with lignocellulosic fibers," in Proceedings of the 53rd Annual Technical Conference. Part 1 (of 3), May 7, 1995 - October 11, 1995, Boston, MA, USA, 1995, pp. 2091-2095. 
[72] Y.-H. P. Kim, Jun-Mu ; Yoon, Sung-Won ; Lee, Jin-Woo ; Jung, Min-Kyo ; Murakami, Ri-Ichi ;, "The Effect of Moisture Absorption and Gel-coating Process on the Mechanical Properties of the Basalt Fiber Reinforced Composite," International Journal of Ocean System Engineering, vol. 1, pp. 148-154, 2011.

[73] J.-F. Lebel, "Effect of moisture on composites coated with gelcoat," Master thesis, École Polytechnique Montréal 1999.

[74] S. Advani and E. Sozer, "Liquid molding of thermoset composites," vol. 2, ed: Elsevier Science: Amsterdam, 2003.

[75] T. Centea, "Material - processing - quality relationships during the consolidation of out-of autoclave prepregs," Doctor of Philosophy, Departement of Mechanical Engineering McGill University, 2013.

[76] http://www.bmwblog.com/.

[77] T. Lundström, R. Stenberg, R. Bergström, H. Partanen, and P. Birkeland, "In-plane permeability measurements: a nordic round-robin study," Composites Part A: Applied Science and Manufacturing, vol. 31, pp. 29-43, 2000.

[78] S. Bickerton, E. Sozer, P. Šimácek, and S. Advani, "Fabric structure and mold curvature effects on preform permeability and mold filling in the RTM process. Part II. Predictions and comparisons with experiments," Composites Part A: Applied Science and Manufacturing, vol. 31, pp. 439-458, 2000.

[79] C. Demaria, E. Ruiz, and F. Trochu, "In-plane anisotropic permeability characterization of deformed woven fabrics by unidirectional injection. Part II: Prediction model and numerical simulations," Polymer Composites, vol. 28, pp. 812-827, 2007.

[80] C. Demaria, E. Ruiz, and F. Trochu, "In-plane anisotropic permeability characterization of deformed woven fabrics by unidirectional injection. Part I: Experimental results," Polymer Composites, vol. 28, pp. 797-811, 2007.

[81] A. Stamboulis, C. Baillie, and T. Peijs, "Effects of environmental conditions on mechanical and physical properties of flax fibers," Composites Part A: Applied Science and Manufacturing, vol. 32, pp. 1105-1115, 2001.

[82] N. Vernet, E. Ruiz, S. Advani, J. Alms, M. Aubert, M. Barburski, et al., "Experimental determination of the permeability of engineering textiles: Benchmark II," Composites Part A: Applied Science and Manufacturing, vol. 61, pp. 172-184, 2014.

[83] J. Zhou and J. P. Lucas, "Hygrothermal effects of epoxy resin. Part II: variations of glass transition temperature," Polymer, vol. 40, pp. 5513-5522, 1999.

[84] L. A. Carlsson, D. F. Adams, and R. B. Pipes, Experimental characterization of advanced composite materials: CRC press, 2014.

[85] K. Potter, "RTM mould tool design," in Resin Transfer Moulding, ed: Springer Netherlands, 1997, pp. 74-145. 
[86] EntropyResins. (2013). Technical Data Sheet SUPER SUPER SAP INF Epoxy System - Clear, Low Viscosity Epoxy Resin for Vacuum Infusion or RTM. Available:

https://entropyresins.com/product/super-sap-inf/

[87] Henkel, "Technical Data Sheet LOCTITE MAX 3," 2013.

[88] A. F. Abdelkader and J. R. White, "Water absorption in epoxy resins: The effects of the crosslinking agent and curing temperature," Journal of Applied Polymer Science, vol. 98, pp. 2544-2549, 2005.

[89] ASTM, "Standard Test Method for Short-Beam Strength of Polymer Matrix Composite Materials and Their Laminates," in ASTM D2344 / D2344M-13, ed. West Conshohocken, PA, 2013.

[90] ASTM, "Standard Test Method for Compressive Properties of Polymer Matrix Composite Materials with Unsupported Gage Section by Shear Loading," in ASTM D3410 / D3410M03(2008), ed. West Conshohocken, PA, 2008.

[91] K. V. Pochiraju, G. Tandon, and G. A. Schoeppner, Long-Term Durability of Polymeric Matrix Composites: Springer US, 2011.

[92] P. Nogueira, C. Ramírez, A. Torres, M. J. Abad, J. Cano, J. López, et al., "Effect of water sorption on the structure and mechanical properties of an epoxy resin system," Journal of Applied Polymer Science, vol. 80, pp. 71-80, 2001.

[93] ASTM, "Standard Test Method for Glass Transition Temperature (DMA Tg) of Polymer Matrix Composites by Dynamic Mechanical Analysis (DMA)," in ASTM D7028-07e1, ed. West Conshohocken, PA, 2007.

[94] P. Król and B. Król, "Surface free energy of polyurethane coatings with improved hydrophobicity," Colloid and polymer science, vol. 290, pp. 879-893, 2012.

[95] Henkel, "Application Recomandation LOCTITE MAX series," 2013. 